\title{
Removal of Bacteria from Solids by Bubbles: Effect of Solid Wettability, Interaction Geometry, and Liquid-Vapor Interface Velocity
}

\author{
Alex T. Kriegel
}

Thesis submitted to the faculty of the Virginia Polytechnic Institute and State University in partial fulfillment of the requirements for the degree of

Master of Science

In

Chemical Engineering

\author{
William A. Ducker \\ Michael J. Bortner \\ Aaron S. Goldstein
}

August $14^{\text {th }}, 2019$

Blacksburg, Virginia

Keywords: bacteria, air-liquid interface, bubble, detachment, adhesion, deposition 


\title{
Removal of Bacteria from Solids by Bubbles: Effect of Solid Wettability, Interaction Geometry, and Liquid-Vapor Interface Velocity
}

\author{
LT Alex Timothy Kriegel
}

\begin{abstract}
Air bubbles are a promising means of controlling fouling for a range of applications, particularly delaying fouling in marine environments. This work investigates the mechanism by which the collision of an air bubble with a solid removes adsorbed bacteria. A key feature of the work is that the numbers of bacteria were monitored via video microscopy throughout the collision, so we were able to explore the mechanism of bacteria removal. When a bubble collides with a solid, an air-liquid interface crosses the solid twice, and we were able to distinguish the effects of the first and second air-liquid interface. The bacterium Pseudomonas aeruginosa was allowed to adhere to smooth polydimethylsiloxane (PDMS) and then a collision with a bubble was investigated for one of three different approach geometries: perpendicular, parallel, and oscillating parallel to the solid surface. Other factors examined were the speed of the bubble, the duration of bacterial adhesion on the solid surface, and the wettability of the solid. Surface wettability was identified as the most significant factor. When the solid dewets, almost all bacteria were removed from hydrophobic surfaces upon the passage of the first airliquid interface. In contrast, when a thin liquid film remained between the solid and the bubble (a hydrophilic solid), variable amounts of bacteria remained. Although almost all bacteria were initially removed from hydrophobic solids, many bacteria were redeposited on hydrophobic surfaces upon the passage of the second air-liquid interface, especially when the first and second air-liquid interfaces moved in opposite directions. As described previously, a lower velocity of the bubble allows more time for the thin liquid film to drain, and improved removal efficiency on hydrophilic solids. A rougher solid ( $8 \mu \mathrm{m}$ diameter hemispherical protrusions) decreased the detachment efficiency because bacteria and liquid were able to shelter in concavities. Air bubbles are capable of removing bacteria over a range of conditions and are a potentially efficient means of combating biofilm growth for practical applications.
\end{abstract}




\title{
Removal of Bacteria from Solids by Bubbles: Effect of Solid Wettability, Interaction Geometry, and Liquid-Vapor Interface Velocity
}

\author{
Alex T. Kriegel \\ GENERAL AUDIENCE ABSTRACT
}

A major problem for equipment submerged in seawater is their eventual coverage in marine organisms including bacteria, barnacles, seaweed, and algae. This work investigates how effectively an air bubble removes bacteria adhered to a submerged solid. Adhered bacteria were observed and counted throughout the interaction of a bubble with a solid. When a bubble collides with a solid and is then removed, the bubble edge passes over the solid twice. The edge of the bubble is referred to as an air-liquid interface. The effects on adhered bacteria removal of the first and second passes of the bubble air-liquid interface were observed. Pseudomonas aeruginosa, a bacterial species common to both marine and medical environments, was allowed to adhere to flat solids made up of the polymer polydimethylsiloxane (PDMS) prior to a collision with an air bubble. The air bubble was collided with the solid in three distinct ways: directly from above, across the solid surface in one direction, and across the solid surface in one direction before being pulled back in the other direction. The speed of the bubble, the amount of time bacteria were adhered to the solid prior to bubble collision, and the extent to which the solid could be wet were all also examined for their effects on adhered bacteria removal. The extent to which a solid surface could be dewetted was identified as the most significant factor. For solids that are easily dewetted, almost all adhered bacteria were removed with the passage of the first air-liquid interface. Many bacteria were then redeposited back onto the solid surface upon the passage of the second air-liquid interface, especially when it moved in a direction opposite to the first. In contrast, for solids that are easily wet by water, variable amounts of bacteria remained after the first air-liquid interface swept across its surface. Slower moving air-liquid interfaces were also shown to be more effective at removing adhered bacteria. Solid surfaces with rough patterning made it more difficult to remove bacteria. Air bubbles can be an effective method to combat adhered bacteria and potentially prevent eventual biological growth on different types of underwater applications. 


\section{Acknowledgements}

I would not have been able to complete my work without the help and support of many friends, family, and mentors that have been here for me throughout my journey at Virginia Tech.

First and foremost, I would like to thank my beautiful fiancé Marisa Avallone for always believing in me and providing me with that extra little bit of encouragement just when I needed it before a big exam, or while I was neck deep in research and coming home at all hours of the night. I love you and can't wait to call you my wife later this year! I am sure we have many grand adventures in store for us in the near future, both in and out of the Navy.

A huge thank you to my research advisor Dr. William Ducker for all of his help and mentorship both in and out of the laboratory. You are not only a great scientist, but also a competent leader and a trusted friend. You have taught me new ways to think about problems and how to work through them calmly with an open mind. I will be taking many of the lessons I have learned from you with me as I report to my submarine as a Department Head.

Without the mechanical expertise of Michael Vaught and Kevin Holshouser I would not have had the equipment necessary to perform any of my experiments. You guys were always more than willing to work with me during the tedious process of developing and refining all of my flow cell iterations and more. Thank you both!

I would like to give a special thanks to Yow-Ren Chang who showed me the ropes of bacterial work and spent countless hours helping me with MATLAB scripts as well as providing me with general sound advice. If not for Jimmy Ritter, I would have been lost during the statistical analysis portion of my research, and I am grateful for your patience with me. Thank you to Jared Arkfeld for your work with the goniometer and determining calibrated interfacial tensions. I would also like to thank my other lab mates Zechen Zhang, Prudvi Gaddam, and Jon Hittel for not only helping me in the laboratory, but also for just being a great group of guys to spend time with outside of the laboratory as well.

Thank you, Cannoli, for always excitedly greeting me at the door with a bunch of tail-wags and a big lick to the face whenever I got home, no matter what the hour!

Thank you to 4VA for funding and lastly a big "Hooyah!" to the world's best fighting force, the United States Navy, for financially supporting me during such an outstanding shore tour opportunity. 


\section{Table of Contents}

Chapter 1. Introduction

1.1 Objective and Application

1.2 Biofouling

1.3 Effects of Biofilms on Human Endeavors

1.4 Combating Biofilms

1.5 Practical Application of Air Bubbles to Combat Marine Fouling 7

Chapter 2. Literature Review $\quad 8$

2.1 Using Air Bubbles for the Removal of Biofilms 8

2.2 Time of Bacterial Adhesion $\quad 15$

Chapter 3. Motivation and Aims of the Thesis 16

$\begin{array}{ll}3.1 \text { Variable Factors } & 16\end{array}$

3.2 Timeline of Bubble Interaction $\quad 18$

3.3 How the Experiments Here Compare to Applications 18

Chapter 4. Experimental Section $\quad 21$

4.1 Fabrication of PDMS-Coated Glass Solids $\quad 21$

4.2 Characterization of Wettability 22

4.3 Bacterial Growth $\quad 23$

4.4 Bacteria-Bubble Interactions 24

4.5 Microscopy $\quad 25$

4.6 Bacterial Identification and Data Analysis 25

$\begin{array}{ll}\text { Chapter 5. Results } & 27\end{array}$

5.1 Qualitative Description of Time Series $\quad 27$

5.2 Quantitative Analysis of Detachment and Deposition 29

5.3 Time Course of Bacterial Removal 32

5.4 Surface Wettability is the Dominant Factor in Adhered Bacteria Removal 36

5.5 Air-Liquid Interface Velocity Affects Removal from the Hydrophilic Solid 36

5.6 The Geometry of Bubble Interaction Affects Detachment and Deposition 37

5.7 Overall Detachment Efficiencies Increase with Longer Times of Adhesion 38

Chapter 6. Discussion $\quad 39$

6.1 Importance of Solid Wettability $\quad 39$

$\begin{array}{ll}\text { 6.2 Deposition of Bacteria } & 40\end{array}$

6.3 Effect of Surface Roughness $\quad 42$

6.4 Bacterial Rearrangement on the Surface $\quad 43$

$\begin{array}{ll}\text { Chapter 7. Conclusions } & 44\end{array}$

$\begin{array}{ll}\text { Chapter 8. Future Work } & 46\end{array}$ 


\section{Appendix}

Appendix A: Supporting Methods - Flow Cells

Appendix B: Supporting Methods - Microscopy

Appendix C: Supporting Information

Appendix D: Experimental Data

\section{References}

60 


\section{List of Figures}

\section{Chapter 1. Introduction}

Fig. 1.1 The biofouling process on a surface including approximate settlement times

Fig. 1.2 Picture of fouled ship hull out of the water on blocks

\section{Chapter 2. Literature Review}

Fig. 2.1 Schematic showing bubble collision $\quad 8$

Fig. 2.2 Schematic illustrating the probabilities used in Eqn. $2.1 \quad 10$

Fig. 2.3 Schematic of air-liquid interface interaction with an individual bacterium 11

\section{Chapter 3. Motivation and Aims of the Thesis}

Fig. 3.1 Schematic of the three different geometries used in my experiments

\section{Chapter 4. Experimental Section}

\section{Chapter 5. Results}

Fig. 5.1 Time series of fluorescent images depicting the interaction of a bubble

with a hydrophilic solid or a hydrophobic solid

Fig. 5.2 P. aeruginosa adhered to a hydrophilic surface imaged using (a)

fluorescence microscopy and (b) RICM (same field of view)

Fig. 5.3 Image of fluorescent bacteria adhered to the leading air-liquid interface of a through bubble after being stripped off of the solid surface

Fig. 5.4 Number of bacteria adhered to the solid surface as a function of the passage of the bubble

Fig. 5.5 Percentage of initial bacteria remaining adhered to the solid surface

\section{Chapter 6. Discussion}

Fig. 6.1 Image of a hydrophilic surface in the through geometry with streak-lines caused by motion of the bacteria during the exposure of a single frame

Fig. 6.2 Schematic of cross-section of liquid flow around the bubble at the center point of the flow cell

Fig. 6.3 Vertical bubble collision with a hydrophobic PDMS surface with $8 \mu \mathrm{m}$ diameter hemispherical textured topography following 30 minutes of bacterial adhesion to the surface 


\section{Chapter 7. Conclusions}

\section{Chapter 8. Future Work}

\section{Appendix A: Supporting Methods - Flow Cells}

\section{Appendix B: Supporting Methods - Microscopy}

\section{Appendix C: Supporting Information}

Fig. C.2 Components of lateral bubble experiments

Fig. C.3 Schematic of the apparatus used to view the profile of the bubble during vertical approach

Fig. C. 4 Images taken using the profile view of a vertical bubble impacting a hydrophobic solid surface with the black arrows indicating bubble direction of motion

Fig. C.5 Growth of $P$. aeruginosa at room temperature (approximately $23.5^{\circ} \mathrm{C}$ ) in 56 liquid TSB during the first 8 hours after inoculation

Fig. C.6 Images illustrating the procedure for counting bacteria that become clumped as a result of action by the bubble

\section{Appendix D: Experimental Data}

\section{References}




\section{List of Tables}

\section{Chapter 1. Introduction}

Chapter 2. Literature Review

Chapter 3. Motivation and Aims of the Thesis

Table 3.1 Summary of factors varied in this thesis

Chapter 4. Experimental Section

Table 4.1 Contact angles of liquid droplets on the solids

Table 4.2 Contact angles of captive bubbles on the solids

Chapter 5. Results

Table 5.1 Detachment efficiencies and percent deposition for vertical bubble experiment geometry

Table 5.2 Detachment efficiencies and percent deposition for lateral oscillatory bubble experiment geometry

Table 5.3 Detachment efficiencies and percent deposition for lateral through bubble experiment geometry

Table 5.4 Factors, interactions, and ANOVA results for all overall detachment efficiencies

Table 5.5 Factors, interactions, and ANOVA results for overall detachment efficiencies of hydrophilic surfaces only

\section{Chapter 6. Discussion}

Chapter 7. Conclusions

Chapter 8. Future Work

Appendix A: Supporting Methods - Flow Cells

Appendix B: Supporting Methods - Microscopy

Appendix C: Supporting Information 


\section{Appendix D: Experimental Data}

Table D.1 Raw bacterial and retention counts for vertical bubble experiments

Table D.2 Raw bacterial and retention counts for lateral through bubble experiments

Table D.3 Raw bacterial and retention counts for lateral oscillatory bubble experiments

\section{References}




\section{Chapter 1: Introduction}

\subsection{Objective and Application}

The objective of this study is to determine the effect of collisions between individual air bubbles and bacteria that are adhered to a solid-liquid interface. The major application would be the use of bubble collisions to reduce biofouling of solids immersed in natural waters.

\subsection{Biofouling}

When an air bubble collides with a solid-liquid interface, particles can be removed from the interface. Here my particular interest is the removal of bacteria to reduce biofouling. Biological fouling of various structures, equipment, and vessels is of crucial importance to many different industries due to its significant economic ${ }^{1}$ and environmental ${ }^{2-3}$ impact. Marine biological fouling, also referred to as marine biofouling, is defined by Yebra et al. as "the undesirable accumulation of microorganisms, plants, and animals on artificial surfaces submerged in seawater." 4 Although marine biofouling is typically given the vast majority of attention, freshwater biofouling has many of the same consequences. ${ }^{5}$ Marine and freshwater biofouling both occur according to similar multi-stage processes involving both physical and biochemical processes, starting with the development of a conditioning film (Fig. 1.1). ${ }^{6-8}$

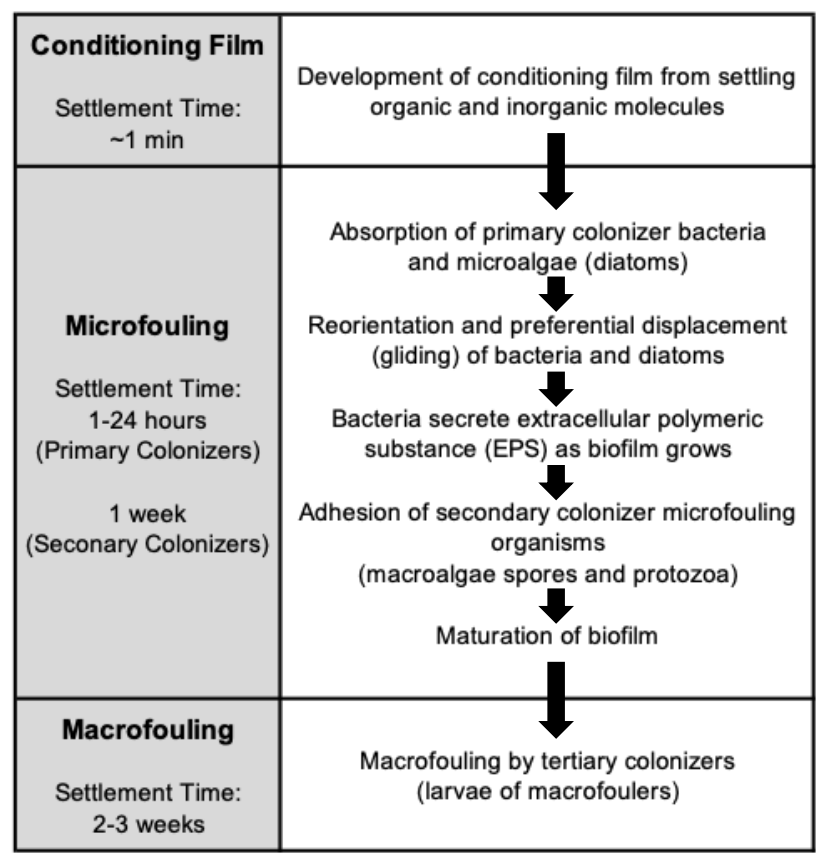

Fig. 1.1. The biofouling process on a surface including approximate settlement times. Figure adapted from Cao et al. (2011) and Abarzua and Jakubowski (1995). ${ }^{7-8}$ 
Most natural aqueous solutions contain polymers such as proteoglycans, proteins, polysaccharides, and other organic and inorganic molecules. When a solid is immersed into such a solution, these molecules adsorb to the solid-liquid interface to form what is known as a conditioning film. ${ }^{8}$ The creation of the conditioning film alters the chemistry and wettability of the solid-liquid interface, which impacts subsequent colonization by bacteria, algae, and other microorganisms. ${ }^{9}$ After adsorption, microorganisms reproduce and secrete an extracellular polymeric substance (EPS) ${ }^{8,10}$ that can adhere to various biological or non-biological surfaces. ${ }^{11}$ This matrix of microorganisms is known as a biofilm. Biofilms can colonize any surface located in a non-sterile environment with a sufficient supply of water and nutrients. ${ }^{12-13}$ A biofilm begins to form as planktonic (free-floating) bacteria first reversibly settle onto the modified surface and then non-reversibly adhere through the self-secretion of EPS made up largely of fructose, glucose, and nucleic acids (DNA). ${ }^{8,10}$ These adhered bacteria then replicate via division or travel across the interface to adjacent bacterial clusters to form a microcolony embedded within an extracellular matrix. ${ }^{14}$ Microcolonies eventually amalgamate through the use of various developmental signals to form larger three-dimensional macrocolonies that release bacteria which restart the biofilm development cycle. ${ }^{15}$

The initial covering of a surface with conditioning film and primary colonization by bacteria are only the beginnings of the biofouling process: within a day, secondary colonizing organisms adsorb to the solid-liquid interface. For marine biofilms, unicellular diatoms begin to predominate within one day, and spores of macroalgae and protozoa adsorb after about a week of immersion of a solid in impure water. ${ }^{8}$ Over the course of the subsequent weeks a macrofouling community of algae and invertebrates such as soft corals, mussels, barnacles, anemones, and hydroids, among others, may develop atop the existing microfouling community. ${ }^{16}$ These invertebrates are large $(>1 \mathrm{~cm})$ and so can significantly alter fluid flow over the surface.

Other mechanisms have been proposed for biofilm formation, particularly a more dynamic and non-sequential fouling model based on water composition and the availability of different types of foulers within the associated water column. ${ }^{17}$ Whatever the exact mechanism, adhered biofilms are known to influence the settlement of successive colonizers through interactions known as biofilm cueing. Biofilms, depending on size and species, can promote, discourage, or have no influence on the colonization of a surface by macroalgae spores and marine invertebrate larvae. ${ }^{18}$ The density of bacteria and diatoms within a biofilm, ${ }^{19-20}$ as well as 
its emitted extracellular products, ${ }^{21}$ quorum sensing signals, ${ }^{18}$ and other chemical components expressed when contacting a biofilm surface ${ }^{22}$ can all serve as settling cues for colonizing invertebrate larvae. The settlement of these organisms and their subsequent growth into complex biological communities on manmade surfaces and structures contribute to a number of diverse problems throughout the world.

\subsection{Effects of Biofilms on Human Endeavors}

Biological fouling of various structures, equipment, and vessels affects many processes, ${ }^{1-}$ ${ }^{3}$ but the most important is arguably the fouling of ships (see Fig. 1.2). The biofilms that grow below the water-line increase drag (friction), which causes slower speeds and greater fuel costs. This increased drag is caused primarily by enhanced surface roughness. ${ }^{23}$

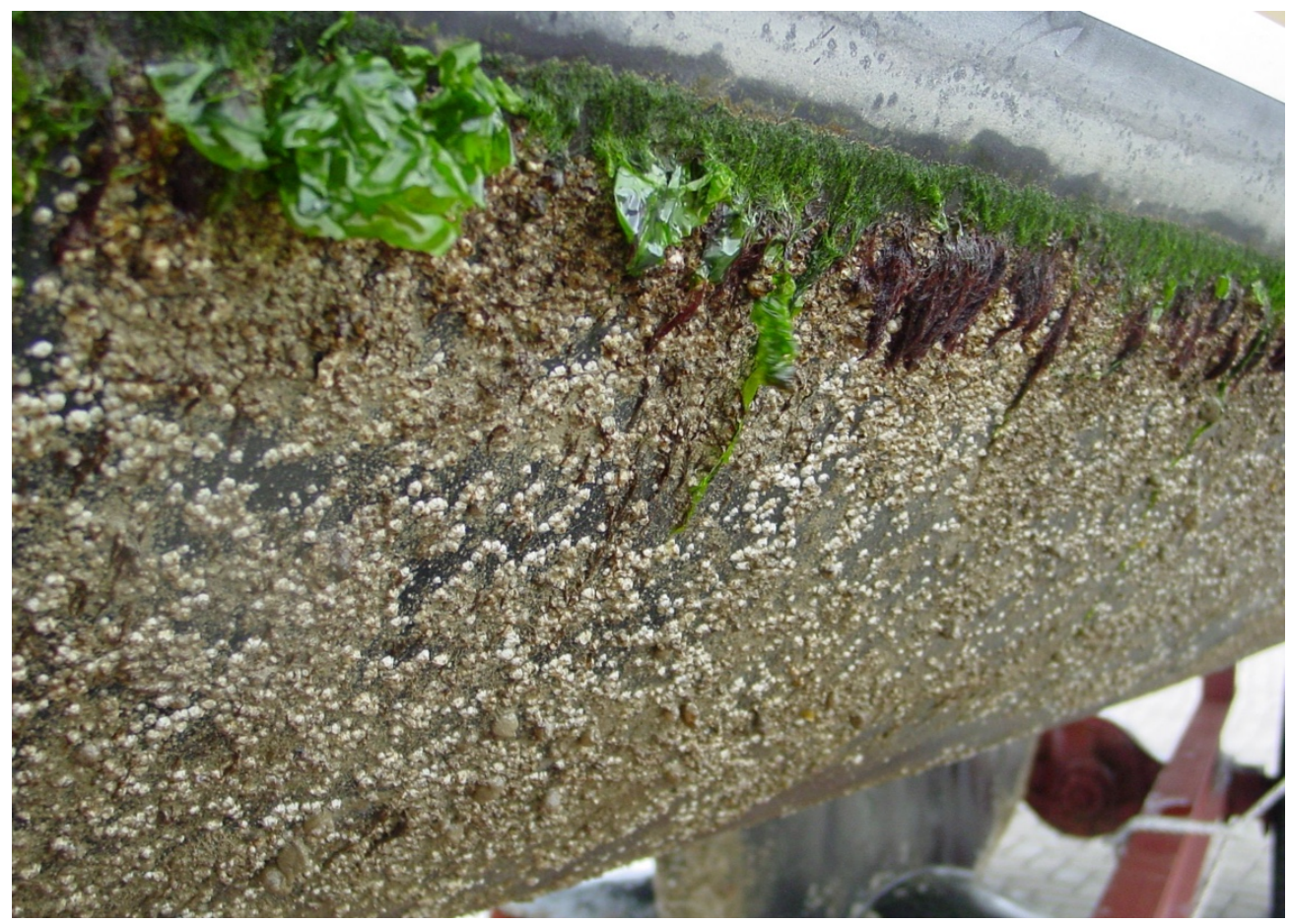

Fig. 1.2. Picture of fouled ship hull out of the water on blocks. Image courtesy of Tone 4751 [CC BY-SA 4.0 (www.creativecommons.org/licenses/by-sa/4.0)].

Marine biofouling mainly occurs when ships are moving slowly or are stationary. At speeds greater than 6 knots $(7 \mathrm{mph} \approx 3 \mathrm{~m} / \mathrm{s})$ turbulent shear stresses inhibit biofilm growth. ${ }^{24}$ As a result, the vast majority of marine biofouling on ships occurs while they are stationary in port.

A large body of research has examined hydrodynamic and drag force effects of adhered biofilms, ${ }^{25-27}$ algae, ${ }^{28-29}$ and marine-based macroorganisms. ${ }^{30-32}$ All of these studies reach the similar conclusion that biofouling impedes ship movement through the water, albeit to a varying 
degree based on fouling type, thickness, and coverage. ${ }^{31}$ The principal consequences are lower vessel speed, range, and maneuverability and greater fuel consumption. All these are undesirable for both civilian and military applications. ${ }^{4}$ For example, substantial marine biofouling of a merchant ship hull can raise voyage costs up to $70 \%$ for a trip across the Pacific from San Francisco, USA to Yokohama, Japan. ${ }^{33}$ Heavy slime commonly coating the bottom of U.S. Navy surface combatant Arleigh Burke-class destroyers following routine operations can increase yearly fuel usage by $10.3 \%$ and fuel costs by $\$ 1.15 \mathrm{M}$ for each vessel. ${ }^{1}$ In 1992 , it was estimated that marine fouling cost the U.S. Navy an additional \$75-100 M a year across the fleet. ${ }^{34}$ Ships must also dedicate considerable time for regular cleaning, or painting with antifouling paint, ${ }^{33}$ which results in lost combat readiness for the navy or revenue for commercial ships. In addition to the economic considerations, marine biofouling is also an environmental concern due to the transportation of organisms between distant places and the concomitant risk that a transported species will invade a new environment and threaten local species. $^{35}$

The medical and dental industries are also heavily invested in the prevention and removal of biofilms from affected instruments and equipment. Water supplied by at least $83 \%$ of dental unit water systems failed the guidelines presented by the American Dental Association for microbial levels due to biofilm coverage of 3-in-1 syringes and water lines. ${ }^{36}$ Intrusive medical devices such as catheters, pacemakers, drainage tubes, and various prostheses provide suitable interfaces for microbial colonies to develop and potentially result in significant human suffering or death. ${ }^{37}$ It is estimated that as many as 10 million people in the United States every year are affected by biofilm infections thriving on permanent medical implants within the body. ${ }^{38}$ Hospital-acquired infections lead to more than $\$ 5$ billion in medical costs per year and have become the fourth leading cause of death in the United States, with about $60-70 \%$ of these illnesses in part due to an implanted medical device. ${ }^{39}$

Industrial water storage systems, piping networks, and heat exchangers all face similar negative effects from biofilms and biofouling, producing a cost of billions of dollars each year for reduction, elimination, and replacement. ${ }^{12}$ 


\subsection{Combating Biofilms}

Throughout history, there have been numerous methods of combating biofilm growth on surfaces in aquatic environments. These approaches can be characterized as either (1) preventative: inhibiting biofilm and biofouling formation or (2) corrective: removing existing films. Corrective methods, although generally effective in removing established growth, can be costly and time consuming. Biofilm removal is typically accomplished industrially either through the application of oxidizing chemical biocides like chlorine or peroxyacetic acid or through the use of dynamic force, such as high pressure sprays, bubble jet streams, or mechanical scrubbing. ${ }^{40-42}$ Other methods of biofilm removal or increasing biocide effectiveness, although thus far more limited in application, include electric fields,${ }^{43}$ ultrasound, ${ }^{44}$ and surface catalysts incorporated at the biofilm-substratum interface. ${ }^{45}$

The use of copper sheathing as a surface covering was one of the most widespread approaches to biofouling prevention on ship hulls starting in the $18^{\text {th }}$ century. As copper metal oxidizes in water, copper ions dissolve into the surrounding seawater and create a toxic environment for a multitude of marine organisms. ${ }^{46}$ Although effective, copper sheathing was abandoned due to the destructive galvanic corrosion that occurred with the iron-hulled ships of the modern age. ${ }^{47}$ The copper ions also kill marine species not adhered on ships, which is a substantial negative environmental impact.

A variety of antifouling paints and coatings were developed on the basis of releasing a biological toxicant from an applied polymer, many of which incorporated soluble copper or mercuric oxides. ${ }^{4}$ The most well-known, effective, and versatile of these organometallic coatings were self-polishing tributyltin (TBT)-based antifouling paints. ${ }^{46}$ In TBT-based antifouling paints, tributyltin methacrylate copolymerized with methyl methacrylate undergoes a hydrolysis reaction with seawater to slowly and consistently produce TBT biocide along with a soluble copolymer chain. ${ }^{48}$ The self-polishing quality of these paints ensures a smooth, lowfriction surface as the brittle copolymer films washes away while also exposing fresh coating for biocide release. ${ }^{46}$ Although a successful and economically practical biofouling inhibitor, the International Maritime Organization forbid the application of TBT-based antifouling paints on all seagoing vessels on January $1^{\text {st }}, 2008$ due to its effect on the environment. ${ }^{49}$ TBT causes substantial mortality rates in oyster larvae, severe abnormalities of adult oyster shells,${ }^{50}$ and the superimposition of male sexual organs onto female dogwhelks' genitalia. ${ }^{51}$ This ban has 
prompted an increase in the research and development of environmentally friendly antifouling paint alternatives such as tin-free biocides to combat copper-tolerant marine species, foul-release coatings to reduce fouling adhesion strength, and biomimetics based on naturally-occurring antifouling compounds produced by marine organisms and surfaces. ${ }^{52}$

Anti-adhesion compounds have also shown promise for use in preventing the early stages of fouling (Fig 1.1) in a diverse range of fields and industries. Surface-modified polymeric biomaterials incorporating large amounts of polyethylene oxide (PEO) have proven to cause significant reductions in the adherence of common infectious bacteria compared to control surfaces. ${ }^{53}$ PEO is effective because it creates a barrier to adsorption between the surface and any approaching proteins, cells, or microorganisms. ${ }^{54}$ While the use of PEO in biological fluids still inhibits the ability of bacteria to adhere to a surface, it has been shown to be effective for short-term periods of less than 48 hours, making it unrealistic for more permanent clinical or marine applications. ${ }^{55-56}$ A relatively newer class of nonfouling materials are zwitterionic polymers: long polymeric chains made up of evenly distributed cationic and anionic groups capable of diverse chemical makeups. Zwitterionic polymers are versatile substances as their structures can be made to incorporate a variety of ionic and charged group arrangements allowing for differentiation in $\mathrm{pH}$ sensitivity, charge density, and counterion association, among others. ${ }^{57}$ Zwitterionic surfaces have shown strong resistance to adhesion by electrostatically binding to water to form a hydration layer that rejects protein and bacterial adsorption. ${ }^{56,58}$ Unlike PEO, zwitterionic materials have shown to exhibit lasting antifouling properties while exposed to complex biological media, making them ideal for use in medical implants and devices. ${ }^{59}$ Slippery liquid-infused porous surfaces (SLIPS) are bioinspired synthetic marine coatings that also provide significant fouling resistance. SLIPS are hyper-repellant to liquid due to their lubricant-saturated surface layer and have shown good deterrence against bacterial and eukaryotic cells as well as Ulva linza algae spores and Balanus amphitrite barnacle larvae with better long-term stability than polyethylene glycol. ${ }^{60}$ Chemical and synthetic materials such as these, among others not discussed here, are promising for use in a variety of marine, medical, and industrial settings. 


\subsection{Practical Application of Air Bubbles to Combat Marine Fouling}

While the ability to control marine biofouling on ship hulls using air bubbles was first identified in 1946, only recently has there been a renewed interest in aeration as a promising endeavor for environmentally friendly and cost-effective preventative marine antifouling. ${ }^{61-64}$ In 2009, Scardino et al. demonstrated the effectiveness of using an air bubble curtain to reduce marine biological macrofouling on the hull of a ship moored in Melbourne, Australia. Continuous aeration with air bubbles reduced macrofouling on the hull to less than $5 \%$ coverage after approximately six months of treatment even while microfouling coverage (predominantly slime and hydroids) remained greater than $70 \%$ throughout exposure. ${ }^{62}$ Aeration work by Bullard et al. showed similar results for short term marine biofouling settlement on PVC and concrete panels under varying geographical and seasonal conditions, with panels exposed to a continuous stream of air bubbles having approximately $4.0 \%$ of the mass of fouling as the nonaerated control panels after 4 weeks of bubble treatment. As with Scardino et al.'s work, hydroids were reduced to a lesser degree (57\% coverage as compared to control conditions) than other biofouling organisms. ${ }^{63}$ For areas of continuous single bubble stream contact, biofouling growth can be reliably prevented in sections where the average shear stresses exceed approximately $0.01 \mathrm{~Pa}$, with organisms adhered for longer periods of time requiring a higher critical stress. ${ }^{64}$ All of these results show an encouraging potential for the use of air bubbles as a valuable antifouling measure for numerous maritime applications. 


\section{Chapter 2: Literature Review}

2.1 Using Air Bubbles for the Removal of Biofilms

This thesis describes the use of air bubbles to combat early-stage biofilm formation. Specifically, this thesis reports on the removal of the rod-shaped bacterium Pseudomonas aeruginosa from a solid. The Pseudomonas genus is common within marine waters ${ }^{65}$ and $P$. aeruginosa was investigated because it is a well-characterized laboratory organism. $P$. aeruginosa itself is commonly present in coastal environments, such as the waters of Tokyo Bay. ${ }^{66}$ Experiments were conducted at $21^{\circ} \mathrm{C}$ to simulate ambient seawater surface conditions that a ship's hull would be exposed to while in port.

When an air bubble collides normally with a solid, material adsorbed at the solid-liquid interface can be transferred onto the vapor-liquid (bubble) interface, displaced to another location on the solid-liquid interface, or swept into solution (Fig. 2.1). This can potentially be used to remove both conditioning films and small organisms.

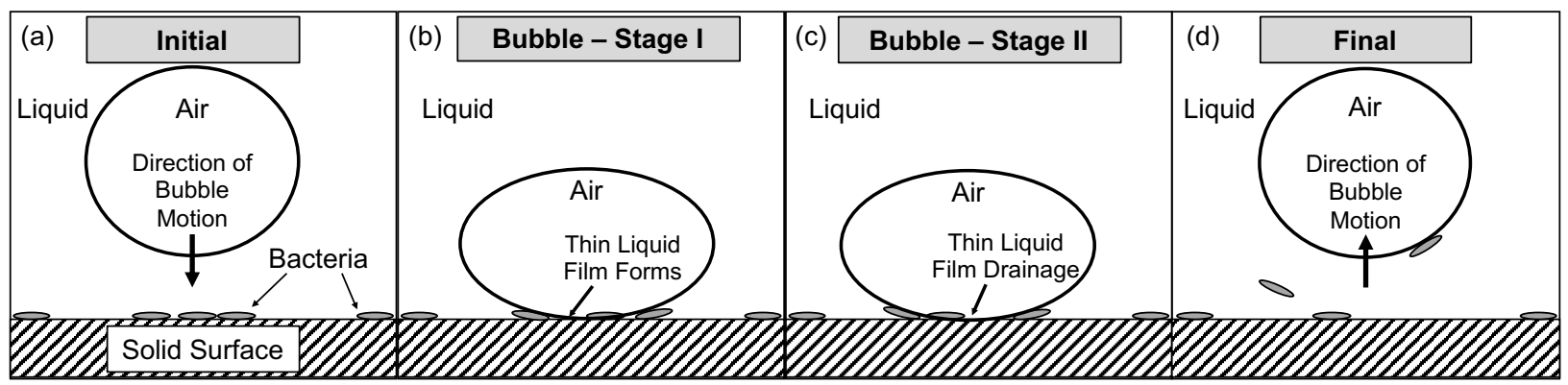

Fig. 2.1. Schematic showing bubble collision. (a) Initial Stage: An air bubble is directed towards a solid surface with adhered bacteria. (b) Bubble - Stage I: The bubble collides with the solid surface and forms a thin liquid film or immediately dewets the solid. (c) Bubble - Stage II: More time has elapsed enabling a thinner film and perhaps dewetting. (d) Final Stage: When the bubble is removed, some bacteria may remain attached to the bubble, are displaced on the solid surface, or are swept into the liquid.

The majority of research thus far on biofilm removal by interactions with the air-liquid interface interactions has focused on applications within the medical and health science industries. Pitt et al. first described the tendency for an air-liquid interface to disrupt the spatial distribution of bacteria adhered to a glass substrate, identifying a commonly overlooked artefact resulting from conventional rinsing procedures. ${ }^{67}$ Similar findings later highlighted and quantified the significant impact of air bubble surface tension forces in the removal of negatively charged, polystyrene colloid particles from various glass surfaces as bubbles passed through parallel plate flow chambers. ${ }^{68}$ Aramrak et al. provides a thorough review of theoretical forces 
and interactions involved in the displacement of adhered colloid particles by the advancing and receding air-liquid interfaces of a bubble within a cylindrical glass channel. ${ }^{69}$

A means of expressing the overall bubble-particle attachment probability by a single bubble was developed by Derjaguin and Dukhin in 1961 based on the interactions between air bubbles and methylated quartz microparticles in a controlled environment. ${ }^{70}$ According to them, the bubble-bacterium detachment probability $\left(P_{\text {bubble }}\right)$ is:

$$
P_{\text {bubble }}=P_{\mathrm{C}} \times P_{\mathrm{A}} \times P_{\mathrm{S}},
$$

where $P_{\mathrm{C}}$ is the air bubble-bacterium collision probability, $P_{\mathrm{A}}$ is the air bubble-bacterium attachment probability, and $P_{\mathrm{S}}$ is the combined bubble-bacterium aggregate probability. ${ }^{71}$ This equation expresses the overall probability of a bacterium to become unadhered and then carried away from a surface by a bubble air-liquid interface. An illustration of these relative probability determinations is given in Fig. 2.2. The $P_{\mathrm{C}}$ is influenced by the size, shape, and collision angle between the bubble and bacteria as well as the bubble Reynolds number. ${ }^{72}$ For the experiment described in this thesis, I always forced a bubble to collide with the test section of the solid, so $P_{\mathrm{C}}$ was always $1 . P_{\mathrm{A}}$ depends on the thinning of the liquid film between the solid and the air bubble, which creates a three-phase contact line with the bacterium. ${ }^{70}$ The flow-induced shear force developed by the passage of a bubble air-liquid interface over a surface without significant subsequent film drainage may also contribute to bacteria adhesion energy, ${ }^{73}$ but this effect is small for experiments in this thesis. Once a bacterium has been removed from a solid surface, the force balance between the adhesive forces at the bubble air-liquid interface and the detachment forces developed from the surrounding liquid flow establish $P_{\mathrm{s} .}{ }^{74}$ However, the use of Eqn. 2.1 in determining detachment probabilities for the work described in this thesis can be cumbersome as not all bacteria removed from a solid surface are necessarily adhered to the bubble air-liquid interface following interaction with a bubble (as shown in Fig. 2.1). Therefore, an alternative expression will be used for detachment probability and will be discussed later (Eqn. 2.3a and Eqn. 2.3b). 


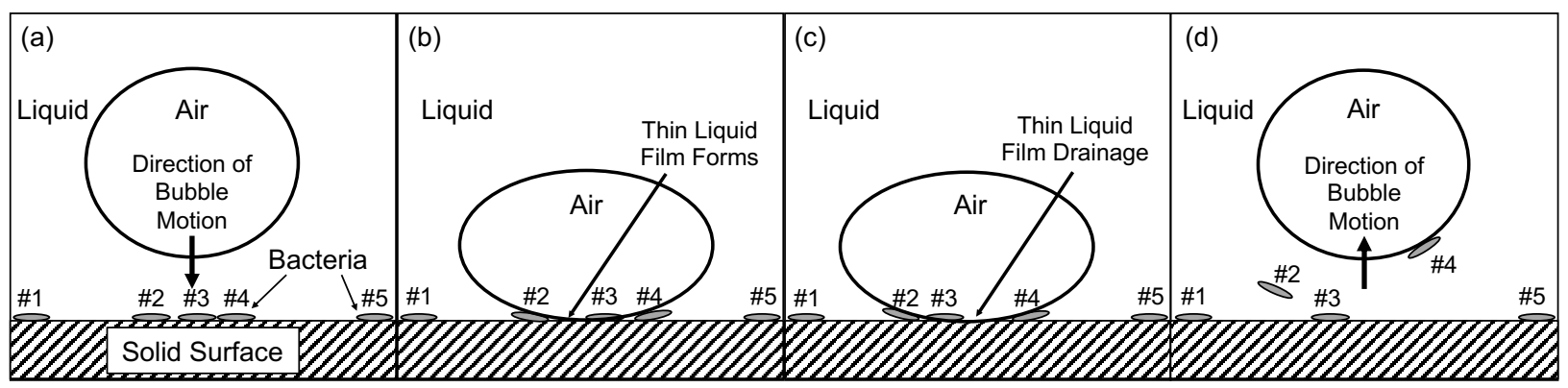

Fig. 2.2. Schematic illustrating the probabilities used in Eqn. 2.1. (a) An air bubble is directed towards a solid surface with adhered bacteria labeled \#1-\#5. (b) The collision probability $\left(P_{\mathrm{C}}\right)$ is higher for bacteria \#2, \#3, and \#4 than for bacteria \#1 and \#5 based on their potential for interaction with the bubble air-liquid interface. (c) The development and subsequent drainage of a thin liquid film at the air-liquid interface influences the extent of contact between the air, liquid, and individual bacteria. The establishment of sufficient three-phase contact increases the attachment probability $\left(P_{\mathrm{A}}\right)$ for bacteria \#2, \#3, and \#4. (d) As the bubble moves away from the solid surface, bacterium \#2 detaches from the bubble surface while bacterium \#4 remains attached. Bacterium \#3 is displaced to another area of the solid surface. Bacterium \#4 contributes to estimates of $P_{\text {bubble }}$ although bacterium \#2 was also removed.

As a bubble approaches a solid, a thin liquid film forms between the solid and the air phases, and sometimes that film ruptures to form a three-phase line. For particles, GómezSuárez et al. described that the air-liquid surface tension pulls the particle away from the solid. ${ }^{75}$ They also developed an equation for the force applied by the surface tension force $\left(F_{\gamma}\right)$ on a model spherical bacterium:

$$
F_{\gamma}=2 \pi R_{B} \gamma_{l v} \sin [\phi(t)] \sin [\beta-\phi(t)]
$$

where $R_{B}$ is the bacterium radius, $\gamma_{l v}$ is the air-liquid interfacial tension, $\phi$ is the angle between the solid-liquid normal and the normal to the bacterium at the three-phase line, $t$ is time in seconds, and $\beta$ is the contact angle between the bacterium-liquid and the air-liquid interface (measured through the liquid). Some of these symbols are described in Fig. 2.3a. Positive forces are directed away from the solid surface. ${ }^{71}$ Three principal conclusions can be reached from Eqn. 2.2: (1) a greater contact angle of the liquid on the bacterium gives a greater maximum force; (2) the degree of immersion affects the force (e.g., for a contact angle of $60^{\circ}, F_{\gamma}$ rises to a maximum at an immersion angle of $30^{\circ}$ ); (3) the magnitude of $F_{\gamma}$ is in the range $0-10^{-7} \mathrm{~N}$ for $R_{B}=800 \mathrm{~nm}, \gamma_{l v}=72 \mathrm{~mJ} / \mathrm{m}^{2}$, which are of much larger magnitudes than the applicable buoyancy and hydrodynamic forces. ${ }^{68,71}$ It is important to note that, in general, the contact angle of the liquid can be quite different on the bacterium than on the solid (Fig. 2.3b). It is possible that the dewetting of the solid prior to the interaction between the air-liquid interface and the bacterium also affects the removal of bacteria, and this is a focus of the current study. 


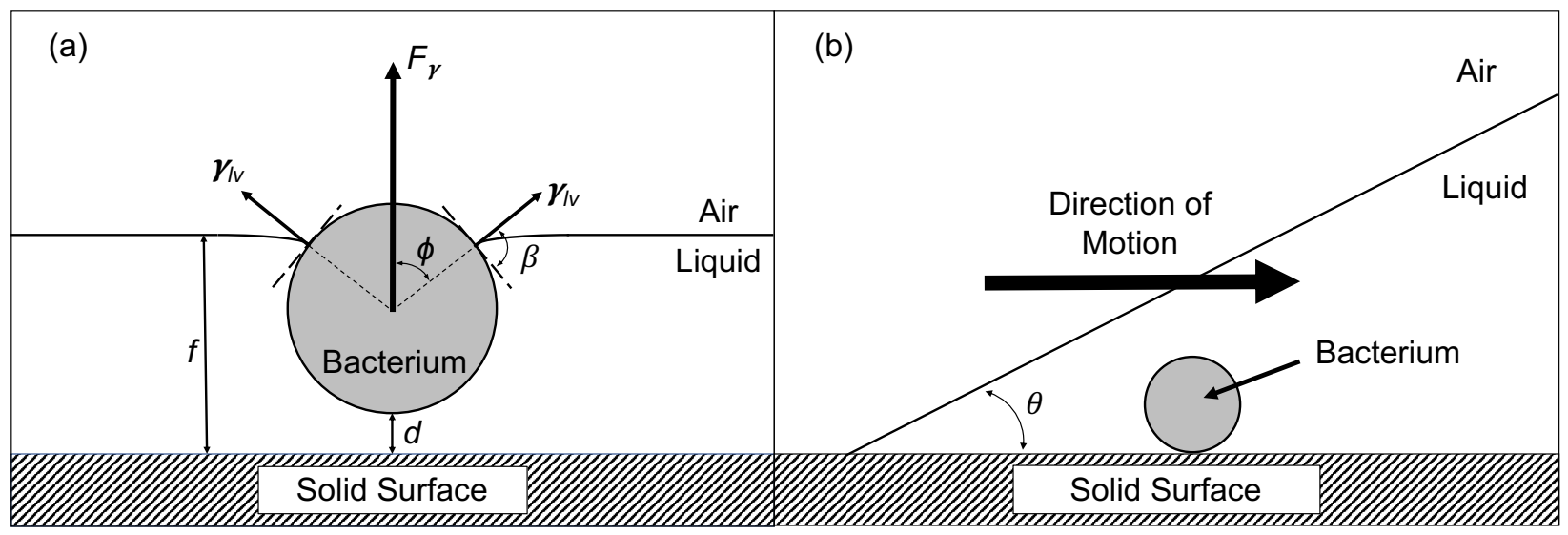

Fig. 2.3. Schematic of air-liquid interface interaction with an individual bacterium. The bacterium is modelled as a sphere, shown in cross-section. (a) The liquid film is draining at the point of the bacterium. $f$ is the liquid film layer thickness, $d$ is the distance between the bacterium and the solid surface, $\beta$ is the contact angle between the bacterium surface and the air-liquid interface, $\phi$ is the immersion angle, which increases as more of the bacterium is dewet, $\gamma_{l v}$ is the air-liquid interfacial tension, and $F_{\gamma}$ is the net force produced by the liquid-vapor interface. Figure adapted from Gómez-Suárez et al., 2001.71 (b) The liquid film has already drained to zero thickness remote from the bacterium, and the air-liquid interface is advancing to the right. Schematic is drawn such that the receding contact angle of the liquid on the solid, $\theta$ is about $30^{\circ}$. Note that the contact angle of the liquid on the bacterium and the solid can be different.

For a bacterium to detach from a solid, $F_{\gamma}$ must exceed the force of attachment $\left(F_{\mathrm{A}}\right)$ of the bacterium to the solid. The force of attachment is very difficult to calculate for a bacterium because bacteria are not homogenous, rigid, or simple solids. Some bacteria have appendages such as pili and flagella, which are usually longer than the bacterium itself, and strongly influence adhesion. Type IV pili are fine, threadlike fibers that protrude from the poles of many gram-negative bacteria, including $P$. aeruginosa, and perform a variety of functions such as surface adherence, movement via twitching motility, and aiding in the transfer of genetic information through conjugation. ${ }^{76}$ Bacterial pili are polymers primarily made up of identical protein subunits called pilin. ${ }^{77}$ They are distinctively smaller and shorter than the whip-like flagella, which are the primary source of motility for bacteria in liquid medium. Typically, type IV pili have diameters between 5-7 nm and can be fully extended to several micrometers in length. ${ }^{78}$ Upon reaching a surface either through their own locomotion via the flagella, Brownian motion, gravitation, or other physical force, the pili are essential in the early stages of biofilm formation and reversible attachment. Acting as a sort of grappling hook, the type IV pili of $P$. aeruginosa are able to extend and attach at their tips to an inert surface, exert a force, and retract. ${ }^{79}$ Adhesin proteins at the tip of a pili are integral in its adherence to the surface. ${ }^{76}$ The conditioning film formed at the surface from a mixture of adsorbed water, ions, and proteins establishes a point of adherence, with the structure of the conditioning film influencing the strength of the biofilm in its infancy. ${ }^{80}$ 
Many loosely bound microorganisms, including $P$. aeruginosa, then begin to extensively synthesize exopolysaccharides that complex with surface materials or the receptor-sites of other microorganisms. ${ }^{81}$ EPS more concretely adheres bacteria to a surface in the absence of physical or chemical intervention as they incorporate into the conditioning film and allows for the process of biofilm maturation to begin. Aggregates of bacteria begin to form within the excreted EPS as cells replicate and cohere with one another, increasing both the density and complexity of the overall biofilm. ${ }^{82}$

Many authors have attempted to calculate the adhesion forces on an entire bacterium using models and theories (e.g. DLVO (Derjaguin-Landau-Verney-Overbeek) theory) that were derived for inorganic colloidal particles, but the application of such models is fraught with inconsistencies owing to the neglect of appendages, adhesins, and other "biological" molecules. ${ }^{83}$ Although quantitative treatment of adhesion via a fundamental colloidal-force approach is not viable, colloidal and molecular forces still act on the individual biological components, and are considered here briefly. The longest range forces are electrostatic and polymer steric forces. Most bacteria, including $P$. aeruginosa, are negatively charged ${ }^{74,83}$ so typically there is an electrostatic double-layer repulsion from anionic solids, such as glass. There is typically an energy required to compress polymer chains to a smaller volume, ${ }^{84}$ so the polymer coating on bacteria typically leads to a repulsive component between the bacterium and the solid. The van der Waals force is typically negligible because the bacterium is composed primarily of water ${ }^{85}$ Although the van der Waals force between micrometer-sized bodies becomes very strong at small separations, the polymer coating and double-layer force prevents this close approach from occurring. On a smaller scale there are numerous electrostatic, dipolar, hydrophobic, and acidbase interactions that contribute to the local forces that appendages and the body of the bacterium feels, but there is insufficient knowledge to treat these in detail. ${ }^{84}$

It is possible, however, to measure the force of adhesion. Touhami et al. measured the force required to detach $P$. aeruginosa from mica using atomic force microscopy (AFM). The mean rupture force of $P$. aeruginosa with Type IV pili tethered to a mica surface for 15 minutes was observed to be approximately $10^{-10} \mathrm{~N}$, at which point the adherence of pili to the substrate was broken or the attached pili themselves broke. ${ }^{86}$ This force is much smaller than the maximum surface tension force estimated from Eqn. $2.2\left(2 \times 10^{-7} \mathrm{~N}\right)$. An issue with the use of Eqn. 2.2 is that the equation does not include any control variables: there is no obvious way to 
alter the contact angle of the bacterium, and it is even quite difficult to measure. The sessile water contact angle for a dried lawn of $P$. aeruginosa was reported to be $43^{\circ} .{ }^{71}$ The drainage angle is a function of time, history, the bacterial contact angle, and the wettability of the solid. Since there is no clear way to alter the wettability of the bacterium, in this thesis I focus on the wettability of the solid, not the bacterium.

When bubbles are used to clean ships, free bubbles collide normal to the solid and then may roll up the side of the ship. In contrast, when bubbles are used to clean the interior of pipes, the bubbles sometimes span the pipe and are thereby flattened. Bubbles in pipes also typically travel in a single direction through the pipe parallel to the solid-liquid interface, rather than the oscillatory motion developed when a free bubble bounces perpendicularly off a solid.

Khodaparast et al. studied flow through confined parallel-plate microgeometries and reported results in terms of a detachment efficiency, defined as: ${ }^{71,73}$

$$
P_{\text {det }}=\frac{\text { Initial Number }- \text { Final Number }}{\text { Initial Number }} \times 100 \% .
$$

where "Initial Number" refers to the numerical count of bacteria in the particular area of interest prior to bubble interaction and "Final Number" refers to the numerical count of bacteria in the same area of interest after the bubble has passed. A key component of the work reported here is that we look at intermediate stages in order to elucidate the mechanism: I looked at the detachment efficiency after three specified points (Fig. 2.1): Bubble - Stage I, Bubble - Stage II, or Final. Hence, we use the metric:

$$
P_{\mathrm{det}}=\frac{\text { Initial Number }- \text { Stage Number }}{\text { Initial Number }} \times 100 \% \text {, }
$$

where "Stage Number" refers to one of the three stages listed above.

Gómez-Suárez et al. reported that the higher the velocity of a passing air-liquid interface over a glass surface, the lower the bacterial detachment efficiency. ${ }^{22}$ Such a result is counterintuitive if the dominating force were hydrodynamic, since movement of the air-liquid interface imparts a viscous-drag force $\left(F_{\mathrm{s}}\right)$ on particles adhered to a plane wall:

$$
F_{\mathrm{S}}=1.7(6 \pi) \mu R_{\mathrm{P}} V
$$

where $R_{\mathrm{P}}$ is the particle radius and $V$ is the fluid velocity. ${ }^{87}$ However, this force is typically too small to independently remove adhered bacteria from a solid surface. The authors therefore conclude that the critical effect is not the lubrication force acting on the bacteria, but whether there is enough time for the film to drain. Liquid film drainage can be potentially influenced by 
a number of factors, including gravity, surface wettability, geometry, and disparities in interfacial tension (the Marangoni effect). ${ }^{88}$ Slower bubbles allow more time for drainage to occur and if there is enough time for the bubble to contact the bacterium then the relatively large surface tension forces (Eqn. 2.2) enable detachment of bacteria from the solid. Bretherton used the motion of bubbles in long glass tubes of radius $r$ to develop an equation that approximates the film thickness $H$ as a function of the air bubble velocity $V$, given as:

$$
\frac{H}{r}=0.643\left(\frac{3 \mu V}{\sigma}\right)^{2 / 3}
$$

where $\mu$ is the dynamic viscosity and $\sigma$ is the interfacial surface tension assuming the ratio of $H$ to $r$ is very small and that the tube is perfectly wetted. ${ }^{89}$ Note that the ratio of viscous to capillary forces, expressed as $\mu V / \sigma$ in Eqn. 2.5 , is a dimensionless quantity in fluid dynamics denoted as the capillary number $(\mathrm{Ca}) .{ }^{90}$ From Eqn. 2.5 , it is readily shown that as the velocity of the air bubble increases, so does the resultant liquid film thickness.

The importance of bacterial detachment on film drainage suggests the importance of the wettability of the solid in addition to the wettability of the bacterium. In prior work, the hydrophobicity of the solid was considered in terms of how it affects the adhesion of the bacterium to the solid $;^{71,91}$ here my main interest is how the hydrophobicity of the solid affects attachment of the bubble to the solid. In general, it is more difficult to remove objects from a hydrophobic surface, which is opposite to the response that I expect for enhancing film drainage, thus making these two different mechanisms easy to distinguish.

Finally, I will describe briefly some factors that are not considered in this thesis. The strain and shape of bacteria adhered can also affect detachment, with spherical coccal cells detaching more easily than rod-shaped particles such as $P$. aeruginos $a,{ }^{71}$ but this effect is not considered here.

Very small bubbles (diameter 135-270 $\mu \mathrm{m}$ ) mixed within flowing liquids have also been shown to increase bacterial removal for larger flow velocities on mature biofilms, highlighting the importance of a combination of fluid dynamics, surface tension, and bacterial dispersion on detachment. ${ }^{92}$ While very high fluid flow rates can by themselves stimulate bacterial detachment due to the sizeable shear rates possible (11,000 to $\left.16,000 \mathrm{~s}^{-1}\right)$ at substratum surfaces, the addition of $>10 \mu \mathrm{m}$ diameter microbubbles to these flows promotes subsequent detachment of more shear-resistant bacterial strains such as Actinomyces naeslundii and its coadhering aggregates. ${ }^{93}$ 
Subsequent research on the biofilm detachment effects of microbubbles yields similar results likely due to the generation of high pressure waves as the microbubbles shrink and collapse under the water's surface, complementing viscous forces already present in the liquid stream. ${ }^{42}$ Such bubbly fluid flows can result in bacterial removal efficiencies on the order of 0.4 per bubble collision with a biofilm and are consistent with developed mathematical models for dynamic biofilm removal. ${ }^{94}$ These findings have recently been incorporated into a novel ship hull cleaning device utilizing an ultrasonically activated stream of microbubbles in water to significantly improve the biofilm cleaning capabilities of fluid flow while maintaining the surface properties of the original material. ${ }^{95}$ However, the effects of high fluid velocities or microbubble interactions on adhered bacteria are not discussed in this thesis.

\subsection{Time of Bacterial Adhesion}

Time of adhesion has been shown to be a significant factor in bacterial detachment. This is likely due to strengthened bonding by pili as well as the gradual accumulation of secreted adherent EPS by individual bacteria. For instance, on platinum electrode surfaces, the longer the amount of time Pseudomonas fluorescens is adhered to the surface, the longer the duration of hydrogen bubble formation required for effective biofilm removal. ${ }^{96}$ This is also exhibited by the cleaning of Staphylococcus aureus after short adhesion times from microfluidic flow channels with rectangular cross sections, where lower bubble velocities resulted in larger detachment efficiencies with the exception of in confined geometries such as sharp corners. ${ }^{73}$

Despite the overall trend of better adhesion over a longer time, there has also been some previous work that suggested that bacteria that have been adhered for a longer duration of time are more easily removed. In studying isolated bacteria, Gómez-Suárez et al. determined that the production of EPS can deter bacterial adhesion due to the surface-active properties of uronic acid-containing polymers within the EPS itself. ${ }^{97}$ Tsuneda et al. expanded on this by concluding that if EPS secretion is relatively small, electrostatic interactions can hinder bacterial adhesion whereas substantial production of EPS, consistent with longer term biofilm development, can enhance bacterial adhesion due to polymeric interactions. ${ }^{98}$ 


\section{Chapter 3: Motivation and Aims of the Thesis}

3.1 Variable Factors

In this work I consider how various factors affect the detachment of bacteria by bubbles and examine the mechanism by studying detachment as a function of the progression of the bubble. These factors and their levels are listed in Table 3.1. A significant aspect of my work is that, by considering several factors in a single experimental design, I can see which factors are most important and also look at the interactions between factors.

Table 3.1. Summary of Factors Varied in this Thesis

\begin{tabular}{|c|c|c|}
\hline Factor & Levels & Hypothesized Effect \\
\hline Wettability of Solid & Hydrophobic, Hydrophilic & $\begin{array}{c}\text { Affects film drainage } \\
\text { (may also affect bacterial adhesion) }\end{array}$ \\
\hline Speometry of Interaction & $\begin{array}{c}\text { Vertical, Lateral Through, } \\
\text { Lateral Oscillatory }\end{array}$ & $\begin{array}{c}\text { Affects direction of air-liquid interface } \\
\text { velocity }\end{array}$ \\
\hline $\begin{array}{c}0.05 \text { and } 0.10 \mathrm{~mL} / \mathrm{min} \text { Injection } \\
\text { Rate }(\text { Vertical); } \\
0.21 \text { and } 0.72 \mathrm{~mL} / \mathrm{min} \text { Flowrate } \\
\text { corresponding to approx. } \\
0.8 \text { and } 3 \mathrm{~mm} / \mathrm{s} \text { (Lateral) }\end{array}$ & $\begin{array}{c}\text { Affects extent of drainage of thin liquid } \\
\text { film between solid and liquid } \\
\text { (will also affect magnitude of lubrication } \\
\text { force) }\end{array}$ \\
\hline Adhesion & $0.5 \mathrm{and} 6 \mathrm{hr}$ & $\begin{array}{c}\text { Affects strength of bacterial adhesion } \\
\text { and possibly the bacterial and solid } \\
\text { contact angle }\end{array}$ \\
\hline Solid Texture & Smooth, Hemispherical & $\begin{array}{c}\text { Affects drainage of liquid film and } \\
\text { adhesion of bacteria }\end{array}$ \\
\hline
\end{tabular}

The first factor is the wettability of the solid, which was previously discussed with respect to resultant surface tension forces and bacterial adhesion in Section 2.1. The second factor is how the geometry of interaction affects the detachment efficiency. I consider the geometries related to the two basic applications: perpendicular collision of a free bubble with a solid, which is related to removing external fouling from the hulls of ships, and translation of a bubble through a channel parallel to the solid, which is related to the interior cleaning of pipes. Each geometry is shown schematically in Fig. 3.1. When a free bubble strikes a solid, the airliquid interface can have a complex shape that depends on fluid flow near the bubble, ${ }^{99}$ but here I consider only low velocities so that the advance of the bubble against the solid is similar in nature to the advance of a bubble along a pipe interior. Free bubbles usually have a much shorter contact time (typically milliseconds for a $2.5 \mathrm{~mm}$ bubble, see Eqn. 3.2) (4) $^{4}$ than in my experiments but the advantage of a slow approach is that I am able to track the bacteria throughout the collision. After a free bubble collides with a surface perpendicularly, the bubble often bounces 
back such that the motion of the air-liquid interface is oscillatory on the surface (although it may not retrace the same trajectory). Therefore, for comparison purposes, I also considered an oscillatory trajectory of a bubble within a channel. In my experiments on perpendicular bubbles, the bubble is constrained by attachment to the air supply in the channel wall, and grows by addition of air, rather than translating as a finite volume across the solid. The bubble is expanded in the direction of the solid surface, so that the collision is forced. This approach necessitated the concept of a dwell time between the forward and reverse motion of the bubble, which I fixed at approximately $3 \mathrm{~min}$. For the oscillatory lateral bubble, the dwell time was also fixed at $3 \mathrm{~min}$ for comparison. For the lateral geometries, the bubble is always flattened over a large area in contact with the channel walls and the solid surface (see Fig. 3.1).

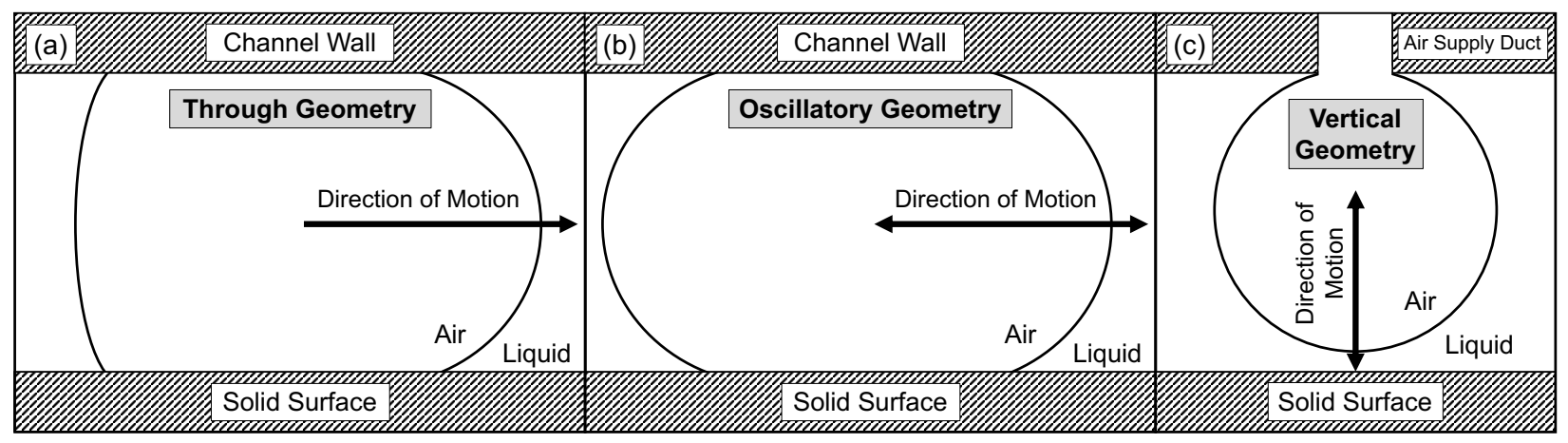

Fig. 3.1. Schematic of the three different geometries used in my experiments. (a) "Through" bubble: air bubble moves parallel to the solid-liquid interface in one direction. (b) "Oscillatory" bubble: air bubble moves parallel to the solid-liquid interface but reverses direction. After passage of the first air-liquid interface through the microscope field of view, the bubble is held stationary for approximately 3 minutes and then the direction of motion is reversed. (c) "Vertical" bubble: air bubble moves perpendicular to the solid-liquid interface, first toward the bacteria and then away after an approximately 3 minute stationary period on the solid surface.

Others have shown that the speed of the bubble affects the removal efficiency, so I also studied this factor. The fast and slow air injection rates used for the vertical bubble geometry were $0.05 \mathrm{~mL} / \mathrm{min}$ and $0.10 \mathrm{~mL} / \mathrm{min}$, respectively. For the lateral bubble geometry, the slowest flow rate that I could conveniently examine without routine bubble pinning was $0.21 \mathrm{~mL} / \mathrm{min}$, so I used this flow rate and a faster flow rate of $0.72 \mathrm{~mL} / \mathrm{min}$. Using Bretherton's equation (Eqn. $2.5),{ }^{89}$ these flows correspond to film thicknesses of 8 and $19 \mu \mathrm{m}$, respectively, compared to the bacterial thickness of about $1.2 \mu \mathrm{m}$.

My final factor was the time that the bacteria remained adhered to the solid before removal was attempted with the bubble. Bacterial adhesion shows a typical time-development where the bacteria attach more strongly over time. ${ }^{100}$ For $P$. aeruginosa under my experimental conditions, I find a moderate density of bacteria adhered (approx. $3.5 \times 10^{4} \mathrm{~cm}^{-2}$ ) after about 30 
minutes, but many are moving (velocity $\sim 1 \mu \mathrm{m} / \mathrm{min}$ ) ${ }^{101}$ while attached. By about 6 hours, fewer bacteria are moving, and I expected that they might be more strongly adhered by secretion of EPS or the binding of other adhesive elements to the solid surface. ${ }^{98}$ At much longer times, there are so many bacteria that it becomes difficult to count individuals, and the constitutive fluorescence is lost, so I chose the time levels of $30 \mathrm{~min}$ and 6 hours for my experiments.

The surfaces of some solids were also made to be nonhomogeneous by introducing an 8 $\mu \mathrm{m}$ diameter hemispherical textured pattern convex to the liquid. The variations in height and texture on the surface affect not only the behavior of the bubble's interaction with the solid but also the displacement of bacteria in relation to their surrounding topography.

\subsection{Timeline of Bubble Interaction}

A novel aspect of my work is that I imaged the adsorbed bacteria as a function of time during the entirety of their interaction with the bubble. The intent here is to separate the effects of (a) the initial passage of the air-liquid interface across the bubble, (b) the period while the bacterium is under the bubble, and (c) the removal of the bubble from the solid. This enables me to examine which of these steps is critical in the removal of bacteria. I capture video of the bacteria throughout the entire interaction, but only provide a quantitative analysis for before the air bubble collision, immediately following collision, immediately prior to removal, and after removal. These stages are shown schematically for the vertical geometry approach in Fig. 2.1 and are referred to as Initial, Bubble - Stage I, Bubble - Stage II, and Final, respectively. As far as I know, all prior bacterial work has only quantitatively considered the effects before and after the interaction with the bubble.

\subsection{How the Experiments Here Compare to Applications}

There were several ways in which my model experiments differ from applications such as cleaning a hull in a marine environment. The idea of using seawater was considered but rejected because seawater is known to be affected by age and Virginia Tech is not on the coast.

Furthermore, seawater is complex. There was no track record of using even simulated seawater or marine organisms in my laboratory, so there would have been considerable start up time. Instead I used a freshwater organism, which still enables elucidation of the physical principles. To stimulate the growth of $P$. aeruginosa and to provide adequate nutrient flow over long 
adhesion time periods, tryptic soy broth (TSB) was used as a liquid medium substitute for seawater although seawater has a much greater ionic strength, less nutrients, and varies from location to location.

The impact velocities used for experiments described in the thesis are also much lower than when a bubble is directed against a ship hull in a large body of water. The terminal velocity $\left(V_{T}\right)$ of a bubble rising through a stationary liquid is dependent on a combination of buoyancy, drag, and gravitational forces. Setting these forces equal to each other at terminal velocity gives:

$$
\left(\rho_{\mathrm{l}}-\rho_{\mathrm{v}}\right) g \frac{\pi d^{3}}{6}=C_{\mathrm{D}} \frac{1}{2} \rho_{\mathrm{l}} V_{\mathrm{T}}^{2} \frac{\pi d^{2}}{4}
$$

where $C_{\mathrm{D}}$ is the drag coefficient, $d$ is the bubble diameter, $g$ is gravitational force, and $\rho$ is the phase density. ${ }^{102}$ Solving for terminal velocity gives:

$$
V_{T}=\sqrt{\frac{4 d\left(\rho_{l}-\rho_{v}\right) g}{3 \rho_{l} C_{D}}} .
$$

For a $2.5 \mathrm{~mm}$ diameter bubble in $21^{\circ} \mathrm{C}$ water with a $C_{\mathrm{D}}$ of $0.53,{ }^{103}$ Eqn. 3.2 results in a calculated $V_{T}$ of $0.25 \mathrm{~m} / \mathrm{s}$. This is reasonable considering experimental values that show terminal velocities of $0.15-0.20 \mathrm{~m} / \mathrm{s}$ for similarly sized bubbles in $29^{\circ} \mathrm{C}$ water. ${ }^{102}$ Bubble impact velocities observed in this study were considerably slower. Note that gravitational forces scale with $d^{3}$ and become more significant for much larger bubbles. Unlike freely moving bubbles with constant volumes, the bubbles observed in the vertical geometry portion of this study were moved toward the solid by volume expansion rather than driven by buoyancy, as shown in Fig. 3.1. The velocity of approach is thus dependent on the rate of air injection from the syringe pump. Using this methodology, bubbles in vertical geometry experiments are not moving freely within the medium but are rather tethered to the air duct opposite to the solid surface of interest. Bubbles moving laterally through a flow chamber span the entire flow chamber, the geometry of which influences the shape of the bubble.

It is important to note that the bubbles observed during vertical geometry experiments were also not perfectly spherical. Although 1-2 mm diameter bubbles freely rising in clean water are ellipsoidal, shaped by hydrodynamic forces, pressure difference effects can also influence their radius. ${ }^{104}$ The general form of the Young-Laplace equation:

$$
\Delta p=\sigma\left(\frac{1}{R_{1}}+\frac{1}{R_{2}}\right)
$$


provides the pressure difference $(\Delta p)$ across the bubble interface due to surface tension $(\sigma)$, where $R_{1}$ and $R_{2}$ are the principal radii of curvature and the higher pressure is on the concave side of the bubble. The mean curvature of the bubble is directly proportional to this pressure difference. ${ }^{105}$ For a spherical bubble, $R_{1}$ is equal to $R_{2}$.

The air bubble contact time with the substrate can also be significantly shorter in application than in my experiments. An estimate for the contact time of a free rebounding bubble is given by:

$$
t_{\mathrm{c}}=0.717 \sqrt{\frac{0.73 \rho_{\mathrm{l}} d^{3}}{\sigma}}
$$

where $d$ is the bubble diameter, $\rho_{1}$ is the density of the liquid, $\sigma$ is the surface interfacial energy, and $t_{\mathrm{c}}$ is the contact time. ${ }^{94}$ For a $2.5 \mathrm{~mm}$ diameter bubble in water contacting a low surface energy polymer such as PDMS the contact time is in the range of milliseconds. In my experiments the contact time of a vertical geometry bubble is much longer on the order of three minutes. Ralsten et al. provided a review of the different equations for estimating the film thickness of a bubble pressed against a flat solid surface. All of these equations are based on the combined effects of bubble surface tension, bubble radius, radius of the barrier ring, viscosity, and time. ${ }^{74}$ As such, there were was a substantial amount of time allowed for the film to drain as it contacted the surface during my experiments. A significant advantage of this approach is that I was able to resolve what happens to the bacteria during the actual collision, and thus separate the effects of dewetting during bubble attachment from the rewetting when the bubble departs.

While the lateral bubble experiments simulate the immediate impact of a bubble collision with a ship hull to a lesser degree, they are more applicable to the interaction developed as a bubble translates up the exterior of the hull. Lateral bubbles are also an approximation of a potential method used to clean fouled piping systems by translating bubbles through them that span the entirety of the pipe diameter. 


\section{Chapter 4: Experimental Section}

4.1 Fabrication of PDMS-Coated Glass Solids

In all experiments, the test bacteria were adsorbed to a thin $(\sim 8 \mu \mathrm{m})$ film of polydimethylsiloxane (PDMS) rubber on a microscope cover slide $(24 \mathrm{~mm} \times 50 \mathrm{~mm}$, Fisher Scientific). These slides were cleaned first by sonication (B2500A-DTH, VWR) in acetone (Fisher Chemical) and then in 200 proof ethanol (Decon Labs) each on low power for 10 minutes at room temperature, followed by deionized water for 30 minutes at room temperature and then dried. PDMS polymer (Sylgard 184, Dow Chemical) was prepared by mixing silicone elastomer base with curing agent in a 10:1 ratio by weight. The PDMS was then degassed under vacuum in a desiccator for approximately 30 minutes until uniform and spin-coated onto the cleaned glass slides at $3000 \mathrm{rpm}$ for 30 seconds (Laurell Technologies). The PDMS-coated glass slides were then cured by heating from $80{ }^{\circ} \mathrm{C}$ to $150{ }^{\circ} \mathrm{C}$ over 30 minutes, and then held at $150{ }^{\circ} \mathrm{C}$ for at least 48 hours to remove volatile low molecular weight chains that diffuse to the surface. This procedure hinders the return to the hydrophobic state (recovery) of PDMS made to be hydrophilic by $\mathrm{O}_{2}$ plasma treatment. ${ }^{106}$ As shown in Table 4.1, untreated samples had high contact angles and are described as "Hydrophobic". "Hydrophilic" solid surfaces were $\mathrm{O}_{2}$ plasma treated for 5 minutes at $100 \mathrm{~W}$ (Plasma Prep III, SPI Supplies) under vacuum. These PDMS samples were very flat and smooth as the root-mean-square (rms) roughness measured using an Asylum Research Cypher ES atomic force microscope (AFM) with Bruker ORC8-10 probes was $<1 \mathrm{~nm}$ over an area of $1 \mu \mathrm{m} \times 1 \mu \mathrm{m}$.

PDMS samples with $8 \mu \mathrm{m}$ diameter hemispherical textured topographies were also prepared. PDMS negative mold stamps were created from $8 \mu \mathrm{m}$ diameter monodisperse silica microspheres using the topographical fabrication procedure described by Chang et al. ${ }^{101}$ The PDMS stamps were $\mathrm{O}_{2}$ plasma treated for 5 minutes at $100 \mathrm{~W}$ and then placed under vacuum in a desiccator with $50 \mu \mathrm{L}$ nonafluorohexyltrichlorosilane (Gelest) for one hour to create an antiadhesion layer. The PDMS stamps were then pressed against microscope cover glass slides spin-coated with PDMS as described above and air pockets gently squeezed out. The hemispherical topographies were imaged using AFM and confirmed to have hemispherical textured topographies of approximately $8 \mu \mathrm{m}$ in diameter and approximately $2 \mu \mathrm{m}$ in height. 


\subsection{Characterization of Wettability}

The contact angles of both bacterial growth medium and deionized water were measured using a goniometer (FTA125, First Ten Angstroms) ${ }^{107}$ at $21^{\circ} \mathrm{C}$. All hydrophilic PDMS measurements were taken approximately 18 hours following the completion of $\mathrm{O}_{2}$ plasma treatment to replicate the overnight curing time used for the construction of experimental bubble cells before each bacterial experiment. Each reported angle is the average of three measurements on independent samples, where each measurement is the average of the left and right side of the field of view. The contact angles were measured in two ways: (1) a liquid droplet (2-3 mm diameter) on the solid in air and (2) an air bubble (2-3 mm diameter) on the solid in the liquid approaching from underneath the solid (captive bubble method ${ }^{105}$ ). Resultant contact angles are presented in Table 4.1 and Table 4.2, respectively. The advantage of the captive bubble method is that we were able to investigate a solid with adsorbed bacteria in the nutrient solution without disturbing the bacteria prior to interacting with the test bubble. For bacteria-coated surfaces, the early exponential culture (see Section 4.3) was diluted to $\mathrm{OD}_{600}=0.0125$ in tryptic soy broth (TSB, $30 \mathrm{~g} / \mathrm{L}, \mathrm{BD}$ Difco) nutrient solution and used as the liquid phase. Time of bacterial adhesion was determined based on the time at which the bacteria solution was poured into the cuvette.

The PDMS had a high water contact angle before plasma treatment $\left(\theta_{\mathrm{adv}}=121^{\circ}\right)$ and a lower contact angle $\left(\theta_{\mathrm{adv}}=46^{\circ}\right)$ after plasma treatment, justifying my use of the terms "hydrophilic" and "hydrophobic" to describe these surfaces. In TSB, the receding angle on both surfaces were much lower, which indicates significant adsorption to the surface of both materials. Three sides of the fluid cell were constructed from polycarbonate, which had a lower advancing contact angle than the hydrophobic solid, and probably enabled liquid to flow around the spanning bubble. The contact angle of captive bubbles using TSB as the liquid phase was also measured because this is more relevant to the bubble impact experiments discussed later. The solids were equilibrated in the relevant liquid for $5 \mathrm{~min}$ prior to testing with the bubble, such that adsorption of TSB can occur over the entire solid-liquid interface. The contact angles were always measured through the liquid phase for both contact angle methods, but receding and advancing contact angles for the captive bubble method correspond to opposite directions of the interface compared to the liquid droplet measurements. TSB never dewet hydrophilic solids during bubble impact experiments, so the angles are listed as $<15^{\circ}$ for the captive bubble method. 
In general the angles for the droplet and bubble are very similar, except for hydrophilic solids, where the angles are much lower because the liquid film did not break.

It is interesting to examine the TSB contact angles for solid surfaces with adhered bacteria using the captive bubble method. Over time there is very little variation in contact angle. This shows that the bacteria are not having a large effect on changing the wettability of the solid.

Table 4.1. Contact Angles of Liquid Droplets on the Solids.

Advancing $\left(\theta_{A}\right)$ and receding $\left(\theta_{R}\right)$ contact angles are the average \pm standard error, based on at least three independent experiments. The average equilibrium contact angle $\left(\theta_{e q}\right)$ for each surface was calculated using Tadmor's equation. ${ }^{108}$

\begin{tabular}{cccccc}
\hline Liquid & Solid Suface & Surface Wettability & $\boldsymbol{\theta}_{\mathbf{e q}}$ & $\boldsymbol{\theta}_{\mathbf{A}}$ & $\boldsymbol{\theta}_{\mathbf{R}}$ \\
\hline Water & PDMS & Hydrophobic & 96 & $121 \pm 1$ & $80 \pm 2$ \\
& & Hydrophilic & 35 & $46 \pm 1$ & $23 \pm 4$ \\
& Polycarbonate & Untreated & 48 & $68 \pm 6$ & $28 \pm 7$ \\
& & & & & \\
TSB & PDMS & Hydrophobic & 59 & $116 \pm 1$ & $24 \pm 1$ \\
& & Hydrophilic & $<15$ & $42 \pm 2$ & $<15$ \\
& Polycarbonate & Untreated & 50 & $77 \pm 3$ & $26 \pm 2$ \\
\hline
\end{tabular}

Table 4.2. Contact Angles of Captive Bubbles on the Solids.

Advancing $\left(\theta_{A}\right)$ and receding $\left(\theta_{R}\right)$ contact angles are the average \pm standard error, based on at least three independent experiments. The average equilibrium contact angle $\left(\theta_{e q}\right)$ for each surface was calculated using Tadmor's equation. ${ }^{108}$ Time of Adhesion refers to the length of time the solid was exposed to bacterial suspension before the contact angle was measured.

\begin{tabular}{ccccccc}
\hline Liquid & Solid Surface & Surface Wettability & Time of Adhesion & $\boldsymbol{\theta}_{\text {eq }}$ & $\boldsymbol{\theta}_{\mathbf{A}}$ & $\boldsymbol{\theta}_{\mathbf{R}}$ \\
\hline TSB & PDMS & Hydrophobic & 0 & 71 & $43 \pm 2$ & $115 \pm 1$ \\
& & $30 \mathrm{~min}$ & 70 & $46 \pm 2$ & $107 \pm 1$ \\
& & $6 \mathrm{hr}$ & 69 & $43 \pm 1$ & $107 \pm 1$ \\
& & 0 & $<15$ & $<15$ & $<15$ \\
\hline
\end{tabular}

In keeping with previous methodology, we measured the contact angle of water on the bacteria by using a large colony of $P$. aeruginosa that had been grown on an agar plate and then dried. The colony was completely wet by water, in contrast to the previous report of $43^{\circ}$ for dried bacterial lawns of $P$. aeruginosa.$^{71}$ However, my bubble experiments showed that bacteria did readily stick to bubbles, so the bacteria must have a finite contact angle under the conditions of the flow cell experiments.

\subsection{Bacterial Growth}

The methods used in this experiment to culture bacteria are similar to those previously used by Chang et al. ${ }^{101}$ P. aeruginosa PA01, a rod-shaped bacteria strain genetically modified to constitutively express the bright red fluorescent protein tdTomato (maximum excitation at 554 $\mathrm{nm}$ and a maximum emission at $581 \mathrm{~nm})^{109}$, and exhibit resistance to the antibiotic gentamycin, 
was used exclusively throughout all experiments. From previous work in my lab, the dimensions of $P$. aeruginosa are $2.90 \pm 0.07 \mu \mathrm{m}$ in length and $1.21 \pm 0.02 \mu \mathrm{m}$ in diameter. ${ }^{101}$ Bacteria were streaked onto tryptic soy agar (40 g/L, BD Difco) plates and incubated overnight at $37^{\circ} \mathrm{C}$. A single colony from the overnight culture was used to inoculate $50 \mathrm{~mL}$ of TSB and shaken at 300 rpm (211DS, Labnet) overnight at room temperature (approximately $23.5^{\circ} \mathrm{C}$ ). The following day, $50 \mu \mathrm{L}$ of the overnight culture was used to inoculate $50 \mathrm{~mL}$ of TSB which was shaken at $300 \mathrm{rpm}$ and room temperature. After four hours, a sample of the culture was diluted to $\mathrm{OD}_{600}=$ 0.0125 in TSB and used to inoculate the bubble cell chambers. The period of four hours was chosen because there is exponential growth of the bacteria during this time (see Fig. C.5), as is standard practice for microbiological research.

\subsection{Bacteria-Bubble Interactions}

The ability of single bubbles to remove bacteria from solids was measured in two types of custom designed cells that each (a) allowed for the flow of nutrients and waste, and (b) allowed for the generation of single bubbles. These experiments are referred to as "bubble cell experiments". All bubble cell experiments were performed at room temperature $\left(21^{\circ} \mathrm{C}\right)$ to approximate common natural surface water conditions and to minimize any temperature induced surface tension differences between phases. The geometries are shown schematically in Fig. 3.1 and both photographs and schematics of the fluid handling setup are depicted in Figs. S3 and S4. Each set-up contained the typical components of a bubble cell experiment, as described by Chang et al. ${ }^{101}$ This consisted of a media storage bottle containing TSB, a multi-channel peristaltic pump (205U, Watson-Marlow), a bubble trap, the polycarbonate bubble cell, and a second media storage bottle used as a waste container all interconnected with $1.6 \mathrm{~mm}$ inner diameter biocompatible BPT tubing (PharMed). Components were sterilized prior to use in an autoclave at $121{ }^{\circ} \mathrm{C}$ for 15 minutes. The plungers of the air supply syringes were sterilized separately using ethanol prior to use. The vertical approach bubble cell was $\mathrm{O}_{2}$ plasma-treated for 5 minutes at $100 \mathrm{~W}$ to deter bubble interaction with channel walls during experimentation. The solid surface (see Section 4.1) was then adhered to the bubble cell using PDMS applied to the upper channel walls and cured overnight at $80^{\circ} \mathrm{C}$. Details of the flow cell experiments are provided in Appendix A: Supporting Methods - Flow Cells. 


\subsection{Microscopy}

A detailed description of the imaging procedures used for this experiment are included in Appendix B: Supporting Methods - Microscopy. It is important to note that for the vertical geometry there is an additional level of uncertainty regarding the actual velocity of the air-liquid interface for comparisons. Although the rate of air injection was held constant at either 0.05 $\mathrm{mL} / \mathrm{min}$ or $0.10 \mathrm{~mL} / \mathrm{min}$, in the field of view the velocity of the air-liquid interface varied. This is partly because the bubble expands radially, but also because the point at which the bubble impacted the solid surface varied greatly between experiments: it was not always in the center of the field of view. Thus, even in the vertical bubble experiment, the air-liquid interface would often translate laterally, rather than be radial from a central point in the field of view.

\subsection{Bacteria Identification and Data Analysis}

The presence of the bubble degraded the contrast so imaging in brightfield was unsuccessful, requiring me to use fluorescent bacteria. Even then, changes to the bubble geometry caused significant changes in image contrast such that I was not able to readily manage in automated identification using MATLAB scripts. Therefore, bacteria were identified and counted manually. Bacteria that were not adhered to the solid were excluded on the basis of their high speed, with a threshold of approximately $10 \mu \mathrm{m} / \mathrm{min}$. Bacteria were counted in four individual frames of each bubble interaction: Initial, Bubble - Stage I, Bubble - Stage II, and Final (see Fig. 2.1). To ensure an adequate sample size, data was only analyzed if there were at least 20 individual bacteria in the Initial frame. During vertical bubble experiments, Initial counts were performed at a point between the bubble being emitted from the air duct and prior to it impacting the solid surface. This time was chosen so that any bacteria that were removed or deposited by hydrodynamic effects or pressure arising from the rapid expansion of the bubble out of the air duct were not included in the analysis. ${ }^{105}$ Bubble - Stage I counts were completed immediately after the bubble's air-liquid interface moved entirely across the microscope's field of view during air injection or after the interface became stationary, whichever came first. Bubble - Stage II counts were completed immediately prior to the second passing of the airliquid interface across the field of view as the air bubble was being withdrawn. Final counts were performed after the bubble detached from the solid, but prior to it being withdrawn into the air supply duct. If the bubble was unable to be completely removed, counts were conducted after 
the interface became stationary within the field of view, and only bacteria within the area traversed twice by the air-water interface were considered for counts at all four stages.

For lateral bubble experiments, Initial counts were performed after the bubble completely entered the flow chamber but prior to the air-liquid interface entering the microscope field of view. Bubble - Stage I counts were performed on the frame immediately following the initial passage of the air-liquid interface across the field of view and Bubble - Stage II counts were on the last frame prior to the air-liquid interface moving across the field of view a second time. Final counts were completed following the second passage of the air-liquid interface across the field of view but prior to the bubble leaving the flow chamber and entering the media inlet or outlet port.

Sometimes bacteria were clumped into groups where individual bacteria could not be resolved. This occurred most often on the hydrophilic solid when small liquid droplets or a thin liquid film remained on the solid under the bubble. Under these circumstances, an accurate count of bacteria was achieved by frame by frame analysis of the clumping process (see Fig. C.6).

Following collection of all bacterial counts, Design Expert 11 (Stat-Ease Inc.) - Version 11.0.3.0 64-bit statistical software was used to perform a split-plot analysis of variance (ANOVA) on the data. Each experimental condition was replicated at least three times. Conditions with more than three experimental replicates were averaged together for the ANOVA analysis. 


\section{Chapter 5: Results}

5.1 Qualitative Description of Time Series

An example of a time series of images of the bacteria on the PDMS is shown in Fig. 5.1.

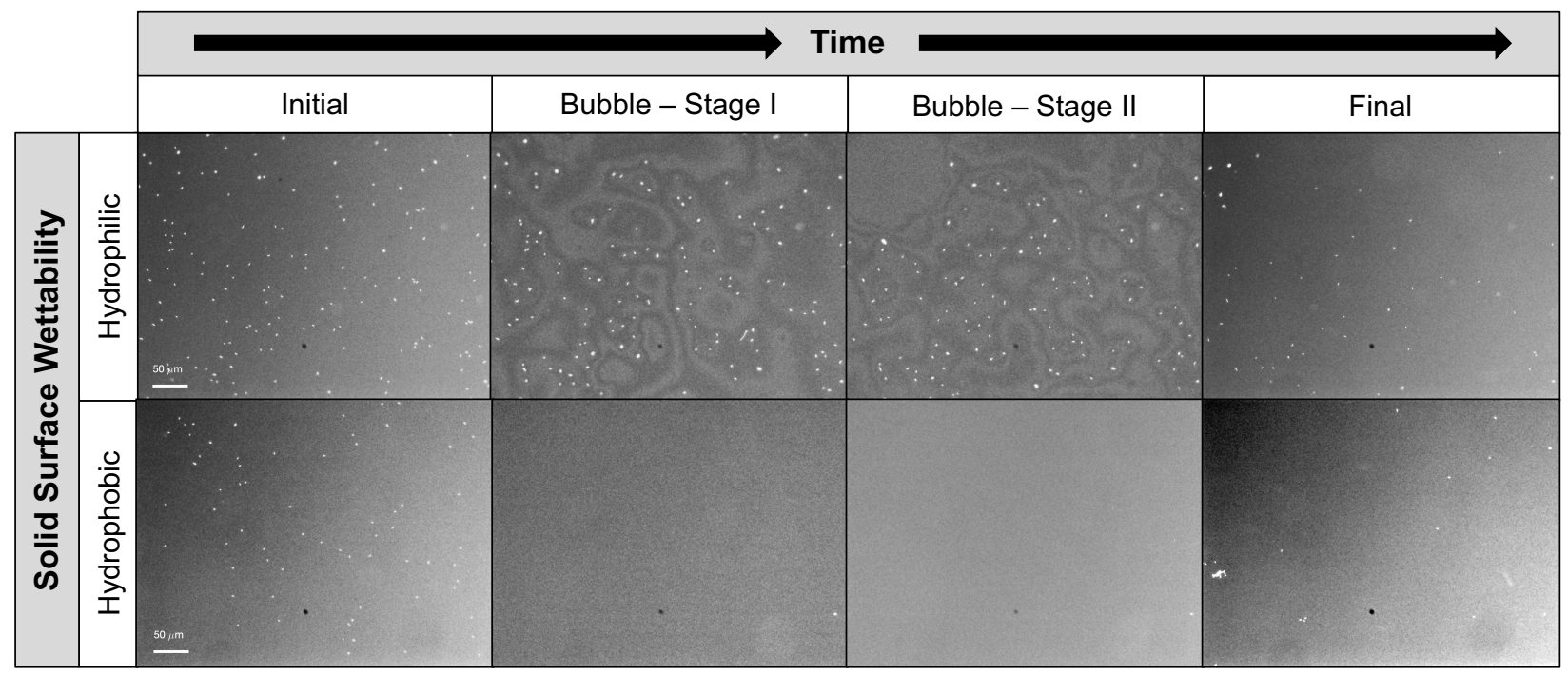

Fig. 5.1. Time series of fluorescent images depicting the interaction of a bubble with a hydrophilic solid or a hydrophobic solid. Adhered $P$. aeruginosa bacteria appear as white dots against the dark solid surface. Both time series depict lateral oscillatory bubbles following 30 minutes of bacterial adhesion with a flow rate of $0.21 \mathrm{~mL} / \mathrm{min}$. The bubble moved to the right before Bubble-Stage I and to the left after Bubble - Stage II.

Although the Initial states are quite similar, and many of the bacteria have been detached after the bubble is removed from the surface (Final), the intermediate images taken as the bubble passes over the bacteria show quite different stories. Most of the bacteria are removed on the hydrophobic solid as soon as the first air-liquid interface passes over the solid, whereas there is still an abundance of bacteria on the hydrophilic solid at this stage. A possible explanation for the resilience of the bacteria on the hydrophilic solid is indicated by the faint interference lines that are visible in the Bubble - Stage I and II images. To further explore this, I used reflection interference contrast microscopy (RICM) with a $445 \pm 50 \mathrm{~nm}$ filter to visually enhance this interference pattern. If there is a liquid film, then the air-liquid interface will act as a mirror yielding interference fringes. Fig. 5.2 shows fluorescence and RICM images for the same area, side by side: every bacterium is encircled by an interference fringe, clearly demonstrating that there is a thin layer of liquid surrounding each bacterium. Video of liquid film drainage shows that the film is thicker around the bacteria and thus the bacteria are hydrophilic, but not so much so that they are unable to adhere to the bubble air-liquid interface (Fig. 5.3). The bacteria are points of stabilization of the liquid film and not initiation points of dewetting. The puddling of liquid around bacteria under an air bubble was also previously reported by Asayesh et al. ${ }^{110}$ The 
lack of complete drying of the solid diminishes the ability of the bubble to remove bacteria, but some bacteria are translated to different areas of the surface as the liquid film thins. Returning to Fig. 5.1, it is clear that as the interference fringes change in shape and intensity over time, which I interpret to be thinning of the film, the bacteria are relocated to different positions on the surface; they have been pushed around by the thinning film. When the trailing edge of the bubble exits the field of view, many of these displaced bacteria are removed from the surface due to hydrodynamic and surface tension forces, whereas bacteria that remained stationary between Bubble - Stage I and Bubble - Stage II tend to stay adhered.

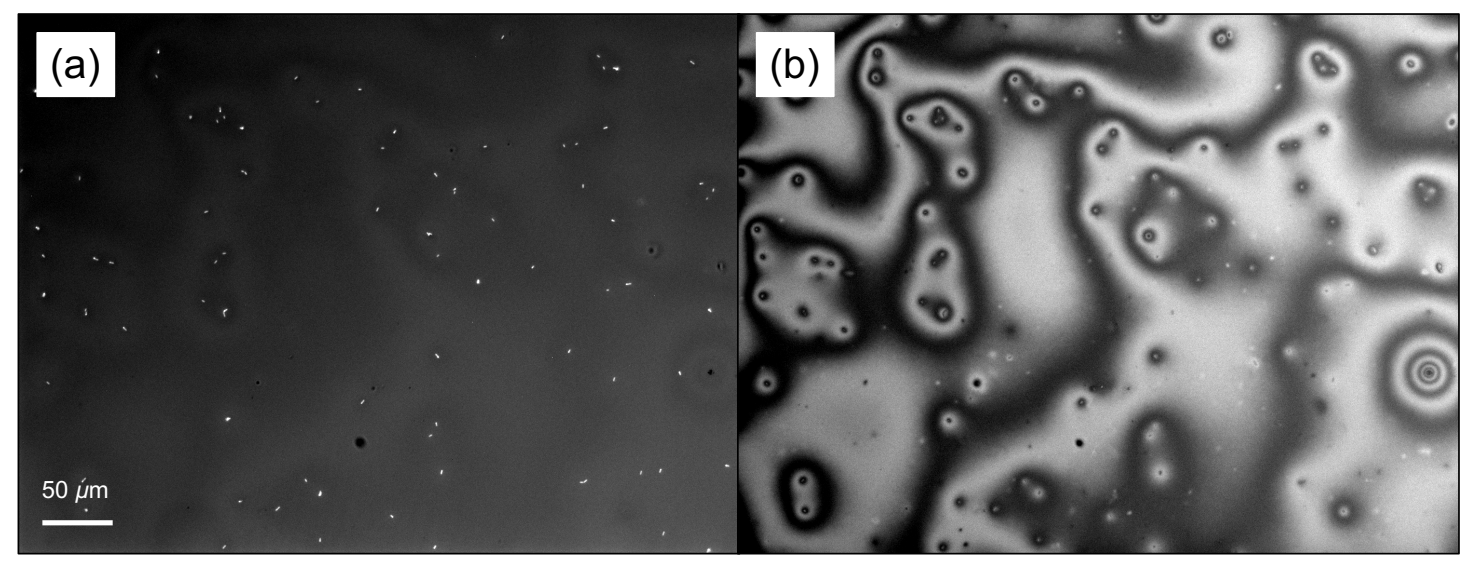

Fig. 5.2. $P$. aeruginosa adhered to a hydrophilic surface imaged using (a) fluorescence microscopy and (b) RICM (same field of view). The bright and dark bands in the RICM image demonstrate that thickness of liquid on the surface varies, that is, the surface has not dewet.

Considering now the hydrophobic solid, there are almost no bacteria left adhered on the solid during Bubble - Stage I and Bubble - Stage II, but after the bubble has left (i.e. the airliquid interface has passed through a second time) there are again some bacteria on the surface. Clearly bubbles are capable of depositing bacteria onto a surface as well as removing them. 


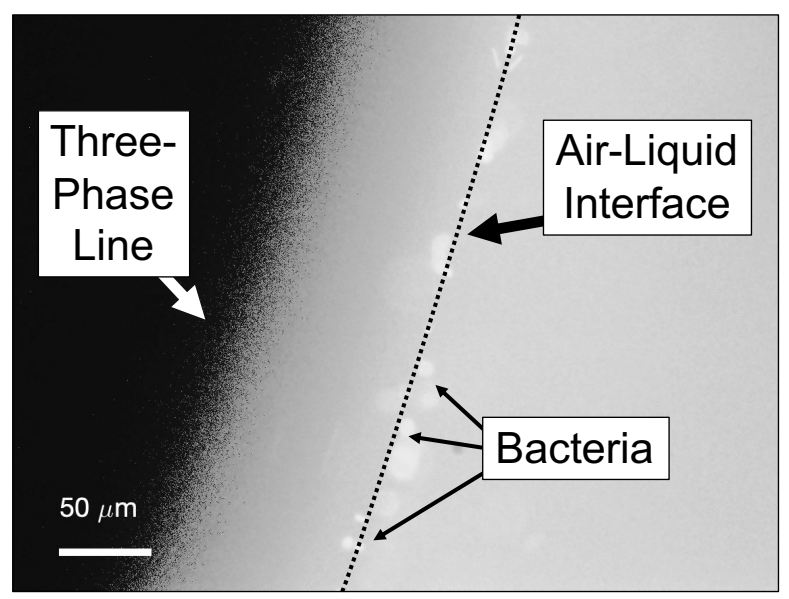

Fig. 5.3. Image of fluorescent bacteria adhered to the leading air-liquid interface of a through bubble after being stripped off of the solid surface. The focal plane is about $500 \mu \mathrm{m}$ above the solid-liquid interface, such that the three-phase line is out of focus and bacteria that are $500 \mu \mathrm{m}$ above the solid are visible, but sometimes out of focus.

\subsection{Quantitative Analysis of Detachment and Deposition}

Bacteria were enumerated at each stage and then the overall detachment efficiency was calculated using Eqn. 2.3a by comparing Initial counts to Final counts for each experiment. To quantify the deposition of bacteria when the air-liquid interface passes a second time, I use:

$$
P_{\text {deposit }}=\frac{\text { Final Number }- \text { Number at Bubble Stage II }}{\text { Final Number }} \times 100 \% \text {. }
$$

Thus, positive values for $P_{\text {deposit }}$ denote a net gain in adhered bacteria as the bubble departs whereas negative values denote a net loss in adhered bacteria. The overall detachment efficiencies and percent depositions are listed for the three geometries in Tables 5.1-5.3. For the vertical bubble I was never able to detach the bubble from the solid on hydrophobic surfaces by decreasing the volume, so only Bubble - Stage I data was recorded. Therefore, there is no data available for the overall detachment efficiency or $P_{\text {deposit }}$ on hydrophobic surfaces in Table 5.1. The raw bacterial counts used to derive these tables are listed for all experimental runs in Tables S1-S3. 
Table 5.1. Detachment Efficiencies and Percent Deposition for Vertical Bubble Experiment Geometry.

All data are presented as an average \pm standard error based on the results of at least three separate experiments.

\begin{tabular}{|c|c|c|c|c|c|c|c|c|}
\hline Surface Wettability: & \multicolumn{4}{|c|}{ Hydrophilic } & \multicolumn{3}{c|}{ Hydrophobic } \\
\hline Time of Bacterial Adhesion (hr): & \multicolumn{2}{|c|}{$\mathbf{0 . 5}$} & $\mathbf{0 . 1 0}$ & $\mathbf{0 . 0 5}$ & $\mathbf{0 . 1 0}$ & $\mathbf{0 . 0 5}$ & $\mathbf{0 . 1 0}$ & $\mathbf{0 . 0 5}$ \\
\hline Rate of Air Injection (mL/min): & $\mathbf{0 . 0 5}$ & $\mathbf{0 . 1 0}$ & $\mathbf{0 . 1 0}$ \\
\hline Overall Detachment Efficiency (\%) & $61 \pm 5$ & $48 \pm 9$ & $59 \pm 8$ & $56 \pm 8$ & - & - & - & - \\
\hline Percent Deposited $\left(\boldsymbol{P}_{\text {deposit }} \%\right)$ & $-88 \pm 18$ & $-74 \pm 18$ & $-157 \pm 61$ & $-140 \pm 51$ & - & - & - & - \\
\hline
\end{tabular}

Table 5.2. Detachment Efficiencies and Percent Deposition for Lateral Oscillatory Bubble Experiment Geometry.

All data are presented as an average \pm standard error based on the results of at least three separate experiments.

\begin{tabular}{|c|c|c|c|c|c|c|c|c|}
\hline Surface Wettability: & \multicolumn{4}{|c|}{ Hydrophilic } & \multicolumn{4}{|c|}{ Hydrophobic } \\
\hline Time of Bacterial Adhesion (hr): & \multicolumn{2}{|c|}{0.5} & \multicolumn{2}{|c|}{6} & \multicolumn{2}{|c|}{0.5} & \multicolumn{2}{|c|}{6} \\
\hline Volumetric Flow Rate $(\mathrm{mL} / \mathrm{min})$ : & 0.21 & 0.72 & 0.21 & 0.72 & 0.21 & 0.72 & 0.21 & 0.72 \\
\hline Overall Detachment Efficiency (\%) & $48 \pm 7$ & $29 \pm 11$ & $60 \pm 4$ & $48 \pm 3$ & $40 \pm 24$ & $46 \pm 19$ & $75 \pm 11$ & $60 \pm 11$ \\
\hline Percent Deposited $\left(\boldsymbol{P}_{\text {deposit }}, \%\right)$ & $-101 \pm 39$ & $-22 \pm 29$ & $-121 \pm 58$ & $-115 \pm 13$ & $80 \pm 17$ & $89 \pm 11$ & $5 \pm 19$ & $86 \pm 7$ \\
\hline
\end{tabular}

Table 5.3. Detachment Efficiencies and Percent Deposition for Lateral Through Bubble Experiment Geometry.

All data are presented as an average \pm standard error based on the results of at least three separate experiments.

\begin{tabular}{|c|c|c|c|c|c|c|c|c|}
\hline Surface Wettability: & \multicolumn{4}{|c|}{ Hydrophilic } & \multicolumn{4}{|c|}{ Hydrophobic } \\
\hline Time of Bacterial Adhesion (hr): & \multicolumn{2}{|c|}{0.5} & \multicolumn{2}{|c|}{6} & \multicolumn{2}{|c|}{0.5} & \multicolumn{2}{|c|}{6} \\
\hline Volumetric Flow Rate (mL/min): & 0.21 & 0.72 & 0.21 & 0.72 & 0.21 & 0.72 & 0.21 & 0.72 \\
\hline Overall Detachment Efficiency (\%) & $48 \pm 6$ & $23 \pm 4$ & $54 \pm 7$ & $43 \pm 11$ & $74 \pm 14$ & $77 \pm 8$ & $78 \pm 3$ & $90 \pm 3$ \\
\hline Percent Deposited $\left(\boldsymbol{P}_{\text {deposit }}, \%\right)$ & $-39 \pm 25$ & $-20 \pm 6$ & $-29 \pm 18$ & $-89 \pm 57$ & $86 \pm 14$ & $59 \pm 21$ & $35 \pm 14$ & $80 \pm 20$ \\
\hline
\end{tabular}

A few key effects are immediately obvious:

(1) The surface wettability plays a substantial role in both bacterial detachment and deposition: the overall detachment efficiencies on hydrophobic solids are generally much larger than for hydrophilic solids for all geometries.

(2) On hydrophilic solids, overall detachment efficiencies are greater for slower air speeds, consistent with previous literature.

(3) When the air-liquid interface passes over the solid a second time, bacteria tend to deposit onto hydrophobic solids $\left(P_{\text {deposit }}>0\right)$ but are removed from hydrophilic solids $\left(P_{\text {deposit }}<0\right)$.

These relationships will be further explored following a statistical screening of the data.

The overall detachment efficiencies listed in Tables 5.1-5.3 were analyzed using a splitplot ANOVA with the first four factors and levels listed in Table 3.1. Each condition was replicated at least three times. Note that the time of bacterial adhesion $(0.5 \mathrm{or} 6 \mathrm{hr})$ refers to the amount of time after injection of the inoculum into the bubble cell prior to any interaction with a bubble. The ANOVA results for all interactions are presented in Table 5.4, giving a whole-plot model $p$-value of 0.0012 , indicative that the model is a good representation for describing the results. However, the subplot model $p$-value of 0.3128 suggests that bubble air speed is not significant when all factors are included within the analysis. 
Table 5.4. Factors, Interactions, and ANOVA Results for All Overall Detachment Efficiencies. A-B interaction not listed because overall detachment efficiency was not measured for hydrophobic surfaces in vertical geometry. There were 56 residual degrees of freedom for this analysis.

\begin{tabular}{|c|c|c|}
\hline & & $p$-value \\
\hline & Whole-Plot Model & 0.0012 \\
\hline & Subplot Model & 0.3128 \\
\hline Factors & A. Geometry & 0.0446 \\
\hline & B. Surface Wettability & 0.0002 \\
\hline & C. Time of Adhesion & 0.0221 \\
\hline & D. Bubble Air Speed & 0.2217 \\
\hline Interactions & $A-C$ & 0.2970 \\
\hline & $B-C$ & 0.7800 \\
\hline & $A-D$ & 0.8127 \\
\hline & $B-D$ & 0.0631 \\
\hline & C-D & 0.5373 \\
\hline & $A-C-D$ & 0.6922 \\
\hline & B-C-D & 0.5526 \\
\hline
\end{tabular}

It is clear from the ANOVA results that surface wettability is an important factor $(p \ll$ $0.01)$. The geometry is important $(p=0.04)$, which means one cannot always compare results from different geometries in the literature. Time of bacterial adhesion $(p=0.02)$ is also important; this is reasonable, because the bacteria are active and change their state. In particular, they excrete extracellular matrix, which may make them more difficult to remove over time. Interestingly, bubble air speed was not found to be of consequence $(p=0.2)$ for my data, despite correlations described in prior literature, but the marginal significance $(p=0.06)$ of the interaction between surface wettability and bubble air speed (B-D) is indicative of the cause. The first passage of the bubble air-liquid interface removes so many bacteria from a hydrophobic surface that it may be difficult to resolve the effect of the speed of the bubble. To eliminate this effect, a second split-plot ANOVA was conducted on the overall detachment efficiencies considering all factors but only including data for the hydrophilic solid surfaces. The results of this second ANOVA are given in Table 5.5.

Table 5.5. Factors, Interactions, and ANOVA Results for Overall Detachment Efficiencies of Hydrophilic Surfaces Only. There were 26 residual degrees of freedom for this analysis.

\begin{tabular}{|l|c|c|}
\hline \multicolumn{1}{|c|}{} & $\boldsymbol{p}$-value \\
\cline { 2 - 2 } & Whole-Plot Model & 0.0427 \\
& Subplot Model & $<0.0001$ \\
& & \\
\hline Factors & A. Geometry & 0.0577 \\
& C. Time of Adhesion & 0.0269 \\
& D. Bubble Air Speed & $<0.0001$ \\
\hline \multicolumn{1}{|l|}{ Interactions } & A-C & 0.2931 \\
\cline { 1 - 1 } & A-D & 0.1931 \\
& C-D & 0.0210 \\
\hline
\end{tabular}


For the hydrophilic surfaces only, the speed of the bubble is now very significant ( $p \ll$ 0.01 ) and the speed of the bubble shows an interaction with the time of adhesion. In the following paragraphs, each significant factor will be discussed in detail.

\subsection{Time Course of Bacterial Removal}

To better visualize the numerical time evolution of bacteria adhered to the solid surface, I plotted in Fig. 5.4 the population of bacteria as the bubble passes over the solid surface. Results are normalized by the Initial counts of bacteria. 


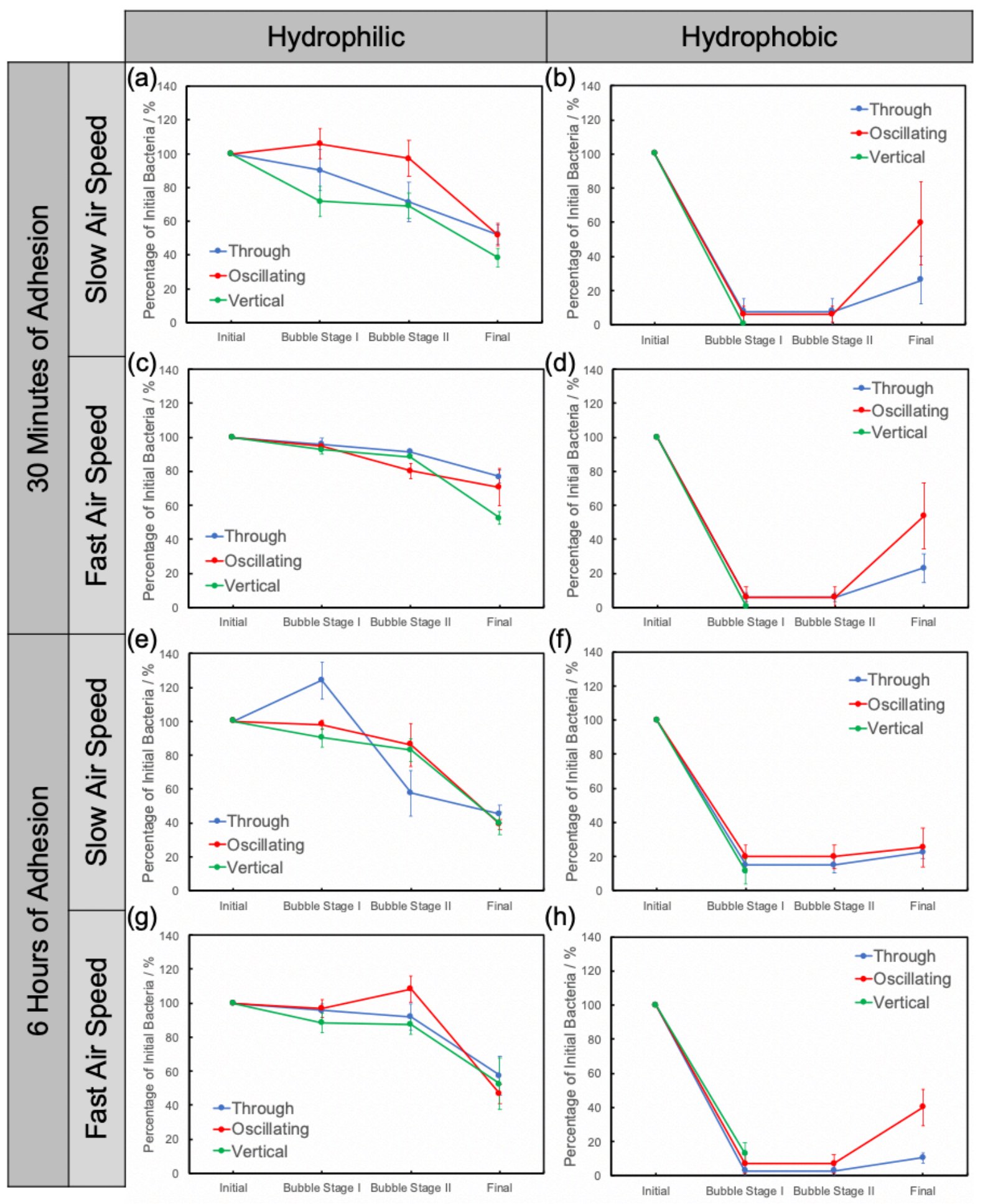

Fig. 5.4. Number of bacteria adhered to the solid surface as a function of the passage of the bubble. Numbers are expressed as a percentage of the initial number. Error bars are the standard error at each data point. 
One of the most striking features is that the numbers do not always go down, so there is both deposition as well as removal of bacteria. While the majority of deposition occurs during the passage of the second air-liquid interface on a hydrophobic surface, some of the bacteria that are deposited during Bubble - Stage I and Bubble - Stage II arise from bacteria in solution becoming trapped from the liquid film as it thins. Bacteria can also be displaced from elsewhere on the surface and into the field of view as drainage occurs. To distinguish between bacteria that that were deposited and those that were original to the Initial stage, I recounted the bacteria, but only those that remained adhered to the solid from the Initial counts were included at each stage (see Fig. 5.5). I defined a "retained" bacterium as one that moved less than $4 \mu \mathrm{m}$ (slightly more than the length of a typical bacterium). From Fig. 5.5 it is clear that virtually none of the original bacteria remained on the hydrophobic solid, but deposition from the second passage of the bubble air-liquid interface lowered the overall detachment efficiency because there are significantly more bacteria adhered to the surface at the Final stage. I now consider the various factors in detail. 


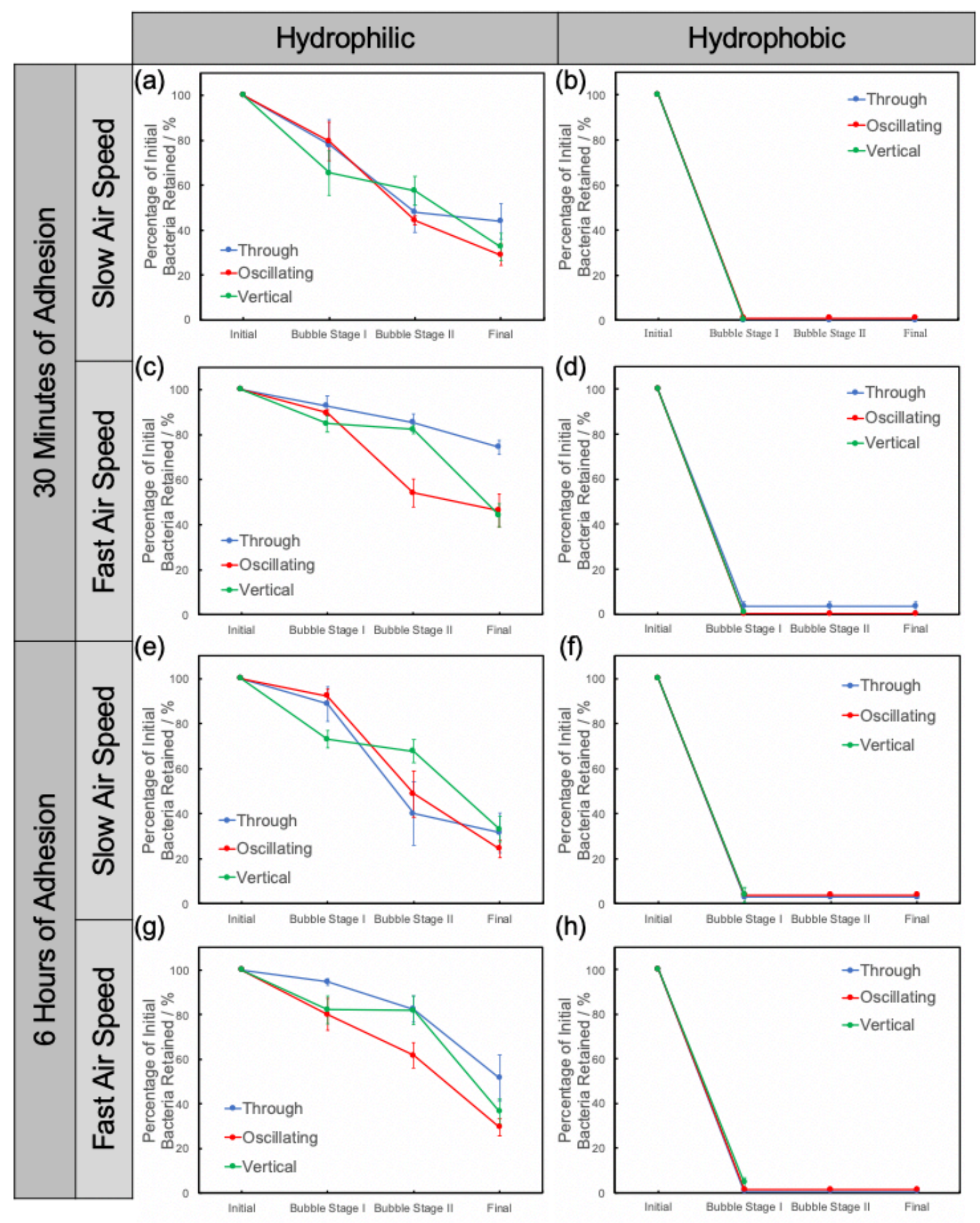

Fig. 5.5. Percentage of initial bacteria remaining adhered to the solid surface. In contrast to Fig. 5.4, newly deposited bacteria or those that moved more than $4 \mu \mathrm{m}$ are not counted. Error bars are the standard error at each data point. 


\subsection{Surface Wettability is the Dominant Factor in Adhered Bacteria Removal}

Figs. 5.4 and 5.5 clearly show the significance of surface wettability, especially during the first passage of the bubble air-liquid interface. About $80-100 \%$ of the bacteria are removed from the hydrophobic solid as soon as the first air-liquid interface passes through, and only about $5 \%$ or less of the bacteria remain in place, although there can be large amounts of redeposition. In contrast, the first pass of the air-liquid interface is not as catastrophic for bacteria on the hydrophilic solid, but the number remaining on the surface progressively decreases as the bubble passes over and the second air-liquid interface passes out of the field of view. The reintroduction of bacteria onto the hydrophobic surface can be substantial and detrimental to the overall detachment efficiency. For example, the percentage of initial bacteria for the oscillatory geometry at Bubble - Stage I and Bubble - Stage II is only $6 \pm 5 \%$. However, the deposition of bacteria with the passage of the second air-liquid interface back across the surface elevates the percentage of initial bacteria at the Final stage to $60 \pm 24 \%$, which is comparable to the hydrophilic surface. That is, the overall detachment efficiencies for hydrophobic and hydrophilic surfaces look similar if I just look at the end-points yet the timecourse and mechanism are completely different.

\subsection{Air-Liquid Interface Velocity Affects Removal from the Hydrophilic Solid}

In the absence of a bubble, flow rates between $0.03 \mathrm{~mL} / \mathrm{min}$ and $1.03 \mathrm{~mL} / \mathrm{min}$ through lateral bubble cells caused virtually no removal of adhered $P$. aeruginosa to either hydrophilic or hydrophobic surfaces following 30 minutes of adhesion. At such slow flow rates, the flow is laminar and does not generate sufficient shear stress at the solid-liquid interface to remove bacteria. However, the inclusion of an air bubble exhibited much more promising results. The effects of air-liquid interface velocity on bacterial removal have been well studied and generally show the same effect as the work here on hydrophilic solids: a slower moving air-liquid interface removes more adhered bacteria than a fast moving one. ${ }^{69,71,73,111}$ This has been explained previously in terms of the liquid film thinning over time until the air-liquid interface encounters the bacteria and the surface tension can then pull the bacteria off the solid. Slower passage allows more time for the liquid film to thin, giving a better chance for the air-liquid interface to thin to bacterial dimensions $(\mu \mathrm{m})$. In this work I also observed the same phenomenon for a bubble that approaches normal to the surface. Speed has no effect on the 
bacteria adsorbed to a hydrophobic solid because (a) almost all of the bacteria are already gone following the passage of the first air-liquid interface and (b) the film readily thins to effectively zero at the start of the interaction so there is no subsequent film thinning. My work suggests that the best way to strip bacteria off solids is to start with a hydrophobic surface.

\subsection{The Geometry of Bubble Interaction Affects Detachment and Deposition}

The vertical approach and rebound of a free bubble is obviously different than the passage of a bubble through a pipe. One key difference is that the air-liquid interface velocity changes direction for the rebounding bubble, whereas for the bubble passing through a pipe, the interfaces always go in the same direction, and the two interfaces are spatially separated. I investigated a third geometry, the oscillating bubble with motion parallel to the solid surface. From Fig. 5.5, it can be seen that all three geometries show a decrease in the percentage of bacteria retained over time for hydrophilic surfaces. However, the Final percentage of initial bacteria retained is about $15-20 \%$ higher for the through geometry than the vertical and oscillatory geometries. This subtle difference is supported by an ANOVA test using the overall percentages of initial bacteria retained for all geometries on hydrophilic surfaces. In determining the significance of geometry as a factor for this interaction, including all three geometries for the analysis resulted in $p=0.007$ whereas excluding the through geometry resulted in $p=0.355$. Therefore, the through bubble is less effective at removing initially adhered bacteria than the oscillatory and vertical bubbles. Similarly, the magnitude of the values of $P_{\text {deposit }}$ in Tables $5.1-$ 5.3 for hydrophilic surfaces are generally smaller for the through geometry than the oscillatory and vertical geometries, indicative of fewer bacteria removed and/or more deposited during the second passage of the air-liquid interface. Thus, fewer bacteria are stripped from the surface when both the advancing and receding air-liquid interfaces proceed in the same direction than when they move in opposite directions.

Considering the net bacteria adsorbed, which includes redeposition (Fig. 5.4), geometry has little impact on the Final percentages for hydrophilic surfaces and an enormous effect for hydrophobic surfaces. Redeposition is strongly dependent on the geometry. For oscillatory bubbles, anywhere from $15-85 \%$ of the initial numbers of bacteria can be redeposited onto hydrophobic surfaces, whereas only $5-40 \%$ are redeposited by the through bubbles. 
Distinguishing the effect of redeposition would have been impossible without observing the time course of the bubble's interaction with the surface.

\subsection{Overall Detachment Efficiencies Increase with Longer Times of Adhesion}

The first air-liquid interface was so efficient at removing almost all adhered bacteria from hydrophobic surfaces that it was difficult to determine the effect of varying the time adhered for hydrophobic solids. For hydrophilic surfaces, a longer adhesion time led to a greater detachment efficiency (fewer bacteria at the Final stage, see Figs. 5.4 and 5.5). Khodaparast et al. also noted similar results when observing the effects of passing air bubbles at different velocities over the spherical bacteria Staphylococcus aureus after it was exposed to a substrate for 30 minutes up to 6 hours. Their reasoning for this phenomenon was that as bacteria mature into a more fully developed biofilm, they begin to aggregate into a three-dimensional structure that is more susceptible to the surface-tension forces of a passing bubble. ${ }^{73}$ However, it is difficult to attribute these results to my work as the bubble velocities in the two works were dissimilar, and in my work the bacteria are all separated into individuals. My original expectation was that a longer attachment time would make it more difficult to detach the bacteria because they would excrete an extracellular matrix to bind them more firmly to the solid. This is not borne out by my results in the first 6 hours, as the bacteria became easier to remove. Since my results show that the hydrophobicity of the solid is paramount in determining the detachment, I hypothesized that the increase in detachment efficiency with attachment time occurred because bacteria modified the surface to make it more hydrophobic. But I reject this hypothesis because my contact angle measurements (Table 4.2) show essentially no change in wettability with time. Since the bacteria have a low density on the surface, it is still possible that the bacteria are more hydrophobic after $6 \mathrm{~h}$ and therefore aid dewetting locally, but that this is not apparent for a macroscopic contact angle measurement. Alternatively, Gómez-Suárez et al. ${ }^{97}$ and Tsuneda et al. ${ }^{98}$ have suggested that the bacterial extracellular matrix itself may decrease adhesion of the cells to the solid, as previously discussed in Section 2.2. 


\section{Chapter 6: Discussion}

\subsection{Importance of Solid Wettability}

Much prior work on the antifouling effect of bubbles has focused on the difference in bacterial adherence before and after the bubble collision, which is the core metric for efficacy, but does not fully describe the mechanism of action. Here I examined the bacteria at different points of the bubble trajectory. Of the factors studied, surface wettability emerged as the dominating factor, which is consistent with the importance of bacterial degree of immersion within the air-liquid interface already established in the literature. ${ }^{69,71,73,75,111}$ Previous literature drew attention to the time taken for the bubble passage, which influenced the drainage. Here we also see that the bigger effect is the overall wettability of the solid. If the solid is very hydrophobic, then the solid dewets quickly and the air-liquid interface sweeps laterally (see Fig. 2.3b) rather than vertically as described previously by Gómez-Suárez et al. (Fig. 2.3a) removing almost all the adhered bacteria by the action of the air-liquid interfacial tension. I estimated the normal force acting around the perimeter of the bacterium by measuring the surface tension for air-TSB solution. A value of $62 \mathrm{mN} / \mathrm{m}$ gives a force in the range of $1-2 \times 10^{-7} \mathrm{~N}$ depending on the impact angle, which is comparable to the maximum detachment forces calculated by GómezSuárez et al. using Eqn. 2.2.71

For the hydrophilic solid, the situation is more complex and it was necessary to observe the process in detail. The interference images (Fig. 5.2) show that the film varies in thickness around the bacteria. Video of the interference fringes also showed that the film varied in thickness with time, displacing bacteria as it drained. Some bacteria were loose in the thin film and could act as tracer particles to assess the flow rate, as shown in Fig. 6.1. The flow was complex and occasionally in the opposite direction to the bubble velocity. The length of the streaklines in Fig. 6.1 was used to determine the fluid velocity. For fluid volumetric flow rates of $0.21 \mathrm{~mL} / \mathrm{min}$ and $0.72 \mathrm{~mL} / \mathrm{min}$, maximum velocities of approximately $305 \mu \mathrm{m} / \mathrm{sec}$ and 440 $\mu \mathrm{m} / \mathrm{sec}$ were calculated, respectively. Assuming a vertical distance from the solid surface of 1.1 $\mu \mathrm{m}$ (approximate diameter of a $P$. aeruginosa bacterium), approximate shear stresses near the surface in a thin film under continuous flow are $0.25 \mathrm{~Pa}$ (shear rate of $277 \mathrm{~s}^{-1}$ ) for volumetric flow rates of $0.21 \mathrm{~mL} / \mathrm{min}$ and $0.36 \mathrm{~Pa}$ (shear rate of $420 \mathrm{~s}^{-1}$ ) for volumetric flow rates of 0.72 $\mathrm{mL} / \mathrm{min}$. I suggest that it is this shear that causes the distinct drop in number of bacteria that are retained between Bubble - Stage I and Bubble - Stage II. For the through geometry, this shear 
stress occurs throughout the entire bubble interaction, but for the oscillatory and vertical bubble geometries the shear is interrupted by the dwell time. Nevertheless, a slower overall speed of the bubble has a larger effect on detachment, suggesting that drainage is more important than shear stress of the fluid flow in the thin film. This is exemplified by a comparison between Bubble Stage I and Bubble - Stage II for the through and oscillating bubble data. More of the initial bacteria are removed (Fig. 5.5) for the oscillating bubble and this is almost certainly because there was much more time for the air-liquid film to drain due to the stopping of the bubble and the three-minute dwell time. Thus the static wettability of the solid is of paramount importance, the speed is secondary, and the shear stress can be significant but is less important than the other factors.

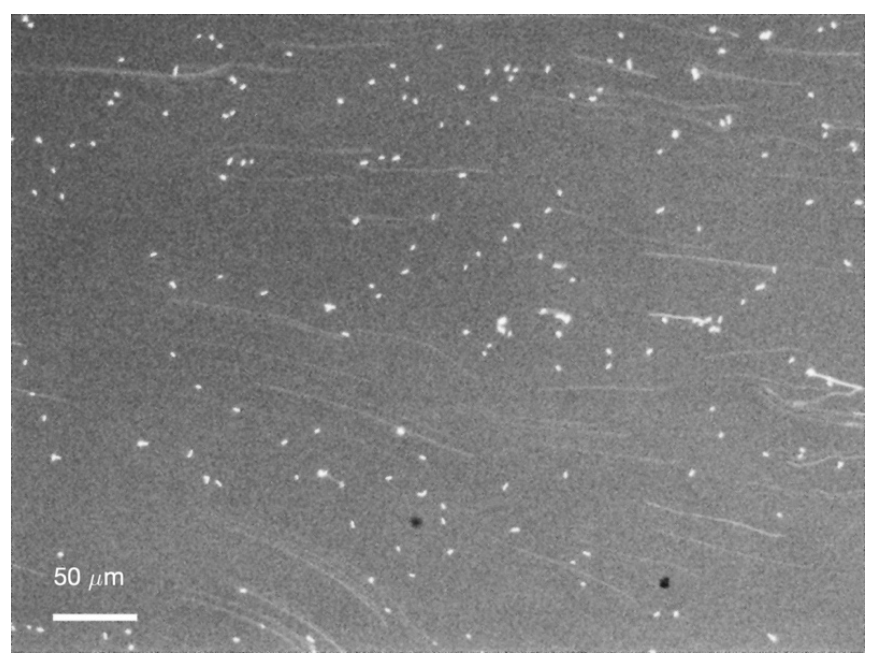

Fig. 6.1. Image of a hydrophilic surface in the through geometry with streak-lines caused by motion of the bacteria during the exposure of a single frame. The bacteria are moving at a velocity of approximately $200 \mu \mathrm{m} / \mathrm{s}$ within the thin liquid film between the bubble and the solid. Small, bright dots are bacteria adsorbed to the solid. Image was taken with a $0.5 \mathrm{sec}$ exposure.

\subsection{Deposition of Bacteria}

An important observation in my work is that there is a large amount of deposition of bacteria from the air-liquid interface when the solid is rewet by liquid as the bubble departs. This is particularly evident for hydrophobic solids (Tables 5.2 and 5.3 and Fig. 5.4) but is also present on hydrophilic solids (Fig. 5.1) when localized drainage occurs. My previous discussion leads us to believe that the air-liquid surface tension acts to pull the bacteria away from the solid (these bacteria are at least moderately hydrophobic) so an alternative explanation is required for this phenomenon.

My videos show that there are many bacteria on the air-liquid interface (see Fig. 5.3), so it is possible that these are the source of the deposited bacteria. For bacteria to transport to the 
solid, motion of the air-liquid interface towards the solid is needed, which I justify as follows for a bubble moving laterally in a flow cell. Far from the bubble, the no-slip boundary conditions at the upper and lower solid-liquid interfaces of the chamber cause parabolic flow in the flow cell (Fig. 6.2). By experiment, it is known that the bubble moves at approximately the average speed of the fluid flow, so the bubble acts similarly to a plug. Assuming that the boundary condition at the air-liquid interface is not full slip, there must be a transition from parabolic flow to plug flow in the fluid near the bubble. As a result of the increase in flow at the walls and the decrease in the centerline during this transition, some component of flow towards the wall is required behind the trailing edge of the bubble (see Fig. 6.2). This normal flow will drive bacteria at the airliquid interface toward the solid, depositing bacteria from the air-liquid interface onto the solidliquid interface. In front of the bubble, the transition from plug to parabolic flow causes a component of flow away from the solid-liquid interface, which should assist in stripping bacteria off the solid, making the air-liquid interface more laden with adhered bacteria. For an oscillating bubble, the same portion of the air-liquid interface passes over the solid a second time in the opposing direction, whereas for the through bubble, the second passage of the air-liquid interface is on the other side of the bubble. Fig. 5.4 shows that many more bacteria are deposited in the oscillatory motion than in the through motion. I explain this occurrence as a result of the same bacteria that were stripped off are then redeposited from the same portion of the oscillating bubble air-liquid interface. For the through bubble, bacteria would need to flow around the bubble to reach the trailing side before redeposition. Recall that the vertical (normal) approach of the bubble is also oscillatory, so redeposition probably also occurs in a similar manner for bubbles impacting the solid perpendicularly. Here I have focused on deposition of bacteria that are at the air-liquid interface, but the normal component of flow of the liquid at the air-liquid interface may also lead to deposition of bacteria that are suspended in the liquid. Such deposition is small in my experiments because I have very few bacteria in suspension.

The importance of flow around the bubble suggests that the distribution of bacteria may be inhomogeneous after the passage of the bubble. Khodaparast et al. confirmed that bacteria located near the corners of a rectangular channel are less affected by higher bubble velocities than bacteria located near the center of the channel. ${ }^{73}$ However, in my experiments, I did not observe a dramatically different density of bacteria near the corners of the flow cell. 


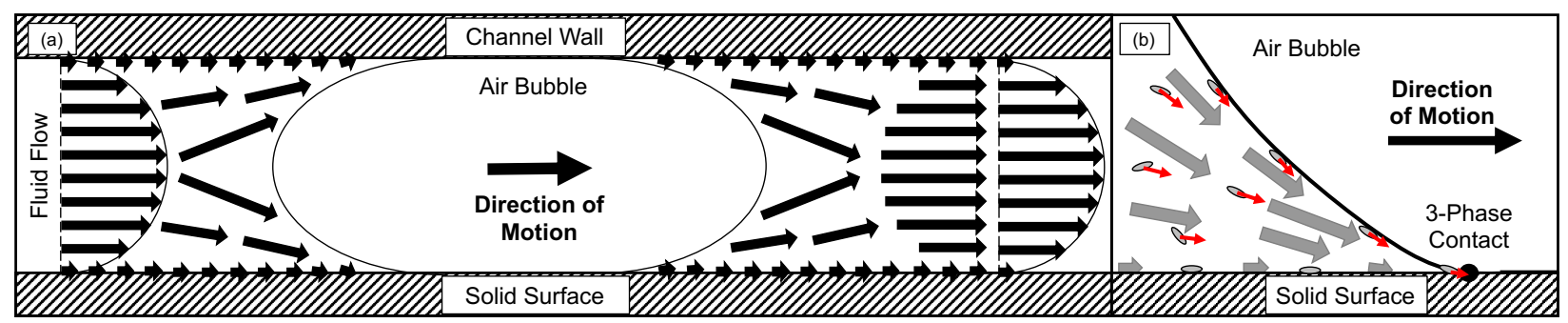

Fig. 6.2. Schematic of cross-section of liquid flow around the bubble at the center point of the flow cell. Black or gray arrows suggest the direction and magnitude of flow for (a) the entire bubble and (b) a magnified view of trailing edge of bubble with bacteria. Red arrows show motion of bacteria towards the 3-phase line. The flow toward the solid is driven by the need to deliver liquid to the solid when there is both no-slip at the solid-liquid interface and bubble curvature.

\subsection{Effect of Surface Roughness}

My results focus on very smooth surfaces $(<1 \mathrm{~nm} \mathrm{rms})$. I have established that if these surfaces are hydrophobic, then the bacteria are easily removed by bubbles. I also briefly examined the effect of a textured surface by molding hydrophobic PDMS with $8 \mu \mathrm{m}$ diameter hemispherical protrusions convex to the liquid. For comparison, the bacteria are about $2.9 \mu \mathrm{m}$ in length and $1.2 \mu \mathrm{m}$ in diameter. Fig. 6.3 shows images from before and after the passage of the initial air-liquid interface on a hydrophobic surface. The textured hemispheres dramatically decrease the detachment efficiency of the passing air-liquid interface compared to a hydrophobic flat surface. Bacteria are swept into the concavities between each hemispherical protrusion where the liquid is able to remain pooled on the solid. Trapped within the droplets between the defects, these bacteria will also be more resistant to removal because the air-liquid interface may not reach them. This result shows that the level of hydrophobicity that I investigated is not alone sufficient to always remove bacteria, and the removal process is more complicated than simply the air-liquid interface pulling the bacteria onto the bubble surface or into solution. 


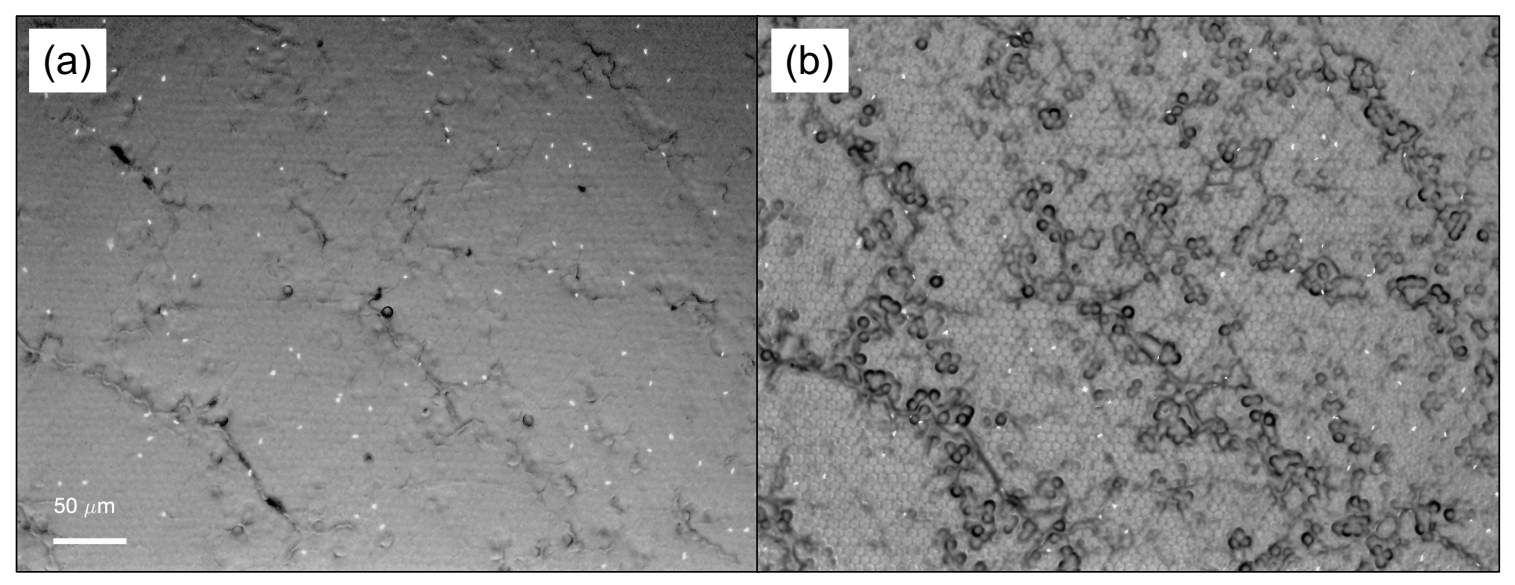

Fig. 6.3. Vertical bubble collision with a hydrophobic PDMS surface with $8 \mu \mathrm{m}$ diameter hemispherical textured topography following 30 minutes of bacterial adhesion to the surface. Images are taken (a) immediately prior to bubble impact with the surface (i.e. Initial) and (b) immediately following the movement of the air-liquid interface across the field of view (i.e. Bubble - Stage I). Air injection rate was $0.10 \mathrm{~mL} / \mathrm{min}$. Note that many bacteria remain on the solid, even though the solid is hydrophobic.

\subsection{Bacterial Rearrangement on the Surface}

An important aspect of this work is that by following the bacteria as a function of the bubble trajectory, I was able to ascertain that the overall efficiency metric was a simplification. There are three types of bacteria at the Final stage: those that never moved, those that were displaced across the surface, and those that were detached and then redeposited. A simple count of numbers before and after bubble interaction does not distinguish between these. However, it is not clear that these three types will all go on to have the same effect of forming a biofilm. For example, when a bacterium is ripped off the surface and is then redeposited, it may lose appendages $^{86}$ or other functional contacts with the solid, or all or part of its extracellular matrix. Bacterial gene expression and metabolic pathways can be triggered by sensing the surface or changes, ${ }^{112}$ so this experience may leave the bacterium altered in some way that hinders or perhaps advances biofilm formation in the long term. 


\section{Chapter 7: Conclusions}

My research showed that bacteria could be removed at several stages during a bubble collision: (a) during the passage of the first air-liquid interface, (b) while the bubble is passing over, and (c) during the passage of the second air-liquid interface. In addition, deposition during the second passage is important for some conditions. Thus, to understand the mechanism of bacterial removal, it is necessary to monitor the bacteria throughout the collision, and not just before and after. For the conditions of my experiments, the most important effect was whether or not the solid surface dewet during the collision with the bubble. The most facile way to dewet the surface is to have a high contact angle. In this case, the liquid film ruptures readily and the air-liquid interface sweeps laterally across the interface at a high angle, removing a very large fraction of the bacteria with the action of surface tension. If the solid is hydrophilic, then the time of drainage is an important factor. The liquid film drains more slowly on a hydrophilic surface (due to repulsive surface forces on the bubble) and may never rupture. For this reason, a slower bubble gives more time for liquid film thinning and rupture to occur and my results show a higher removal efficiency, as described previously by other workers. Even if the film does not rupture, my results show that bacteria are affected by flow in the thin liquid film, and that some of the bacteria are removed during this flow.

I also show that bubbles deposit bacteria onto a solid. Deposition was particularly large for hydrophobic solids, and if one only counts the bacteria before and after the passage of the entire bubble, then the removal efficiency is sometimes quite similar on hydrophobic and hydrophobic surfaces. But, by looking at the time-course, we see that the mechanism is very different. For some conditions, almost all bacteria on a hydrophobic surface are removed and then a large fraction is redeposited back, while a similar net removal efficiency occurs on a hydrophilic surface by a process of continuous removal of bacteria. I explain that deposition may be driven by the normal component of liquid flow that arises due to the transition from parabolic to plug flow at the trailing edge of the bubble. Oscillatory motion of the bubble produces much more deposition, presumably because the same bacteria that were pulled onto the interface are then subsequently redeposited back onto the solid surface by the same portion of the liquid-vapor interface. Surface roughness can negatively impact detachment efficiencies because the bacteria can be pulled into concavities where a protective liquid layers remains over the bacteria, shielding them from the effect of air-liquid interfacial tension. Finally, in general, I 
find that air bubbles do remove bacteria from solids over a wide range of conditions (different surface wettability, air bubble speed, time of bacterial adhesion, and geometry of collision). This suggests that cleaning with bubbles provides an effective method for defouling in a variety of applications with the likely advantages of low cost and low environmental impact of using only air. 


\section{Chapter 8: Future Work}

Future work in this topic provides an excellent opportunity to further explore the effects of bubble interactions with submerged solid surfaces emphasizing real world applications. To further replicate a marine environment, it would be useful to use artificial seawater as the liquid medium and a variety of different bacteria common to the ocean environment for further studies.

A full quantitative analysis on the effects of varying surface roughness would be a significant area of future work. As briefly described in Section 6.3, surface roughness appears to have a significant effect on both bacterial adherence and detachment. Microscopically flat surfaces are rare in both industrial and marine applications. A variety of different surface topographies can be studied each with distinct patterns or structures to model commonplace material features. This also introduces the possibility of observing how bacterial displacement or detachment on a surface may be influenced by the direction of air-liquid interface movement over a surface structure, such as a series of steps.

From Fig. 1.1, it is clear that biofouling is a multistep process that can take weeks for tertiary colonizers to settle on a surface. During this process, adhered bacteria continually secrete EPS as they form an increasingly complex biofilm. This thesis only studied bacteria in the infancy of biofilm formation, i.e., within the first six hours of settling on a surface. Future experiments can observe the effects of bubble interaction with bacteria in a biofilm that has been allowed to mature for much longer times, presumably intensifying bacterial adherence to the solid surface due to stronger polymeric interactions beyond those observed in this thesis. By fluorescently staining the secreted EPS, any changes to its coverage of a surface resulting from the passage of an air-liquid interface can be measured.

In Section 6.4 I briefly discussed the importance of bacterial rearrangement on a solid surface and how it can influence appendage loss as well as the ability of bacteria to perform metabolic processes associated with surface sensing, potentially leading to later changes in biofilm development. Future work can examine whether bacteria that are removed and then redeposited show different growth behaviors at later stages of biofilm development that are not considered in this work.

The practical use of air bubble curtains, such as those described in Section 1.5, to control biofouling on ship hulls would involve a multitude of freely rising bubbles impacting the vessel exterior at a high rate of speed. As considered in Section 3.3 using Eqn 3.2, the bubbles 
observed in this thesis were impacting the solid surface much more slowly than a freely rising bubble traveling at terminal velocity. Therefore, an experimental setup capable of microscopically observing freely rising bubbles at terminal velocity and their influence on bacterial detachment efficiency would be far more realistic than the vertical geometry methods used here. Additionally, since multiple bubbles from an air bubble curtain would interact with the same surface area of the ship's hull over a short period of time, it would be beneficial to observe the effects of multiple bubble interactions with adhered bacteria. Successive passes of many separate bubbles may significantly affect detachment rates of adhered bacteria.

Lastly, since the ability for a solid surface to dewet was identified as the primary influence on bacterial detachment, experimenting with the use of surfactants to change the surface tension of the air bubble or solid surface wettability may prove to be a useful solution in controlling biofouling growth. Different surfactants with varying critical micelle concentrations can be exposed to solid surfaces with their subsequent effects on air bubble liquid film formation and bacterial detachment efficiencies observed. 


\section{Appendix A: Supporting Methods - Flow Cells}

The methods used for the Vertical Geometry and Lateral Geometry flow are described below.

Vertical Geometry. Vertical approach experiments used a bubble cell (Fig. C.1) with 8 air supply ducts ( $0.71 \mathrm{~mm}$ diameter) positioned $2.5 \mathrm{~mm}$ above the solid surface, each of which could be used to generate a bubble. Additional ducts $(0.71 \mathrm{~mm}$ diameter), on the small faces of

the cell, provided inlet and outlet ports so that nutrient for the bacteria and waste products could be washed through the bubble cell. In connecting the bubble cell to the experimental setup, the chamber and all ducts were first filled with TSB charged from the peristaltic pump until liquid droplets emerged. Each bubble cell air supply port was then connected to the barrel of a $1 \mathrm{~mL}$ $26 \mathrm{G}$ syringe with plunger (BD and Company) prefilled with $0.4 \mathrm{~mL}$ air followed by $0.2 \mathrm{~mL}$ TSB. To ensure no air pockets within the BPT tubing the plunger of each syringe was then depressed until small air bubbles were emitted from the flow chamber's respective air supply, at which point $0.2 \mathrm{~mL}$ of TSB was withdrawn back into the syringe from the chamber. The bubble cell was then connected to the waste container and oriented on the inverted microscope stage substrate-side down. TSB was flowed through the setup at $0.41 \mathrm{~mL} / \mathrm{min}$ for at least 15 minutes prior to inoculation.

Immediately before inoculation, media flow was stopped and the tubing just prior to entering the bubble cell was clamped to prevent backflow. Using a $1 \mathrm{~mL} 26 \mathrm{G}$ syringe, $750 \mu \mathrm{L}$ of the inoculum (diluted early exponential culture, see Section 4.3) was injected into the flow chamber via three separate injections of $250 \mu \mathrm{L}$ into each of the bubble cell's inlet tubing to ensure a uniform distribution within the chamber. Bacteria were allowed to adhere to the substrate for 15 minutes prior to unclamping the tubing and then the flow of medium was resumed $0.41 \mathrm{~mL} / \mathrm{min}$ for 15 minutes to flush away any unattached bacteria. The adhered bacteria were then left to grow for one of two times: (1) $0 \mathrm{~h}$ (2) $5.25 \mathrm{~h}$. Experiments involving imaging after six hours of bacterial adhesion continued to have media pumped through the system at $0.45 \mathrm{~mL} / \mathrm{hr}$ for 5.25 hours to provide an adequate flow of nutrients for the bacteria followed by another 15 minutes of fast flow at $0.41 \mathrm{~mL} / \mathrm{min}$ to flush away any unadhered bacteria. The bubble cell was levelled by adjusting four screws on a custom-built leveling stage using a bullseye level prior to air injection. For each experimental run, the air supply syringe injection and withdrawal rates were controlled using a syringe pump (Fusion 720, Chemyx Inc.). With media flow secured, air was injected into the flow chamber at a constant rate of either 0.05 
$\mathrm{mL} / \mathrm{min}$ or $0.10 \mathrm{~mL} / \mathrm{min}$ until the air-liquid interface developed by the bubble moved across the entire field of view or the interface became stationary, whichever occurred first. After an approximately 3 minute dwell time, air was then withdrawn at $0.10 \mathrm{~mL} / \mathrm{min}$ regardless of the initial injection rate until the bubble was withdrawn back into the air supply duct or the interface became stationary, whichever occurred first. The flow chamber was flushed with media flowing at $0.41 \mathrm{~mL} / \mathrm{min}$ between each bubble within the same flow chamber. Each air supply duct in the bubble cell was used only once so that the emitted bubble always interacted with bacteria that had never been subjected to a bubble.

Lateral Geometry. Lateral bubble experiments (see Fig. C.2) utilized a setup similar to that of the vertical bubble experiments with some exceptions. For these experiments, a peristaltic pump provided the driving force for bubble movement through the bubble cell rather than a syringe pump. The bubble trap also acted as a pulse dampener to reduce flow pulsations from peristaltic pump operation by absorbing them into an approximately $2 \mathrm{~mL}$ air pocket above the fluid.

The lateral bubble cell contained two separate chambers (39 $\mathrm{mm} \times 2 \mathrm{~mm} \times 2 \mathrm{~mm}$ ) each with $1.0 \mathrm{~mm}$ inner diameter ducts on either side to permit the passage of media and air. Seven millimeter spacing between the channels themselves and the outer walls provided adequate spacing to apply PDMS without it seeping onto the walls of the channels. Media flowed through the setup at $0.21 \mathrm{~mL} / \mathrm{min}$ for at least 15 minutes prior to inoculation. Just prior to inoculation, media flow was stopped and the tubing just prior to entering the bubble cell was clamped to prevent backflow. Using a $1 \mathrm{~mL} 26 \mathrm{G}$ syringe, $100 \mu \mathrm{L}$ of the inoculum (diluted early exponential culture, see Section 4.3) was injected into each flow chamber via the bubble cell's inlet tubing. Bacteria were allowed to adhere to the solid surface for 15 minutes. The inlet tubing was then unclamped and the bubble cell was again flushed with media at $0.21 \mathrm{~mL} / \mathrm{min}$ for 15 minutes. Experiments involving imaging after 30 minutes of bacterial adhesion commenced immediately following this 15 minute flush. Experiments involving imaging after six hours of bacterial adhesion had media pumped through the system at $1.86 \mathrm{~mL} / \mathrm{hr}$ for 5.25 hours to provide an adequate flow of nutrients for the bacteria followed by another 15 minute flush at $0.21 \mathrm{~mL} / \mathrm{min}$ to remove any unadhered bacteria. Air was injected into each flow chamber in a manner similar to bacterial inoculation. Media flow was stopped and the tubing just prior to entering the bubble cell was clamped to prevent backflow. Using a $1 \mathrm{~mL} 26 \mathrm{G}$ syringe filled with air, $40 \mu \mathrm{L}$ of air 
was slowly injected into the flow chamber via the bubble cell's inlet tubing. The inlet tubing was then unclamped and the peristaltic pump was used to displace the entirety of the bubble into the bubble cell's chamber. Light mechanical agitation was sometimes required to free the tailend of the bubble from the mouth of the chamber. Air bubbles fully spanned the width of the chamber, giving them approximate dimensions of $10 \mathrm{~mm} \times 2 \mathrm{~mm} \times 2 \mathrm{~mm}$. Once the bubble cell was evenly leveled using the leveling stage, the peristaltic pump was used to advance or withdraw the bubble for analysis (see Section 4.6) by controlling the speed and direction of the pump head's rotation. Flow rates of $0.21 \mathrm{~mL} / \mathrm{min}$ and $0.72 \mathrm{~mL} / \mathrm{min}$ were used to displace the bubble, resulting in linear velocities of approximately $0.8 \mathrm{~mm} / \mathrm{s}$ (Reynold's Number 1.8 ) and 3 $\mathrm{mm} / \mathrm{s}$ (Reynold's Number 6.8), respectively. These Reynold's Numbers were calculated for the liquid phase using a $2 \mathrm{~mm}$ characteristic diameter. The minimum flow rate of $0.21 \mathrm{~mL} / \mathrm{min}$ was chosen as the slowest the air bubble could be displaced through the flow chamber without frequent pinning. Often, the actual bubble velocity was slower than the corresponding linear velocity due to minor pinning that could occur due to surface imperfections on the bubble flow cell or solid surface itself. Flow rates up to $1.0 \mathrm{~mL} / \mathrm{min}$ without the presence of an air bubble did not have an observable effect on bacterial detachment and were considered negligible. To maintain a steady interfacial velocity across the solid surface, the bubble had always completely emerged into the flow cell when data was recorded. 


\section{Appendix B: Supporting Methods - Microscopy}

Bacteria were imaged in brightfield and fluorescence in the plane of the PDMS using an inverted Zeiss Axiovert 200 microscope equipped with a 10× objective with a numerical aperture of 0.30. Fluorescence imaging utilized a $550 \pm 25 \mathrm{~nm}$ excitation filter, a $570 \mathrm{~nm}$ dichroic mirror, and a $605 \pm 70 \mathrm{~nm}$ barrier filter. Images were captured with a Zeiss AxioCam ICm 1 monochromatic camera using an average framerate of 2.0 per second, a $0.5 \mathrm{sec}$ exposure time, and $1388 \times 1038$ pixels. At these settings, individual bacteria are about 8 pixels in length and 3 pixels wide. All images were processed and exported for data analysis using Zeiss Zen microscope software.

For all bubble experiments, the fluorescence excitation was used sparingly to minimize phototoxicity: prior work in my lab has shown that similar fluorescence imaging conditions does not significantly affect the motility of bacteria up to one hour of accumulated exposure time. Imaging times for this experiment were much shorter, taking only several minutes for each run.

For vertical bubble experiments, it was essential to know that a single bubble emerges from the air supply duct and subsequently contacts the solid. To verify this, I simultaneously imaged the bubbles in profile and in the plane of the sample during a few experiments using the set-up shown in Fig. C.3. From the profile view I was able to clearly see the emergence of the bubble into the liquid and its approach to the PDMS film (see Fig. C.4). I recorded the simultaneous changes in the PDMS image plane and subsequently used these to determine which stage was occurring. For example, when the bubble first emerged from the air supply duct, there is a significant drop in pixel brightness. Likewise, there was a significant increase in pixel brightness when the bubble is fully withdrawn back into the air supply duct. Imaging of the airliquid interface proceeding across the PDMS image plane was consistent with the expansion and contraction of the air bubble from the profile view. 


\section{Appendix C: Supporting Information}

(a) Bottom View

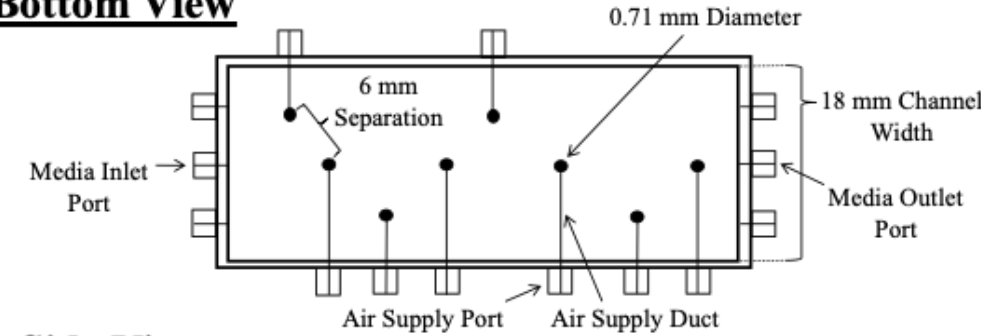

Side View

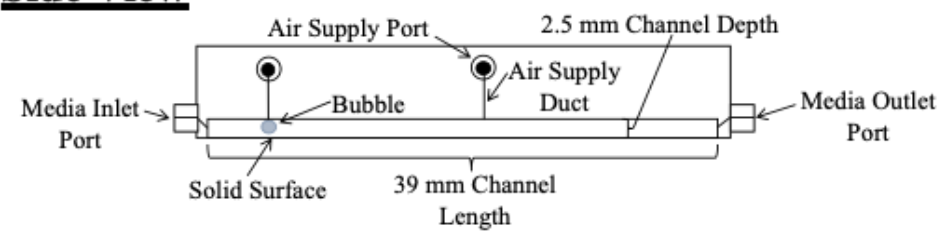

\section{(b)}

(c)

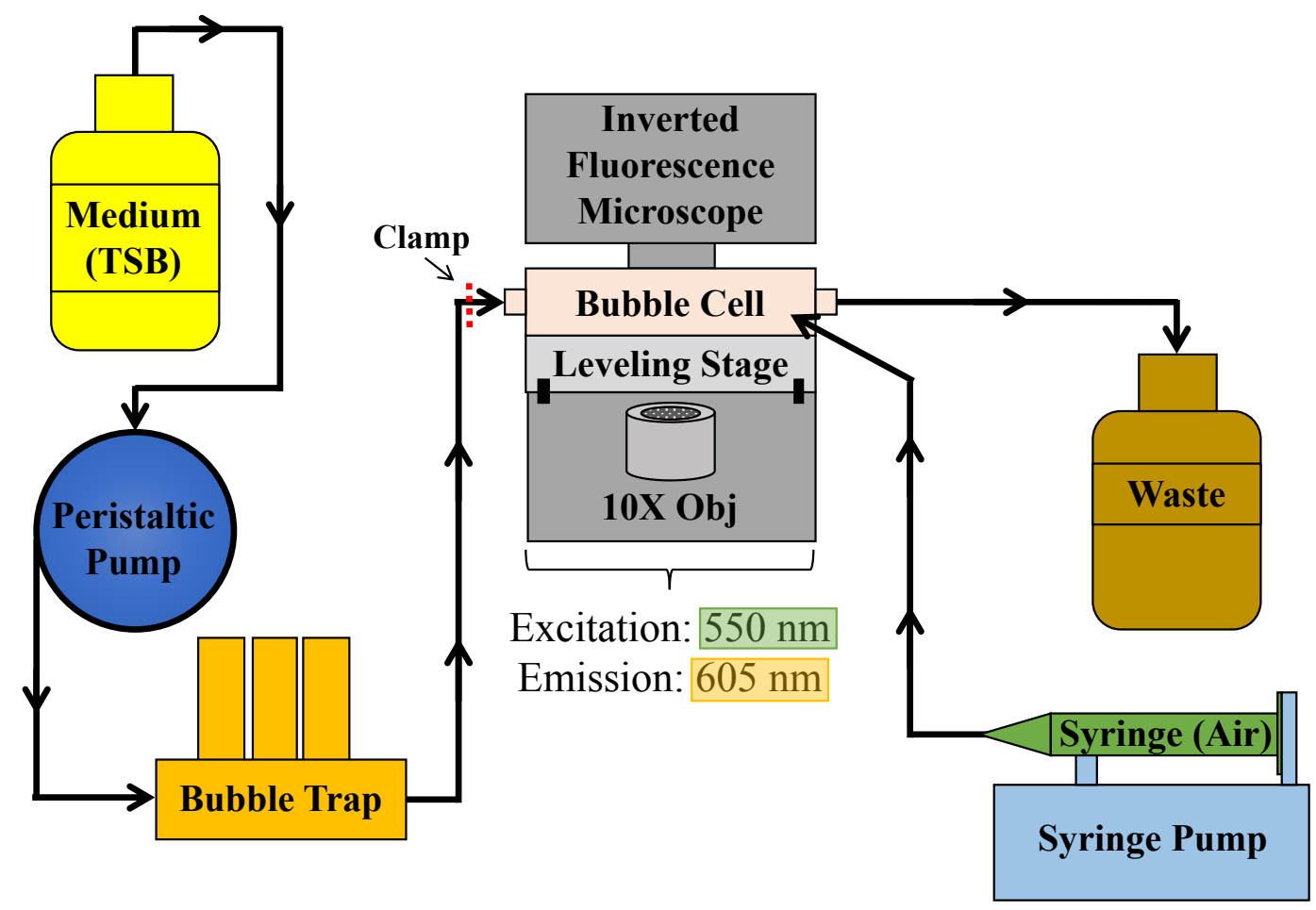

Fig. C.1. Components of vertical bubble experiments: (a) schematic of vertical bubble flow cell, (b) photograph of the vertical bubble flow cell, and (c) flow diagram for vertical bubble experiments. 
(a) Bottom View
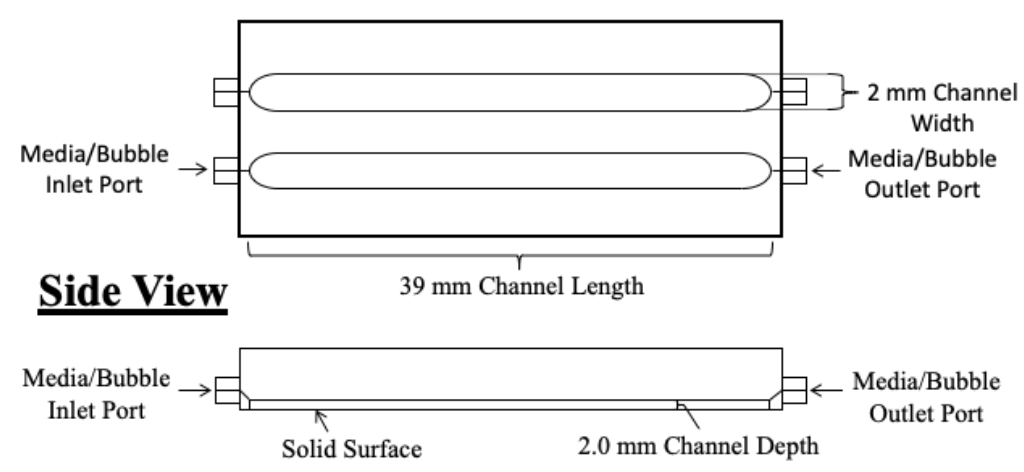

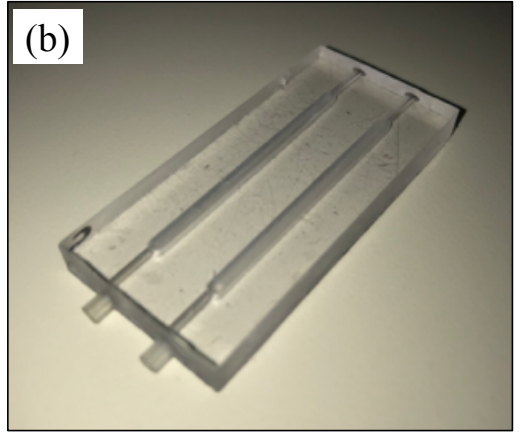

(c)

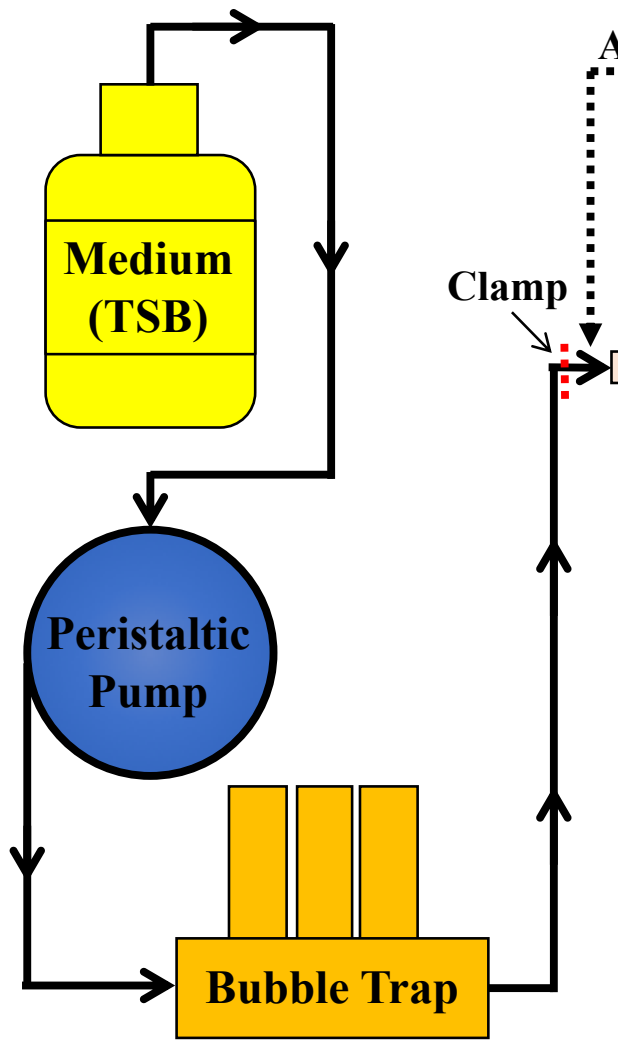

Excitation: $550 \mathrm{~nm}$

Emission: $605 \mathrm{~nm}$

Fig. C.2. Components of lateral bubble experiments: (a) schematic of lateral bubble flow cell, (b) photograph of the lateral bubble flow cell, and (c) flow diagram for lateral bubble experiments.

The dashed line indicates the point at which the syringe is used to inject the air bubble. 


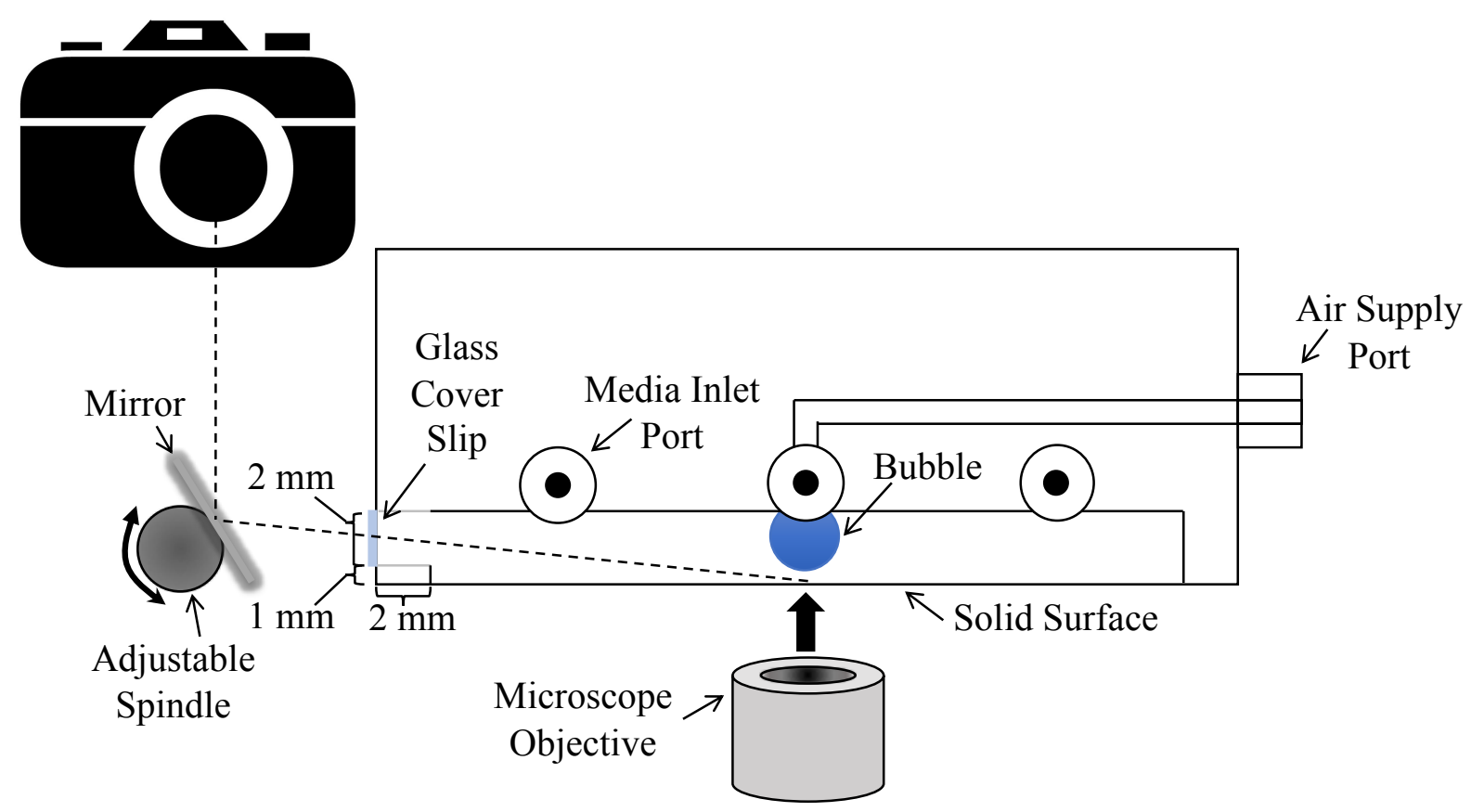

Fig. C.3. Schematic of the apparatus used to view the profile of the bubble during vertical approach. 

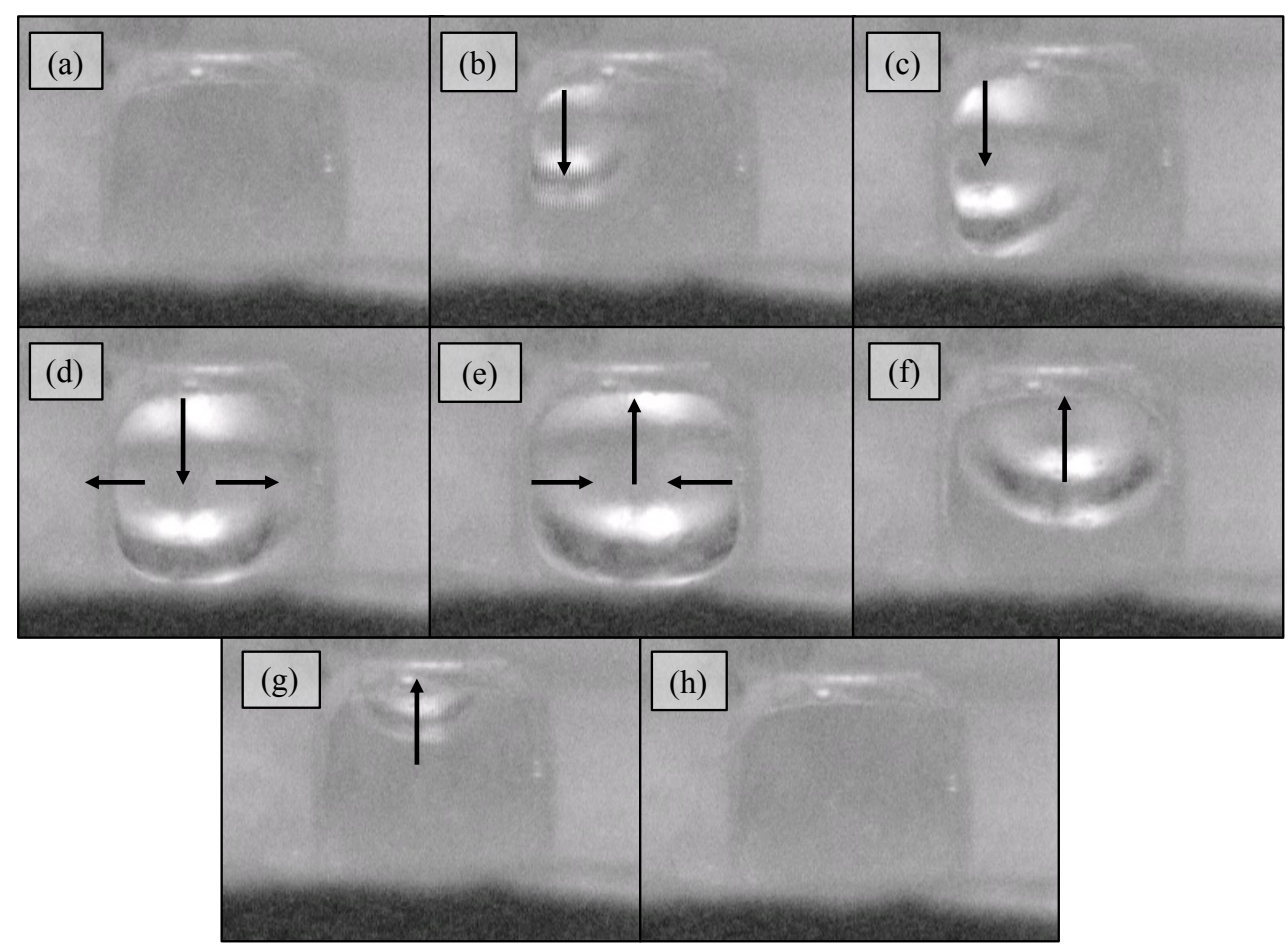

Fig. C.4. Images taken using the profile view of a vertical bubble impacting a hydrophobic solid surface with the black arrows indicating bubble direction of motion. (a) Air is injected into the chamber from the air supply causing (b) the bubble to emerge and expand downward towards the solid surface. (c) The bubble impacts the solid surface and (d) continues to expand outwards until (e) air is withdrawn and the bubble contracts inwards, (f) eventually leaving the solid surface. (g) The bubble continues to contract as air is withdrawn until $(\mathrm{h})$ the bubble is completely withdrawn back into the air supply. 


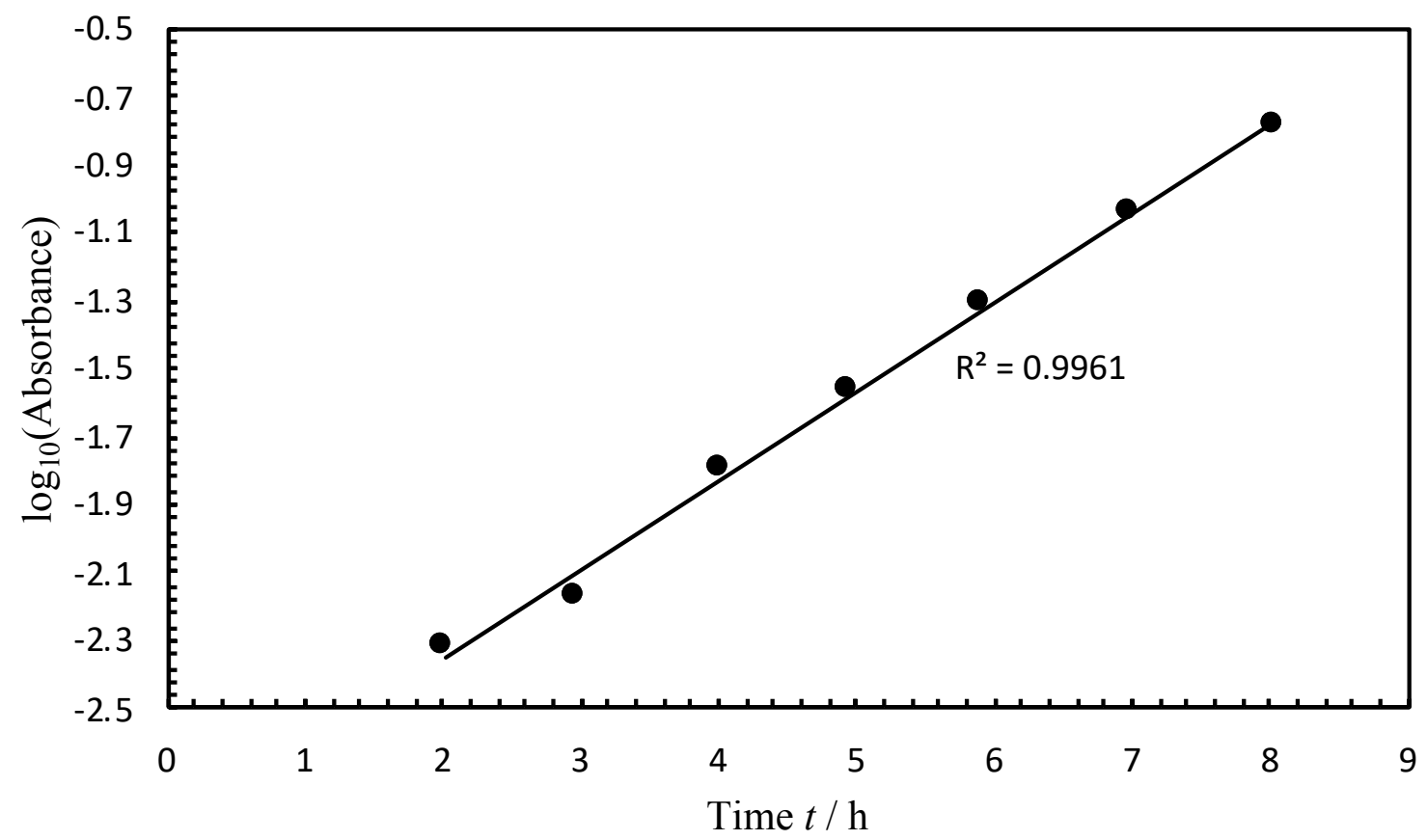

Fig. C.5. Growth of $P$. aeruginosa at room temperature (approximately $23.5^{\circ} \mathrm{C}$ ) in liquid TSB during the first 8 hours after inoculation. The bacteria scatter light, so absorption indicates the amount in suspension. Absorbance was measured at $600 \mathrm{~nm}$. The average doubling time was 64 minutes with a standard error of 3 minutes. The inoculum for experiments was taken at 4 hours where the growth is exponential. 


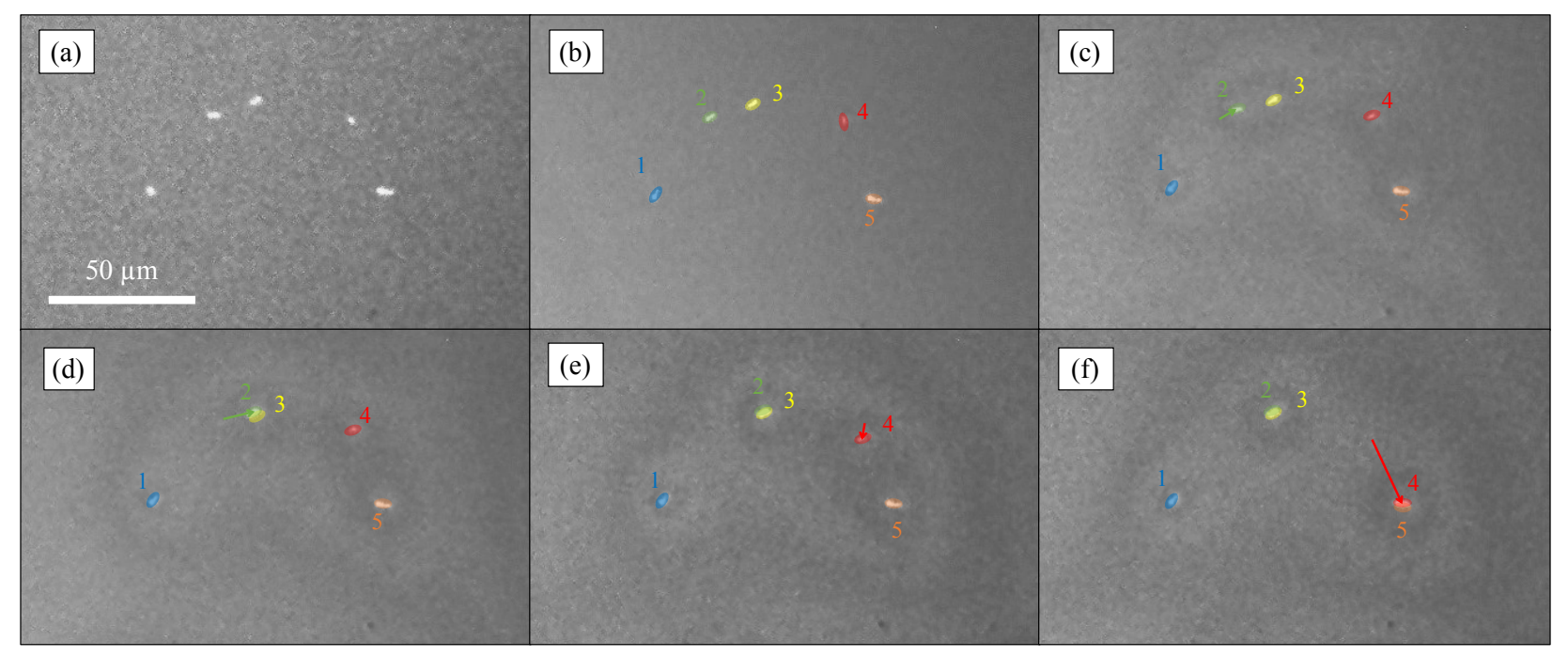

Fig. C.6. Images illustrating the procedure for counting bacteria that become clumped as a result of action by the bubble. Six frames taken at different instances over $16 \mathrm{~s}$ are shown leading up to the final configuration. (a) Five bacteria were adhered to the solid surface prior to bubble impact. (b) These bacteria have been color-coded and enumerated 1-5. The air-liquid interface (not shown) moves towards the bacteria from the bottom-left of the image and (c) displaces bacteria \#2 towards bacteria \#3. (d) Both bacteria \#2 and bacteria \#3 are confined to the same liquid droplet within a thin liquid film. (e) The air-liquid interface displaces bacteria \#4 towards bacteria \#5 and (f) they are both confined to the same liquid droplet within a thin liquid film.

The final bacterial count for the area of interest is five, even though only three fluorescent objects are resolved in the final frame.

Experimental conditions: vertical bubble impact on a hydrophilic substrate following 6 hours of bacterial adhesion with a $0.05 \mathrm{~mL} / \mathrm{min}$ air injection rate forming a thin liquid film. 


\section{Appendix D: Experimental Data}

Table D.1. Raw bacterial and retention counts for vertical bubble experiments. Counts with dashes indicate that the bubble was not able to be pulled off of the solid surface for that

measurement.

\begin{tabular}{|c|c|c|c|c|c|c|c|c|c|c|}
\hline \multirow{2}{*}{ Surface Wettability } & \multirow[b]{2}{*}{ Time of Adhesion (hr) } & \multirow[b]{2}{*}{ Rate of Air Injection (mL/min) } & \multirow[b]{2}{*}{ Run } & \multicolumn{4}{|c|}{ Bacterial Counts } & \multicolumn{3}{|c|}{ Retention Counts } \\
\hline & & & & Initial & Bubble - Stage I & Bubble - Stage II & Final & Bubble - Stage I & Bubble - Stage II & Final \\
\hline \multirow[t]{5}{*}{ Hydrophilic } & 0.5 & 0.05 & $\# 1$ & 26 & 16 & 16 & 10 & 13 & 13 & 7 \\
\hline & & & \#2 & 29 & 20 & 20 & 14 & 20 & 20 & 14 \\
\hline & & & \#3 & 22 & 10 & 10 & 4 & 8 & 8 & 3 \\
\hline & & & \#4 & 51 & 47 & 42 & 22 & 44 & 36 & 22 \\
\hline & & & \#5 & 101 & 92 & 88 & 45 & 86 & 62 & 31 \\
\hline \multirow[t]{6}{*}{ Hydrophilic } & 0.5 & 0.10 & \#1 & 59 & 53 & 53 & 32 & 50 & 50 & 30 \\
\hline & & & \#2 & 28 & 25 & 25 & 11 & 21 & 21 & 8 \\
\hline & & & \#3 & 30 & 29 & 26 & 15 & 25 & 25 & 11 \\
\hline & & & \#4 & 25 & 21 & 21 & - & 19 & - & - \\
\hline & & & $\# 5$ & 86 & 83 & 78 & 53 & 78 & 71 & 49 \\
\hline & & & \#6 & 21 & 21 & 19 & 12 & 21 & 18 & 10 \\
\hline \multirow[t]{7}{*}{ Hydrophilic } & 6 & 0.05 & $\# 1$ & 65 & 50 & 46 & 35 & 45 & 38 & 26 \\
\hline & & & \#2 & 33 & 30 & 28 & 6 & 26 & 25 & 6 \\
\hline & & & $\# 3$ & 38 & 31 & 31 & 27 & 28 & 25 & 22 \\
\hline & & & $\# 4$ & 47 & 36 & 27 & 15 & 28 & 24 & 12 \\
\hline & & & $\# 5$ & 62 & 61 & 61 & 12 & 49 & 49 & 11 \\
\hline & & & \#6 & 27 & 32 & 30 & 15 & 24 & 24 & 12 \\
\hline & & & $\# 7$ & 29 & 26 & 22 & 11 & 18 & 16 & 8 \\
\hline \multirow[t]{6}{*}{ Hydrophilic } & 6 & 0.10 & $\# 1$ & 61 & 57 & 54 & 32 & 50 & 50 & 26 \\
\hline & & & \#2 & 113 & 97 & 97 & 37 & 85 & 83 & 28 \\
\hline & & & $\# 3$ & 30 & 29 & 29 & 21 & 27 & 27 & 15 \\
\hline & & & $\# 4$ & 31 & 29 & 29 & 7 & 29 & 29 & 7 \\
\hline & & & $\# 5$ & 32 & 32 & 32 & 9 & 31 & 31 & 8 \\
\hline & & & $\# 6$ & 54 & 33 & 33 & 32 & 30 & 30 & 29 \\
\hline \multirow[t]{7}{*}{ Hydrophobic } & 0.5 & 0.05 & $\# 1$ & 98 & 0 & - & - & 0 & - & - \\
\hline & & & \#2 & 67 & 0 & - & - & 0 & - & - \\
\hline & & & $\# 3$ & 85 & 1 & - & - & 1 & - & - \\
\hline & & & $\# 4$ & 67 & 0 & - & - & 0 & - & - \\
\hline & & & $\# 5$ & 33 & 0 & - & - & 0 & - & - \\
\hline & & & \#6 & 73 & 0 & - & - & 0 & - & - \\
\hline & & & $\# 7$ & 74 & 0 & - & - & 0 & - & - \\
\hline \multirow[t]{6}{*}{ Hydrophobic } & 0.5 & 0.10 & $\# 1$ & 82 & 1 & - & - & 1 & - & - \\
\hline & & & \#2 & 59 & 2 & - & - & 2 & - & - \\
\hline & & & \#3 & 140 & 1 & - & - & 1 & - & - \\
\hline & & & $\# 4$ & 21 & 0 & - & - & 0 & - & - \\
\hline & & & $\# 5$ & 23 & 0 & - & - & 0 & - & - \\
\hline & & & $\# 6$ & 26 & 0 & - & - & 0 & - & - \\
\hline \multirow[t]{5}{*}{ Hydrophobic } & 6 & 0.05 & $\# 1$ & 275 & 51 & - & - & 8 & - & - \\
\hline & & & \#2 & 43 & 0 & - & - & 0 & - & - \\
\hline & & & $\# 3$ & 29 & 11 & - & - & 5 & - & - \\
\hline & & & $\# 4$ & 25 & 0 & - & - & 0 & - & - \\
\hline & & & $\# 5$ & 35 & 0 & - & - & 0 & - & - \\
\hline \multirow[t]{6}{*}{ Hydrophobic } & 6 & 0.10 & $\# 1$ & 294 & 120 & - & - & 27 & - & - \\
\hline & & & \#2 & 50 & 7 & - & - & 7 & - & - \\
\hline & & & $\# 3$ & 53 & 4 & - & - & 2 & - & - \\
\hline & & & $\# 4$ & 35 & 0 & - & - & 0 & - & - \\
\hline & & & $\# 5$ & 38 & 0 & - & - & 0 & - & - \\
\hline & & & \#6 & 31 & 5 & - & - & 3 & - & - \\
\hline
\end{tabular}


Table D.2. Raw bacterial and retention counts for lateral through bubble experiments.

\begin{tabular}{|c|c|c|c|c|c|c|c|c|c|c|}
\hline \multirow{2}{*}{ Surface Wettability } & \multirow[b]{2}{*}{ Time of Adhesion (hr) } & \multirow[b]{2}{*}{ Flow Rate $(\mathrm{mL} / \mathrm{min})$} & \multirow[b]{2}{*}{ Run } & \multicolumn{4}{|c|}{ Bacterial Counts } & \multicolumn{3}{|c|}{ Retention Counts } \\
\hline & & & & Initial & Bubble - Stage I & Bubble - Stage II & Final & \begin{tabular}{|l|} 
Bubble - Stage I \\
\end{tabular} & Bubble - Stage II & Final \\
\hline \multirow[t]{4}{*}{ Hydrophilic } & 0.5 & 0.21 & $\# 1$ & 131 & 96 & 67 & 64 & 62 & 48 & 42 \\
\hline & & & \#2 & 192 & 208 & 171 & 132 & 178 & 141 & 126 \\
\hline & & & \#3 & 47 & 31 & 24 & 22 & 35 & 23 & 21 \\
\hline & & & $\# 4$ & 36 & 41 & 34 & 16 & 35 & 12 & 12 \\
\hline \multirow[t]{3}{*}{ Hydrophilic } & 0.5 & 0.72 & $\# 1$ & 69 & 63 & 63 & 48 & 58 & 54 & 47 \\
\hline & & & \#2 & 39 & 40 & 36 & 31 & 38 & 34 & 30 \\
\hline & & & \#3 & 32 & 30 & 29 & 26 & 31 & 29 & 25 \\
\hline \multirow[t]{4}{*}{ Hydrophilic } & 6 & 0.21 & $\# 1$ & 89 & 89 & 84 & 52 & 88 & 70 & 46 \\
\hline & & & \#2 & 41 & 48 & 14 & 14 & 39 & 12 & 11 \\
\hline & & & \#3 & 58 & 89 & 34 & 27 & 38 & 7 & 6 \\
\hline & & & $\# 4$ & 86 & 108 & 37 & 36 & 82 & 34 & 32 \\
\hline \multirow[t]{4}{*}{ Hydrophilic } & 6 & 0.72 & $\# 1$ & 80 & 81 & 80 & 67 & 78 & 68 & 61 \\
\hline & & & \#2 & 29 & 27 & 24 & 19 & 27 & 23 & 17 \\
\hline & & & \#3 & 33 & 34 & 36 & 10 & 32 & 32 & 9 \\
\hline & & & $\# 4$ & 54 & 46 & 41 & 27 & 49 & 37 & 24 \\
\hline \multirow[t]{3}{*}{ Hydrophobic } & 0.5 & 0.21 & $\# 1$ & 52 & 12 & 12 & 28 & 0 & 0 & 0 \\
\hline & & & $\# 2$ & 30 & 0 & 0 & 3 & 0 & 0 & 0 \\
\hline & & & $\# 3$ & 69 & 0 & 0 & 10 & 0 & 0 & 0 \\
\hline \multirow[t]{4}{*}{ Hydrophobic } & 0.5 & 0.72 & $\# 1$ & 52 & 6 & 6 & 6 & 1 & 1 & 1 \\
\hline & & & \#2 & 30 & 3 & 3 & 8 & 3 & 3 & 3 \\
\hline & & & $\# 3$ & 42 & 0 & 0 & 19 & 0 & 0 & 0 \\
\hline & & & $\# 4$ & 89 & 2 & 2 & 8 & 2 & 2 & 2 \\
\hline \multirow[t]{3}{*}{ Hydrophobic } & 6 & 0.21 & $\# 1$ & 85 & 12 & 12 & 23 & 3 & 3 & 3 \\
\hline & & & \#2 & 57 & 13 & 13 & 14 & 2 & 2 & 2 \\
\hline & & & $\# 3$ & 115 & 9 & 9 & 18 & 2 & 2 & 2 \\
\hline \multirow[t]{4}{*}{ Hydrophobic } & 6 & 0.72 & $\# 1$ & 78 & 9 & 9 & 11 & 1 & 1 & 1 \\
\hline & & & \#2 & 34 & 0 & 0 & 5 & 0 & 0 & 0 \\
\hline & & & $\# 3$ & 44 & 0 & 0 & 1 & 0 & 0 & 0 \\
\hline & & & $\# 4$ & 47 & 0 & 0 & 5 & 0 & 0 & 0 \\
\hline
\end{tabular}

Table D.3. Raw bacterial and retention counts for lateral oscillatory bubble experiments.

\begin{tabular}{|c|c|c|c|c|c|c|c|c|c|c|}
\hline \multirow[b]{2}{*}{ Surface Wettability } & \multirow[b]{2}{*}{ Time of Adhesion (hr) } & \multirow[b]{2}{*}{ Flow Rate $(\mathrm{mL} / \mathrm{min})$} & \multirow[b]{2}{*}{ Run } & \multicolumn{4}{|c|}{ Bacterial Counts } & \multicolumn{3}{|c|}{ Retention Counts } \\
\hline & & & & Initial & Bubble - Stage I & Bubble - Stage II & Final & Bubble - Stage I & Bubble - Stage II & Final \\
\hline \multirow[t]{4}{*}{ Hydrophilic } & 0.5 & 0.21 & $\# 1$ & 137 & 127 & 133 & 52 & 80 & 53 & 35 \\
\hline & & & \#2 & 106 & 96 & 73 & 72 & 85 & 49 & 45 \\
\hline & & & \#3 & 29 & 37 & 35 & 13 & 23 & 13 & 6 \\
\hline & & & $\# 4$ & 92 & 104 & 94 & 53 & 92 & 44 & 25 \\
\hline \multirow[t]{3}{*}{ Hydrophilic } & 0.5 & 0.72 & \#1 & 39 & 37 & 34 & 19 & 34 & 21 & 14 \\
\hline & & & \#2 & 103 & 99 & 74 & 84 & 94 & 45 & 44 \\
\hline & & & \#3 & 43 & 40 & 35 & 35 & 39 & 28 & 26 \\
\hline \multirow[t]{4}{*}{ Hydrophilic } & 6 & 0.21 & \#1 & 87 & 89 & 43 & 40 & 83 & 22 & 20 \\
\hline & & & \#2 & 53 & 48 & 51 & 17 & 45 & 27 & 13 \\
\hline & & & \#3 & 77 & 79 & 82 & 32 & 69 & 34 & 12 \\
\hline & & & \#4 & 87 & 84 & 80 & 32 & 86 & 65 & 30 \\
\hline \multirow[t]{4}{*}{ Hydrophilic } & 6 & 0.72 & $\# 1$ & 37 & 31 & 36 & 17 & 29 & 18 & 11 \\
\hline & & & \#2 & 33 & 36 & 43 & 18 & 20 & 20 & 13 \\
\hline & & & $\# 3$ & 61 & 61 & 66 & 34 & 54 & 37 & 13 \\
\hline & & & $\# 4$ & 94 & 89 & 92 & 29 & 87 & 72 & 26 \\
\hline \multirow[t]{3}{*}{ Hydrophobic } & 0.5 & 0.21 & $\# 1$ & 66 & 2 & 2 & 29 & 0 & 0 & 0 \\
\hline & & & \#2 & 40 & 6 & 6 & 11 & 1 & 1 & 1 \\
\hline & & & $\# 3$ & 98 & 0 & 0 & 105 & 0 & 0 & 0 \\
\hline \multirow[t]{4}{*}{ Hydrophobic } & 0.5 & 0.72 & $\# 1$ & 30 & 0 & 0 & 18 & 0 & 0 & 0 \\
\hline & & & $\# 2$ & 121 & 29 & 29 & 66 & 1 & 1 & 1 \\
\hline & & & $\# 3$ & 44 & 0 & 0 & 43 & 0 & 0 & 0 \\
\hline & & & $\# 4$ & 101 & 0 & 0 & 3 & 0 & 0 & 0 \\
\hline \multirow[t]{3}{*}{ Hydrophobic } & 6 & 0.21 & $\# 1$ & 68 & 16 & 16 & 19 & 3 & 3 & 3 \\
\hline & & & $\# 2$ & 65 & 4 & 4 & 3 & 2 & 2 & 2 \\
\hline & & & $\# 3$ & 117 & 35 & 35 & 51 & 5 & 5 & 5 \\
\hline \multirow[t]{4}{*}{ Hydrophobic } & 6 & 0.72 & $\# 1$ & 48 & 11 & 11 & 32 & 0 & 0 & 0 \\
\hline & & & \#2 & 35 & 1 & 1 & 13 & 1 & 1 & 1 \\
\hline & & & $\# 3$ & 29 & 0 & 0 & 12 & 0 & 0 & 0 \\
\hline & & & $\# 4$ & 47 & 1 & 1 & 7 & 1 & 1 & 1 \\
\hline
\end{tabular}




\section{References}

1. Schultz, M. P.; Bendick, J. A.; Holm, E. R.; Hertel, W. M., Economic impact of biofouling on a naval surface ship. Biofouling 2011, 27 (1), 87-98.

2. Bax, N.; Williamson, A.; Aguero, M.; Gonzalez, E.; Geeves, W., Marine invasive alien species: a threat to global biodiversity. Marine Policy 2003, 27 (4), 313-323.

3. Pimentel, D.; Zuniga, R.; Morrison, D., Update on the environmental and economic costs associated with alien-invasive species in the United States. Ecological Economics 2005, 52 (3), 273-288.

4. Yebra, D. M.; Kiil, S.; Dam-Johansen, K., Antifouling technology-past, present and future steps towards efficient and environmentally friendly antifouling coatings. Progress in Organic Coatings 2004, 50 (2), 75-104.

5. Nakano, D.; Strayer, D. L., Biofouling animals in fresh water: biology, impacts, and ecosystem engineering. Frontiers in Ecology and the Environment 2014, 12 (3), 167-175.

6. Callow, M. E., A review of fouling in freshwaters. Biofouling 1993, 7 (4), 313-327.

7. Cao, S.; Wang, J.; Chen, H.; Chen, D., Progress of marine biofouling and antifouling technologies. Chinese Science Bulletin 2011, 56 (7), 598-612.

8. Abarzua, S.; Jakubowski, S., Biotechnological investigation for the prevention of biofouling. I. Biological and biochemical principles for the prevention of biofouling. Marine Ecology Progress Series 1995, 123, 301-312.

9. Garg, A.; Jain, A.; Bhosle, N. B., Chemical characterization of a marine conditioning film. International Biodeterioration \& Biodegradation 2009, 63 (1), 7-11.

10. Whitchurch, C. B.; Tolker-Nielsen, T.; Ragas, P. C.; Mattick, J. S., Extracellular DNA required for bacterial biofilm formation. Science 2002, 295 (5559), 1487-1487.

11. Hall-Stoodley, L.; Costerton, J. W.; Stoodley, P., Bacterial biofilms: from the Natural environment to infectious diseases. Nature Reviews Microbiology 2004, 2, 95.

12. Wingender, J.; Flemming, H.-C., Biofilms in drinking water and their role as reservoir for pathogens. International Journal of Hygiene and Environmental Health 2011, 214 (6), 417-423. 13. Flemming, H.-C., Microbial biofouling: unsolved problems, insufficient approaches, and possible solutions. In Biofilm highlights, Springer: 2011; pp 81-109.

14. Monds, R. D.; O'Toole, G. A., The developmental model of microbial biofilms: ten years of a paradigm up for review. Trends in Microbiology 2009, 17 (2), 73-87.

15. O'Toole, G.; Kaplan, H. B.; Kolter, R., Biofilm formation as microbial development. Annual Reviews in Microbiology 2000, 54 (1), 49-79.

16. Callow, M. E.; Callow, J. A., Marine biofouling: a sticky problem. Biologist 2002, 49 (1), 1-5.

17. Clare, A. S.; Rittschof, D.; Gerhart, D. J.; Maki, J. S., Molecular approaches to nontoxic antifouling. Invertebrate Reproduction \& Development 1992, 22 (1-3), 67-76.

18. Qian, P. Y.; Lau, S. C. K.; Dahms, H. U.; Dobretsov, S.; Harder, T., Marine Biofilms as Mediators of Colonization by Marine Macroorganisms: Implications for Antifouling and Aquaculture. Marine Biotechnology 2007, 9 (4), 399-410.

19. Olivier, F.; Tremblay, R.; Bourget, E.; Rittschof, D., Barnacle settlement: field experiments on the influence of larval supply, tidal level, biofilm quality and age on Balanus amphitrite cyprids. Marine Ecology Progress Series 2000, 199, 185-204.

20. binte Ab Rahim, S. A. K. Larval Metamorphosis of the Sea Urchins, Pseudocentrotus depressus and Anthocidaris crassispina Induced by Microbial Films. 2004. 
21. Bao, W.-Y.; Satuito, C. G.; Yang, J.-L.; Kitamura, H., Larval settlement and metamorphosis of the mussel Mytilus galloprovincialis in response to biofilms. Marine Biology 2007, 150 (4), 565574.

22. Hadfield, M. G., Biofilms and marine invertebrate larvae: what bacteria produce that larvae use to choose settlement sites. Annual review of marine science 2011, 3, 453-470.

23. Characklis, W. G.; Cooksey, K. E., Biofilms and Microbial Fouling. In Advances in Applied Microbiology, Laskin, A. I., Ed. Academic Press: 1983; Vol. 29, pp 93-138.

24. Rascio, V. J., Antifouling coatings: where do we go from here. Corrosion Reviews 2000, 18 (2-3), 133-154.

25. Characklis, W. G., Attached microbial growths-II. Frictional resistance due to microbial slimes. Water Research 1973, 7 (9), 1249-1258.

26. Bryers, J. D., Biologically Active Surfaces: Processes Governing the Formation and Persistence of Biofilms. Biotechnology Progress 1987, 3 (2), 57-68.

27. Schultz, M.; Swain, G., The effect of biofilms on turbulent boundary layers. Journal of Fluids engineering 1999, 121 (1), 44-51.

28. Evans, L., Marine algae and fouling: a review, with particular reference to ship-fouling. Botanica Marina 1981, 24 (4), 167-172.

29. Schultz, M. P., Turbulent boundary layers on surfaces covered with filamentous algae. Journal of fluids engineering 2000, 122 (2), 357-363.

30. Townsin, R. L., The Ship Hull Fouling Penalty. Biofouling 2003, 19 (sup1), 9-15.

31. Schultz, M., Effects of coating roughness and biofouling on ship resistance and powering. 2007; Vol. 23, p 331-41.

32. Turan, O.; Demirel, Y. K.; Day, S.; Tezdogan, T., Experimental Determination of Added Hydrodynamic Resistance Caused by Marine Biofouling on Ships. Transportation Research Procedia 2016, 14, 1649-1658.

33. Abbott, A.; Abel, P. D.; Arnold, D. W.; Milne, A., Cost-benefit analysis of the use of TBT: the case for a treatment approach. Science of The Total Environment 2000, 258 (1), 5-19.

34. Alberte, R. S.; Snyder, S.; Zahuranec, B. J.; Whetstone, M., Biofouling research needs for the United States Navy: Program history and goals. Biofouling 1992, 6 (2), 91-95.

35. Frey, M. A.; Simard, N.; Robichaud, D. D.; Martin, J. L.; Therriault, T. W., Fouling around: vessel sea-chests as a vector for the introduction and spread of aquatic invasive species. Management of Biological Invasions 2014, 5 (1), 21-30.

36. Walker, J. T.; Bradshaw, D. J.; Bennett, A. M.; Fulford, M. R.; Martin, M. V.; Marsh, P. D., Microbial Biofilm Formation and Contamination of Dental-Unit Water Systems in General Dental Practice. Applied and Environmental Microbiology 2000, 66 (8), 3363-3367.

37. Mattila-Sandholm, T.; Wirtanen, G., Biofilm formation in the industry: A review. Food Reviews International 1992, 8 (4), 573-603.

38. Costerton, J. W.; Stewart, P. S., Battling Biofilms. Scientific American 2001, 285 (1), 74-81.

39. Bryers, J. D., Medical Biofilms. Biotechnology and bioengineering 2008, 100 (1), 1-18.

40. Gibson, H.; Taylor, J. H.; Hall, K. E.; Holah, J. T., Effectiveness of cleaning techniques used in the food industry in terms of the removal of bacterial biofilms. Journal of Applied Microbiology 1999, 87 (1), 41-48.

41. Meyer, B., Approaches to prevention, removal and killing of biofilms. International Biodeterioration \& Biodegradation 2003, 51 (4), 249-253. 
42. Agarwal, A.; Xu, H.; Ng, W. J.; Liu, Y., Biofilm detachment by self-collapsing air microbubbles: a potential chemical-free cleaning technology for membrane biofouling. Journal of Materials Chemistry 2012, 22 (5), 2203-2207.

43. Blenkinsopp, S. A.; Khoury, A. E.; Costerton, J. W., Electrical enhancement of biocide efficacy against Pseudomonas aeruginosa biofilms. Applied and environmental microbiology 1992, 58 (11), 3770-3773.

44. Carmen, J. C.; Roeder, B. L.; Nelson, J. L.; Ogilvie, R. L. R.; Robison, R. A.; Schaalje, G. B.; Pitt, W. G., Treatment of biofilm infections on implants with low-frequency ultrasound and antibiotics. American journal of infection control 2005, 33 (2), 78-82.

45. Wood, P.; Caldwell, D. E.; Evans, E.; Jones, M.; Korber, D. R.; Wolfhaardt, G. M.; Wilson, M.; Gilbert, P., Surface-catalysed disinfection of thick Pseudomonas aeruginosa biofilms. Journal of applied microbiology 1998, 84 (6), 1092-1098.

46. Almeida, E.; Diamantino, T. C.; de Sousa, O., Marine paints: The particular case of antifouling paints. Progress in Organic Coatings 2007, 59 (1), 2-20.

47. Christie, A.; Dalley, R., Barnacle fouling and its prevention. Barnacle biology 1987, 419-433.

48. Lewis, J. A. In Marine biofouling and its prevention, Materials Forum, 1998; pp 41-6I.

49. IMO, International convention on the control of harmful anti-fouling systems on ships.

International Maritime Organization London: 2001.

50. Alzieu, C., Environmental problems caused by TBT in France: Assessment, regulations, prospects. Marine Environmental Research 1991, 32 (1), 7-17.

51. Evans, S. M.; Leksono, T.; McKinnell, P. D., Tributyltin pollution: A diminishing problem following legislation limiting the use of TBT-based anti-fouling paints. Marine Pollution Bulletin 1995, 30 (1), 14-21.

52. Dafforn, K. A.; Lewis, J. A.; Johnston, E. L., Antifouling strategies: History and regulation, ecological impacts and mitigation. Marine Pollution Bulletin 2011, 62 (3), 453-465.

53. Desai, N. P.; Hossainy, S. F. A.; Hubbell, J. A., Surface-immobilized polyethylene oxide for bacterial repellence. Biomaterials 1992, 13 (7), 417-420.

54. Currie, E. P. K.; Norde, W.; Cohen Stuart, M. A., Tethered polymer chains: surface chemistry and their impact on colloidal and surface properties. Advances in Colloid and Interface Science 2003, 100-102, 205-265.

55. Roosjen, A.; de Vries, J.; van der Mei, H. C.; Norde, W.; Busscher, H. J., Stability and effectiveness against bacterial adhesion of poly(ethylene oxide) coatings in biological fluids. Journal of Biomedical Materials Research Part B: Applied Biomaterials 2005, 73B (2), 347-354. 56. Banerjee, I.; Pangule, R. C.; Kane, R. S., Antifouling Coatings: Recent Developments in the Design of Surfaces That Prevent Fouling by Proteins, Bacteria, and Marine Organisms. Advanced Materials 2011, 23 (6), 690-718.

57. Mi, L.; Jiang, S., Integrated Antimicrobial and Nonfouling Zwitterionic Polymers.

Angewandte Chemie International Edition 2014, 53 (7), 1746-1754.

58. Cheng, G.; Zhang, Z.; Chen, S.; Bryers, J. D.; Jiang, S., Inhibition of bacterial adhesion and biofilm formation on zwitterionic surfaces. Biomaterials 2007, 28 (29), 4192-4199.

59. Jiang, S.; Cao, Z., Ultralow-Fouling, Functionalizable, and Hydrolyzable Zwitterionic Materials and Their Derivatives for Biological Applications. Advanced Materials 2010, 22 (9), 920-932. 
60. Xiao, L.; Li, J.; Mieszkin, S.; Di Fino, A.; Clare, A. S.; Callow, M. E.; Callow, J. A.; Grunze, M.; Rosenhahn, A.; Levkin, P. A., Slippery Liquid-Infused Porous Surfaces Showing Marine Antibiofouling Properties. ACS Applied Materials \& Interfaces 2013, 5 (20), 10074-10080. 61. Smith, F. W., Mechanical control of ship-bottom fouling by means of air bubbles. Quarterly Journal of the Florida Academy of Sciences 1946, 9 (3/4), 153-161.

62. Scardino, A. J.; Fletcher, L. E.; Lewis, J. A., Fouling control using air bubble curtains: protection for stationary vessels. Journal of Marine Engineering \& Technology 2009, 8 (1), 3-10. 63. Bullard, S. G.; Shumway, S. E.; Davis, C. V., The use of aeration as a simple and environmentally sound means to prevent biofouling. Biofouling 2010, 26 (5), 587-593. 64. Menesses, M.; Belden, J.; Dickenson, N.; Bird, J., Measuring a critical stress for continuous prevention of marine biofouling accumulation with aeration. Biofouling 2017, 33 (9), 703-711. 65. Railkin, A.; Ganf, T.; Manylov, O., Marine biofouling: colonization processes and defenses, CRC Press. Boca Raton, FL 2004.

66. Kimata, N.; Nishino, T.; Suzuki, S.; Kogure, K., Pseudomonas aeruginosa Isolated from Marine Environments in Tokyo Bay. Microbial Ecology 2004, 47 (1), 41-47.

67. Pitt, W. G.; McBride, M. O.; Barton, A. J.; Sagers, R. D., Air-water interface displaces adsorbed bacteria. Biomaterials 1993, 14 (8), 605-608.

68. Noordmans, J.; Wit, P. J.; Van Der Mei, H. C.; Busscher, H. J., Detachment of polystyrene particles from collector surfaces by surface tension forces induced by air-bubble passage through a parallel plate flow chamber. Journal of Adhesion Science and Technology 1997, 11 (7), 957-969.

69. Aramrak, S.; Flury, M.; Harsh, J. B., Detachment of Deposited Colloids by Advancing and Receding Air-Water Interfaces. Langmuir 2011, 27 (16), 9985-9993.

70. Hewitt, D.; Fornasiero, D.; Ralston, J., Bubble-particle attachment. Journal of the Chemical Society, Faraday Transactions 1995, 91 (13), 1997-2001.

71. Gómez-Suárez, C.; Busscher, H. J.; van der Mei, H. C., Analysis of bacterial detachment from substratum surfaces by the passage of air-liquid interfaces. Applied and environmental microbiology 2001, 67 (6), 2531-2537.

72. Nguyen-Van, A., The Collision between Fine Particles and Single Air Bubbles in Flotation. Journal of Colloid and Interface Science 1994, 162 (1), 123-128.

73. Khodaparast, S.; Kim, M. K.; Silpe, J. E.; Stone, H. A., Bubble-Driven Detachment of Bacteria from Confined Microgeometries. Environmental Science \& Technology 2017, 51 (3), 1340-1347. 74. Ralston, J.; Fornasiero, D.; Hayes, R., Bubble-particle attachment and detachment in flotation. International Journal of Mineral Processing 1999, 56 (1), 133-164.

75. Suárez, C. G.; Noordmans, J.; van der Mei, H. C.; Busscher, H. J., Detachment of colloidal particles from collector surfaces with different electrostatic charge and hydrophobicity by attachment to air bubbles in a parallel plate flow chamber. Physical Chemistry Chemical Physics 1999, 1 (18), 4423-4427.

76. Touhami, A.; Jericho, M. H.; Boyd, J. M.; Beveridge, T. J., Nanoscale Characterization and Determination of Adhesion Forces of <em>Pseudomonas aeruginosa</em > Pili by Using Atomic Force Microscopy. Journal of Bacteriology 2006, 188 (2), 370-377.

77. Craig, L.; Pique, M. E.; Tainer, J. A., Type IV pilus structure and bacterial pathogenicity. Nature Reviews Microbiology 2004, 2, 363. 
78. Mattick, J. S., Type IV pili and twitching motility. Annual Reviews in Microbiology 2002, 56 (1), 289-314.

79. Skerker, J. M.; Berg, H. C., Direct observation of extension and retraction of type IV pili. Proceedings of the National Academy of Sciences 2001, 98 (12), 6901-6904.

80. Boland, T.; Latour, R. A.; Stutzenberger, F. J., Molecular Basis of Bacterial Adhesion. In Handbook of Bacterial Adhesion: Principles, Methods, and Applications, An, Y. H.; Friedman, R. J., Eds. Humana Press: Totowa, NJ, 2000; pp 29-41.

81. Myszka, K.; Czaczyk, K., Characterization of Adhesive Exopolysaccharide (EPS) Produced by Pseudomonas aeruginosa Under Starvation Conditions. Current Microbiology 2009, 58 (6), 541546.

82. Dunne, W. M., Bacterial Adhesion: Seen Any Good Biofilms Lately? Clinical Microbiology Reviews 2002, 15 (2), 155-166.

83. Hermansson, M., The DLVO theory in microbial adhesion. Colloids and Surfaces B:

Biointerfaces 1999, 14 (1), 105-119.

84. Israelachvili, J. N., Intermolecular and surface forces. Academic press: 2015.

85. Parry, Bradley R.; Surovtsev, Ivan V.; Cabeen, Matthew T.; O’Hern, Corey S.; Dufresne, Eric R.; Jacobs-Wagner, C., The Bacterial Cytoplasm Has Glass-like Properties and Is Fluidized by Metabolic Activity. Cell 2014, 156 (1), 183-194.

86. Touhami, A.; Jericho, M. H.; Boyd, J. M.; Beveridge, T. J., Nanoscale Characterization and Determination of Adhesion Forces of Pseudomonas aeruginosa Pili by Using Atomic Force Microscopy. Journal of Bacteriology 2006, 188 (2), 370-377.

87. Sharma, M. M.; Chamoun, H.; Sarma, D. S. H. S. R.; Schechter, R. S., Factors controlling the hydrodynamic detachment of particles from surfaces. Journal of Colloid and Interface Science 1992, 149 (1), 121-134.

88. Sternling, C. a.; Scriven, L., Interfacial turbulence: hydrodynamic instability and the Marangoni effect. AlChE Journal 1959, 5 (4), 514-523.

89. Bretherton, F. P., The motion of long bubbles in tubes. Journal of Fluid Mechanics 1961, 10 (2), 166-188.

90. Chatzis, I.; Morrow, N. R., Correlation of capillary number relationships for sandstone. Society of Petroleum Engineers Journal 1984, 24 (05), 555-562.

91. Eginton, P.; Gibson, H.; Holah, J.; Handley, P.; Gilbert, P., The influence of substratum properties on the attachment of bacterial cells. Colloids and Surfaces B: Biointerfaces 1995, 5 (3-4), 153-159.

92. Parini Michael, R.; Eggett Dennis, L.; Pitt William, G., Removal of Streptococcus mutans biofilm by bubbles. Journal of Clinical Periodontology 2005, 32 (11), 1151-1156.

93. Sharma, P. K.; Gibcus, M. J.; van der Mei, H. C.; Busscher, H. J., Influence of Fluid Shear and Microbubbles on Bacterial Detachment from a Surface. Applied and Environmental Microbiology 2005, 71 (7), 3668-3673.

94. Parini, M. R.; Pitt, W. G., Dynamic removal of oral biofilms by bubbles. Colloids and Surfaces B: Biointerfaces 2006, 52 (1), 39-46.

95. Salta, M.; Goodes, L.; Maas, B.; Dennington, S.; Secker, T.; Leighton, T., Bubbles versus biofilms: a novel method for the removal of marine biofilms attached on antifouling coatings using an ultrasonically activated water stream. Surface Topography: Metrology and Properties 2016, 4 (3), 034009. 
96. Gião, M. S.; Montenegro, M. I.; Vieira, M. J., The influence of hydrogen bubble formation on the removal of Pseudomonas fluorescens biofilms from platinum electrode surfaces. Process Biochemistry 2005, 40 (5), 1815-1821.

97. Gómez-Suárez, C.; Pasma, J.; van der Borden, A. J.; Wingender, J.; Flemming, H.-C.; Busscher, H. J.; Van der Mei, H. C., Influence of extracellular polymeric substances on deposition and redeposition of Pseudomonas aeruginosa to surfaces. Microbiology 2002, 148 (4), 1161-1169.

98. Tsuneda, S.; Aikawa, H.; Hayashi, H.; Yuasa, A.; Hirata, A., Extracellular polymeric substances responsible for bacterial adhesion onto solid surface. FEMS Microbiology Letters 2003, 223 (2), 287-292.

99. Esmaili, E.; Shukla, P.; Eifert, J. D.; Jung, S., Bubble impact on a tilted wall: Removing bacteria using bubbles. Physical Review Fluids 2019, 4 (4), 043603.

100. Boks, N. P.; Norde, W.; van der Mei, H. C.; Busscher, H. J., Forces involved in bacterial adhesion to hydrophilic and hydrophobic surfaces. Microbiology 2008, 154 (10), 3122-3133. 101. Chang, Y.-R.; Weeks, E. R.; Ducker, W. A., Surface Topography Hinders Bacterial Surface Motility. ACS Applied Materials \& Interfaces 2018, 10 (11), 9225-9234.

102. Liu, L.; Yan, H.; Zhao, G.; Zhuang, J., Experimental studies on the terminal velocity of air bubbles in water and glycerol aqueous solution. Experimental Thermal and Fluid Science 2016, 78, 254-265.

103. Tomiyama, A.; Kataoka, I.; Zun, I.; Sakaguchi, T., Drag coefficients of single bubbles under normal and micro gravity conditions. JSME International Journal Series B Fluids and Thermal Engineering 1998, 41 (2), 472-479.

104. Wu, M.; Gharib, M., Experimental studies on the shape and path of small air bubbles rising in clean water. Physics of Fluids 2002, 14 (7), L49-L52.

105. Berg, J. C., An introduction to interfaces \& colloids: the bridge to nanoscience. World Scientific: 2010; p 2.

106. Eddington, D. T.; Puccinelli, J. P.; Beebe, D. J., Thermal aging and reduced hydrophobic recovery of polydimethylsiloxane. Sensors and Actuators B: Chemical 2006, 114 (1), 170-172. 107. Kwok, D. Y.; Gietzelt, T.; Grundke, K.; Jacobasch, H. J.; Neumann, A. W., Contact Angle Measurements and Contact Angle Interpretation. 1. Contact Angle Measurements by Axisymmetric Drop Shape Analysis and a Goniometer Sessile Drop Technique. Langmuir 1997, 13 (10), 2880-2894.

108. Tadmor, R., Line Energy and the Relation between Advancing, Receding, and Young Contact Angles. Langmuir 2004, 20 (18), 7659-7664.

109. Shaner, N. C.; Steinbach, P. A.; Tsien, R. Y., A guide to choosing fluorescent proteins. Nature Methods 2005, 2, 905.

110. Asayesh, F.; Zarabadi, M. P.; Greener, J., A new look at bubbles during biofilm inoculation reveals pronounced effects on growth and patterning. Biomicrofluidics 2017, 11 (6), 064109. 111. Sharma, P.; Flury, M.; Zhou, J., Detachment of colloids from a solid surface by a moving airwater interface. Journal of colloid and interface science 2008, 326 (1), 143-150.

112. Güvener, Z. T.; Harwood, C. S., Subcellular location characteristics of the Pseudomonas aeruginosa GGDEF protein, WspR, indicate that it produces cyclic-di-GMP in response to growth on surfaces. Molecular microbiology 2007, 66 (6), 1459-1473. 